\title{
Comparing Retrofit Wall Performance Predicted from Hygrothermal Simulations to Measurements
}

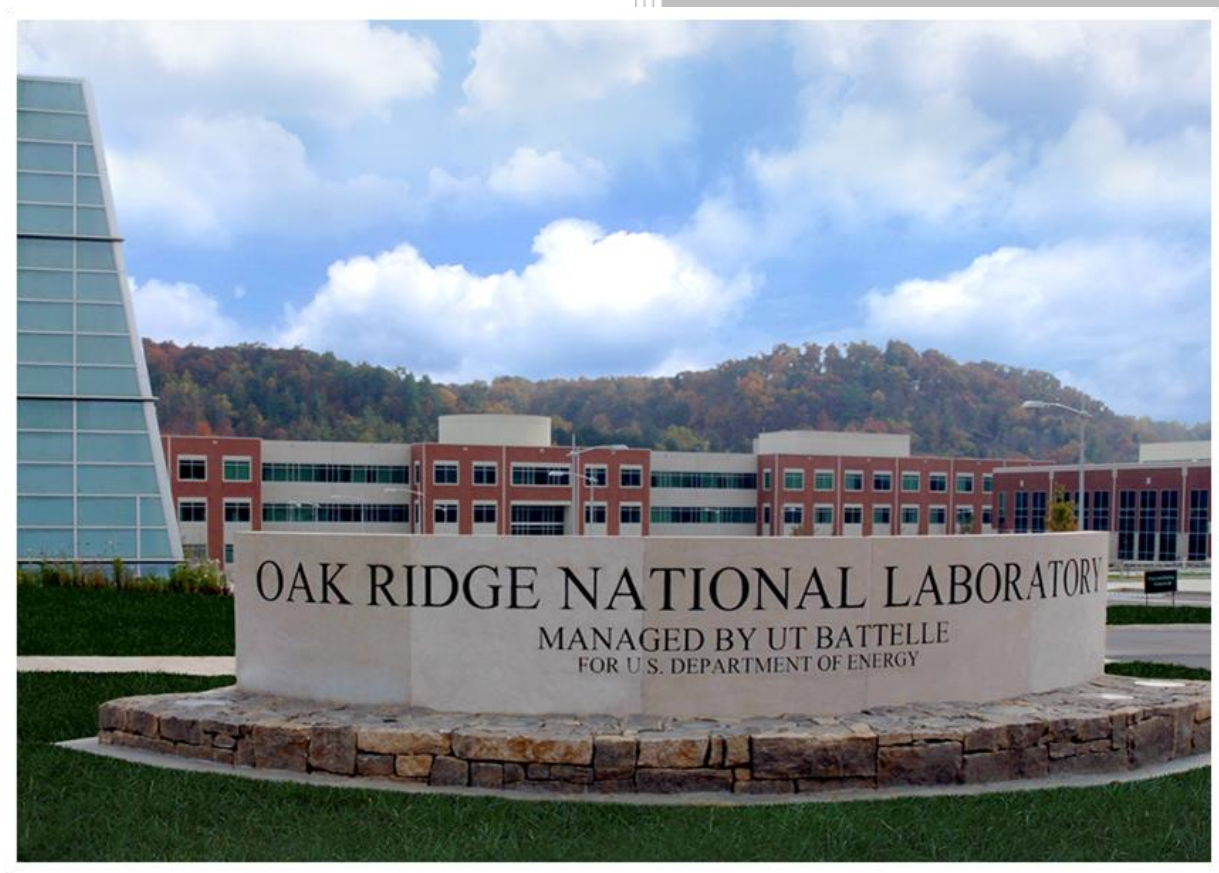

Philip Boudreaux Mikael Salonvaara Andre Desjarlais

April 2021 


\title{
DOCUMENT AVAILABILITY
}

Reports produced after January 1, 1996, are generally available free via US Department of Energy (DOE) SciTech Connect.

Website www.osti.gov

Reports produced before January 1, 1996, may be purchased by members of the public from the following source:

\author{
National Technical Information Service \\ 5285 Port Royal Road \\ Springfield, VA 22161 \\ Telephone 703-605-6000 (1-800-553-6847) \\ TDD 703-487-4639 \\ Fax 703-605-6900 \\ E-mail info@ntis.gov \\ Website http://classic.ntis.gov/
}

Reports are available to DOE employees, DOE contractors, Energy Technology Data Exchange representatives, and International Nuclear Information System representatives from the following source:

Office of Scientific and Technical Information

PO Box 62

Oak Ridge, TN 37831

Telephone 865-576-8401

Fax 865-576-5728

E-mail reports@osti.gov

Website https://www.osti.gov/

This report was prepared as an account of work sponsored by an agency of the United States Government. Neither the United States Government nor any agency thereof, nor any of their employees, makes any warranty, express or implied, or assumes any legal liability or responsibility for the accuracy, completeness, or usefulness of any information, apparatus, product, or process disclosed, or represents that its use would not infringe privately owned rights. Reference herein to any specific commercial product, process, or service by trade name, trademark, manufacturer, or otherwise, does not necessarily constitute or imply its endorsement, recommendation, or favoring by the United States Government or any agency thereof. The views and opinions of authors expressed herein do not necessarily state or reflect those of the United States Government or any agency thereof. 
Energy and Transportation Science Division

\title{
COMPARING RETROFIT WALL PERFORMANCE PREDICTED FROM HYGROTHERMAL SIMULATIONS TO MEASUREMENTS
}

\author{
Philip Boudreaux \\ Mikael Salonvaara \\ Andre Desjarlais
}

April 2021

\author{
Prepared by \\ OAK RIDGE NATIONAL LABORATORY \\ Oak Ridge, TN 37831-6283 \\ managed by \\ UT-BATTELLE, LLC \\ for the \\ US DEPARTMENT OF ENERGY \\ under contract DE-AC05-00OR22725
}





\section{CONTENTS}

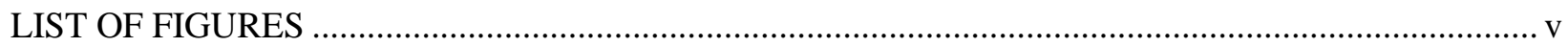

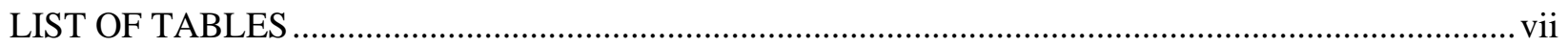

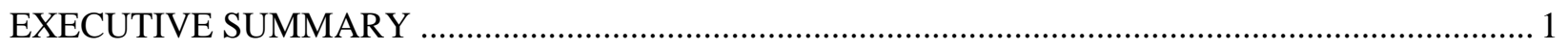

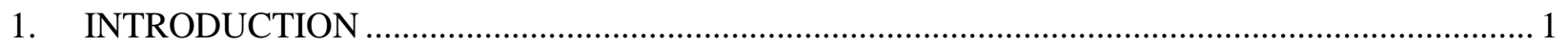

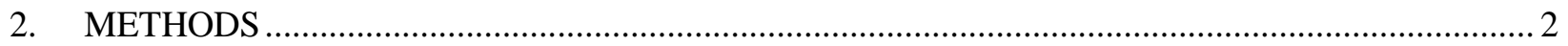

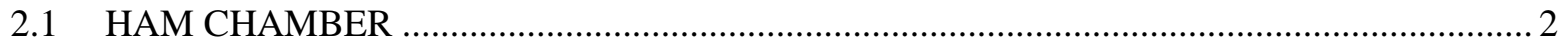

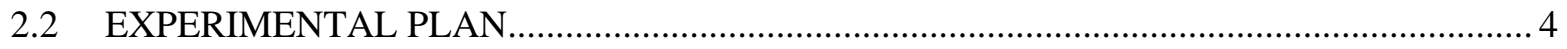

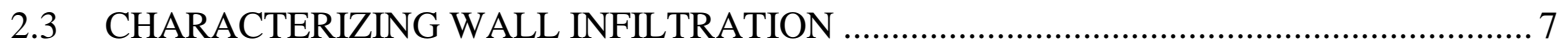

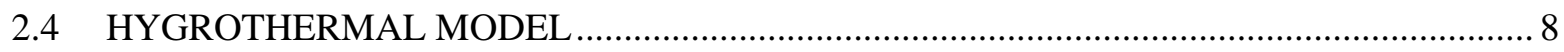

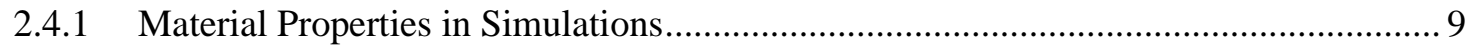

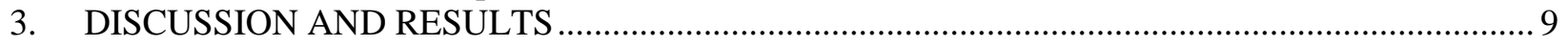

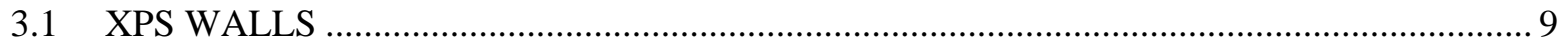

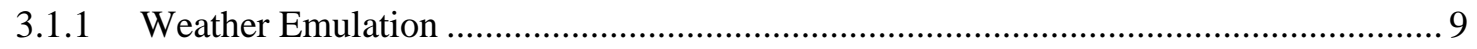

3.1.2 Wall Performance Measurements compared with WUFI Predictions .......................... 12

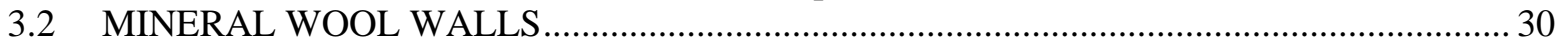

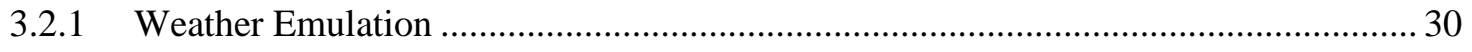

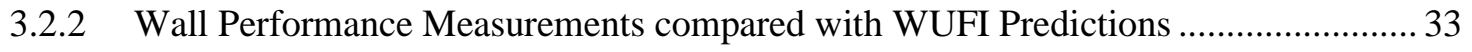

4. ANNUAL SIMULATIONS OF THE RETROFIT WALLS ......................................................... 47

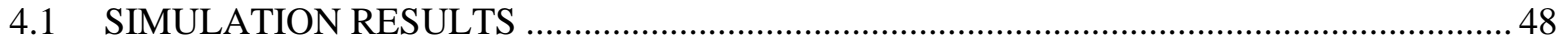

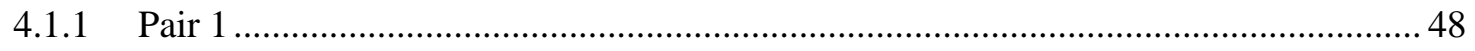

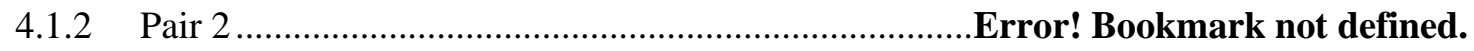

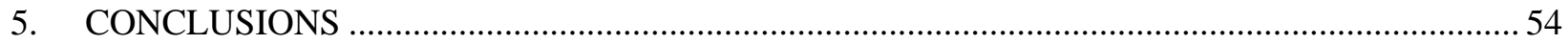

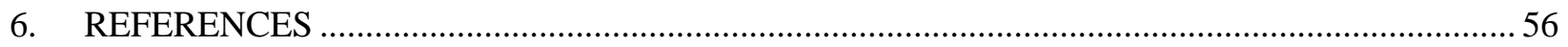





\section{LIST OF FIGURES}

Figure 1. International building codes have decreased the energy consumption of new residential

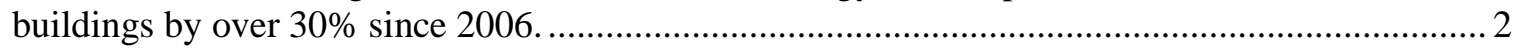

Figure 2. Oak Ridge National Laboratory HAM chamber. ........................................................... 3

Figure 3. Schematic of the low-permeance CI walls to be tested in the chamber. .................................. 5

Figure 4. Schematic of the high-permeance CI walls tested in the chamber. .......................................... 6

Figure 5. Exterior boundary conditions for the test wall were taken from the cold-year Chicago weather conditions file from WUFI....................................................................................... 7

Figure 6. (left) Exterior and (right) interior of the wall frame showing the header and both high-

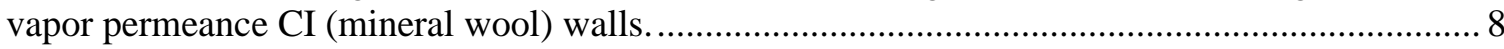

Figure 7. Volumetric leakage versus differential pressure for the whole wall frame for mineral

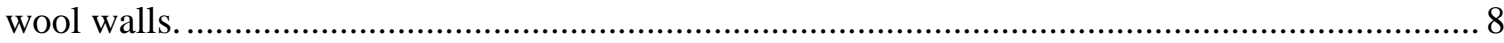

Figure 8. The indoor side of the chamber had targets of $68^{\circ} \mathrm{F}$ and $40 \% \mathrm{RH}$....................................... 10

Figure 9. Outdoor chamber temperature and RH change according to the WUFI Chicago weather

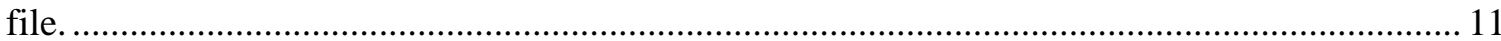

Figure 10. The cladding temperature target changed along with the outdoor weather............................ 12

Figure 11. Measured temperature (T) throughout the XPS wall with a polyethylene interior VR............ 13

Figure 12. Measured RH throughout the XPS wall with a polyethylene interior VR.............................. 14

Figure 13. Measured moisture content at three heights along the cavity side face of the OSB sheathing in the XPS wall with a polyethylene interior VR. .................................................... 15

Figure 14. Layers and materials in the simulated WUFI model for the XPS wall with a

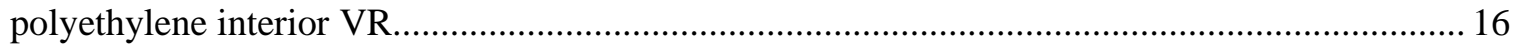

Figure 15. Monitoring points used in comparing the measured and simulated results............................ 17

Figure 16. Comparison of measured and simulated temperature (T) in the XPS wall with a polyethylene interior VR with air leakage through the wall..................................................... 18

Figure 17. Comparison of measured and simulated relative humidity in the XPS wall with a polyethylene interior VR without air leakage through the wall.

Figure 18. Comparison of measured and simulated relative humidity in the XPS wall with a polyethylene interior VR with air leakage through the wall.

Figure 19. Comparison of measured and simulated moisture content of the exterior sheathing (OSB) in the XPS wall with a polyethylene interior VR with air leakage through the wall......... 21

Figure 20. Measured temperature (T) throughout the XPS wall with no interior VR. ............................ 22

Figure 21. Measured RH throughout the XPS wall with no interior VR ............................................ 23

Figure 22. Measured moisture content at three heights along the cavity side face of the OSB

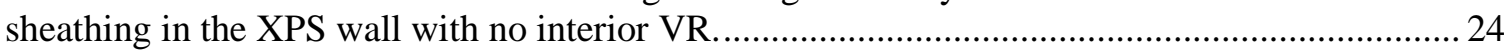

Figure 23. Layers and materials in the simulated WUFI model for the XPS wall with no

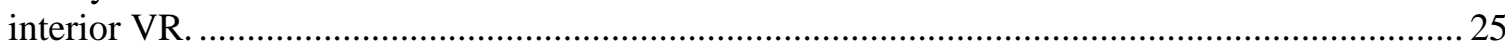

Figure 24. Comparison of measured and simulated temperature (T) in the XPS wall with no

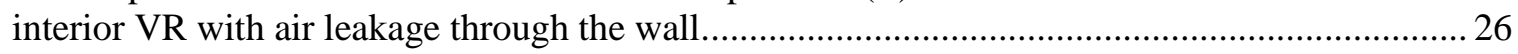

Figure 25. Comparison of measured and simulated relative humidity in the XPS wall with no interior VR without air leakage through the wall. ................................................................... 27

Figure 26. Comparison of measured and simulated relative humidity in the XPS wall with no

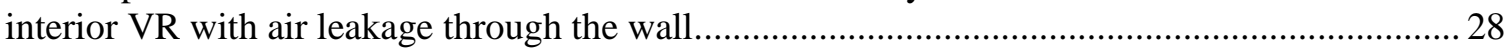

Figure 27. Comparison of measured and simulated moisture content of the exterior sheathing (OSB) in Wall 2 of Pair 1 with air leakage through the wall.......................................................2 29

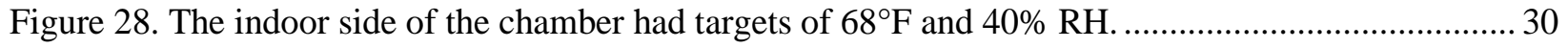

Figure 29. Outdoor chamber temperature and RH change according to the WUFI Chicago weather file.

Figure 30. The cladding temperature target changed along with the outdoor weather. 32 
Figure 31. Measured pressure differential across the test wall.

Figure 32. Measured temperature (T) throughout the wall with mineral wool CI and a felt paper

WRB.

Figure 33. Measured RH throughout the wall with mineral wool CI and a felt paper WRB.

Figure 34. Measured moisture content throughout the wall with mineral wool CI and a felt paper WRB.

Figure 35. Layers and materials in the simulated WUFI model for the wall with mineral wool CI and a felt paper WRB.

Figure 36. Comparison of measured and simulated temperature in felt WRB wall.

Figure 37. Comparison of measured and simulated RH in the wall with mineral wool CI and a felt WRB.

Figure 38. Comparison of measured and simulated moisture content of the OSB (wt \%) in the wall with mineral wool CI and a felt WRB.

Figure 39. Measured temperature (T) throughout wall with mineral wool CI and a spun-bonded polyolefin WRB

Figure 40. Measured RH throughout the wall with mineral wool CI and a spun-bonded polyolefin WRB.

Figure 41. Measured moisture content throughout the wall with mineral wool CI and a spunbonded polyolefin WRB.

Figure 42. Layers and materials in the simulated WUFI model for the wall with mineral wool CI and a spun-bonded polyolefin WRB

Figure 43. Comparison of measured and simulated temperature in Wall 2 of Pair 2 ............................. 45

Figure 44. Comparison of measured and simulated RH in Wall 2 of Pair 2 ............................................. 46

Figure 45. Measured and simulated moisture content of the OSB in Wall 2 for Pair 2 ......................... 47

Figure 46. Annual simulation results for Wall 1 of Pair 1.................................................................... 49

Figure 47. Annual simulation results for Wall 1 of Pair 1 with a Kraft VR instead of polyethylene......... 50

Figure 48. Annual simulation results for Wall 2 of Pair 1................................................................... 51

Figure 49. Mold growth index on the exterior sheathing (OSB) cavity side as predicted by the simulation model for Pair 1 walls with different VR options: no VR, Kraft faced insulation, and polyethylene. .52

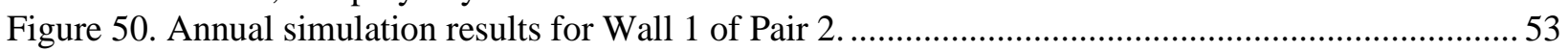

Figure 51. Annual simulation results for Wall 2 of Pair 2 ................................................................. 54 


\section{LIST OF TABLES}

Table 1. HAM chamber specifications.

Table 2. Sensors used in the feedback control loop of the climate chamber environment. ........................ 3

Table 3. Sensors used to measure the hygrothermal state of the test wall materials and the airflow through the wall.

Table 4. Materials used in hygrothermal simulations and the selected material properties........................ 9

Table 5. RMSE between the measured and simulated temperature (T) and relative humidity in the XPS wall with a polyethylene interior VR.

Table 6. RMSE between the measured and simulated temperature $(\mathrm{T})$ and relative humidity in the wall with no VR.

Table 7. RMSE for Wall 1 and Wall 2 of Pair 2 for temperature (T) and RH. 



\section{EXECUTIVE SUMMARY}

Over the past few years, Oak Ridge National Laboratory has demonstrated that WUFI can be used to predict the moisture performance of walls when exposed to diffusion of water vapor, convection of moist air through the wall, and solar-driven moisture. This has been accomplished by comparing the hygrothermal simulation results with carefully instrumented walls exposed to these phenomena in a climate chamber. In FY 2018, three stick-built walls were exposed to typical Chicago, Illinois weather conditions in Oak Ridge National Laboratory's Heat, Air, and Moisture Chamber. The measured temperature, relative humidity, and moisture content within these walls were compared with hygrothermal simulation results. In FY 2019, similar experiments and comparisons with hygrothermal simulation results were completed with two walls: a structural insulated panel-based wall and a concrete masonry unit-based wall. In FY 2020, experiments were completed for a probable exterior retrofit of a wall, which included adding cavity and continuous insulation. Two pairs of walls were tested by exposing them to Chicago winter weather with a positive pressure pushing outside air into the wall. The results from the FY 2020 experiments are reported here.

\section{INTRODUCTION}

This introduction is verbatim from the 2019 report on the previous walls that underwent similar testing in Oak Ridge National Laboratory's Heat, Air, and Moisture (HAM) Chamber (Boudreaux et al. 2019).

Buildings accounted for $41 \%$ of the primary energy consumption (40.2 quads of energy) in the United States in 2010 (DOE 2014). Of this energy, 15.1 quads were consumed by the space heating and cooling of commercial and residential buildings (DOE 2014). Of this amount, 5.8 quads are attributable to roofs and walls and 4 quads to infiltration. Based on these data, reducing thermal conduction and increasing envelope air-tightness are key factors in reducing the energy consumption in buildings. Applicable research has been completed and updated building energy codes have increased the required air tightness and thermal resistance in new constructions across the United States, thereby decreasing the energy consumption of new residential homes by over 30\% since 2006. This trend is shown in Figure 1. According to simulation studies by the National Association of Home Builders, the 2009 and 2012 IECC codes decrease the site energy consumption of the 2006 code-built home by $10.7 \%$ and $33.7 \%$, respectively. According to Pacific Northwest National Laboratory, the 2015 IECC code decreases the site energy consumption of a 2015 code-built home by $1 \%$ more than the 2012 code (Mendon et al. 2015). 


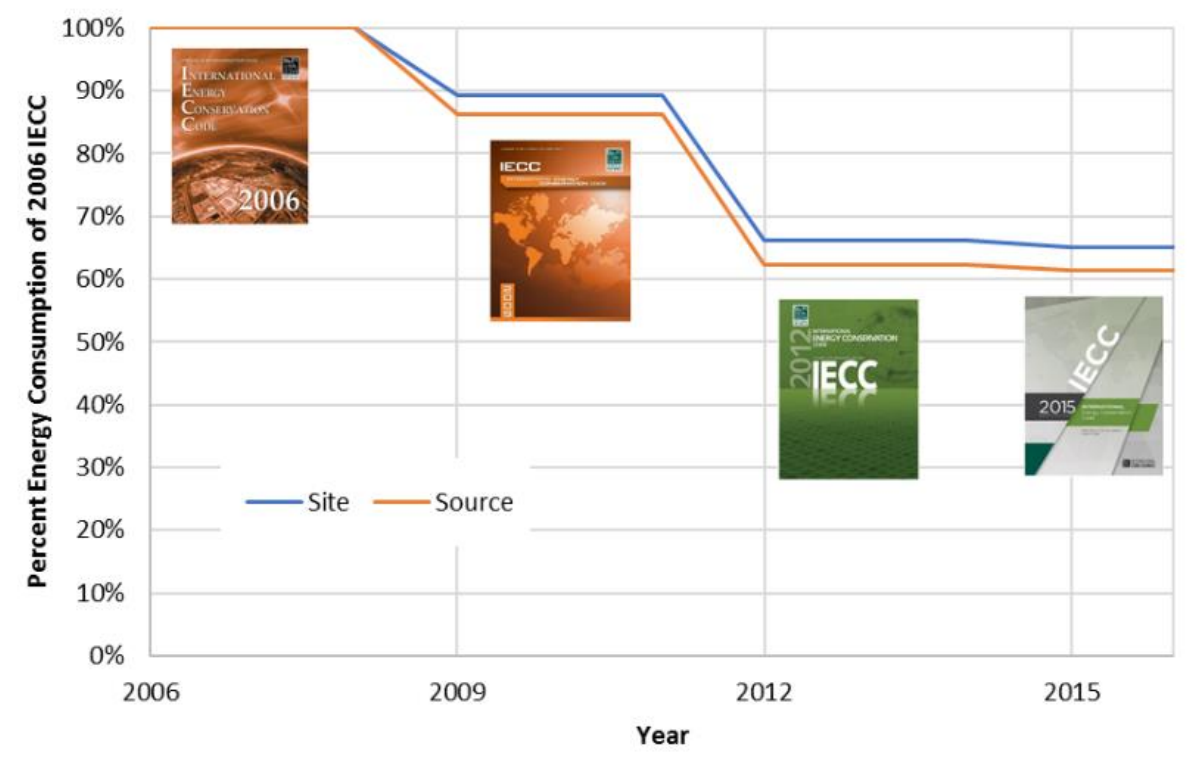

Figure 1. International building codes have decreased the energy consumption of new residential buildings by over 30\% since 2006.

As building envelopes have become more energy-efficient, another challenge has arisen. Moisture plays a key role in building performance. Unwanted moisture can cause mildew, mold, wood rot, fastener corrosion, material degradation through freeze-thaw cycles, condensation on cold surfaces within the envelope, and more. Studies have shown that highly insulated walls have a great risk of high moisture, which can cause structural and health problems. According to Building America, high- $R$ wall assemblies (walls $>R$ 30) have many hours throughout the year when condensation can potentially form inside the wall ("High-R Walls" 2013).

Oak Ridge National Laboratory is developing a web tool, built on a rule-based expert system, that aids stakeholders in designing energy-efficient moisture-durable walls. Currently, the tool's expert system database is mostly populated with expert opinion, but work is being done to incorporate durability assessment based on stochastic hygrothermal modeling. To validate the hygrothermal models that are being used, chamber experiments have been conducted to compare measured temperature and humidity with those the hygrothermal model predicts when the boundary conditions are matched in the model to the experiment. The results from four experiments compared with hygrothermal modeling results will be presented.

\section{METHODS}

\subsection{HAM CHAMBER}

The HAM Chamber at Oak Ridge National Laboratory, shown in Figure 2, was used for the experimental trials to determine the moisture performance of the walls exposed to a month of Chicago, Illinois winter weather. The test chamber can emulate interior and exterior environments on either side of the wall. The HAM chamber specifications are displayed in Table 1. 


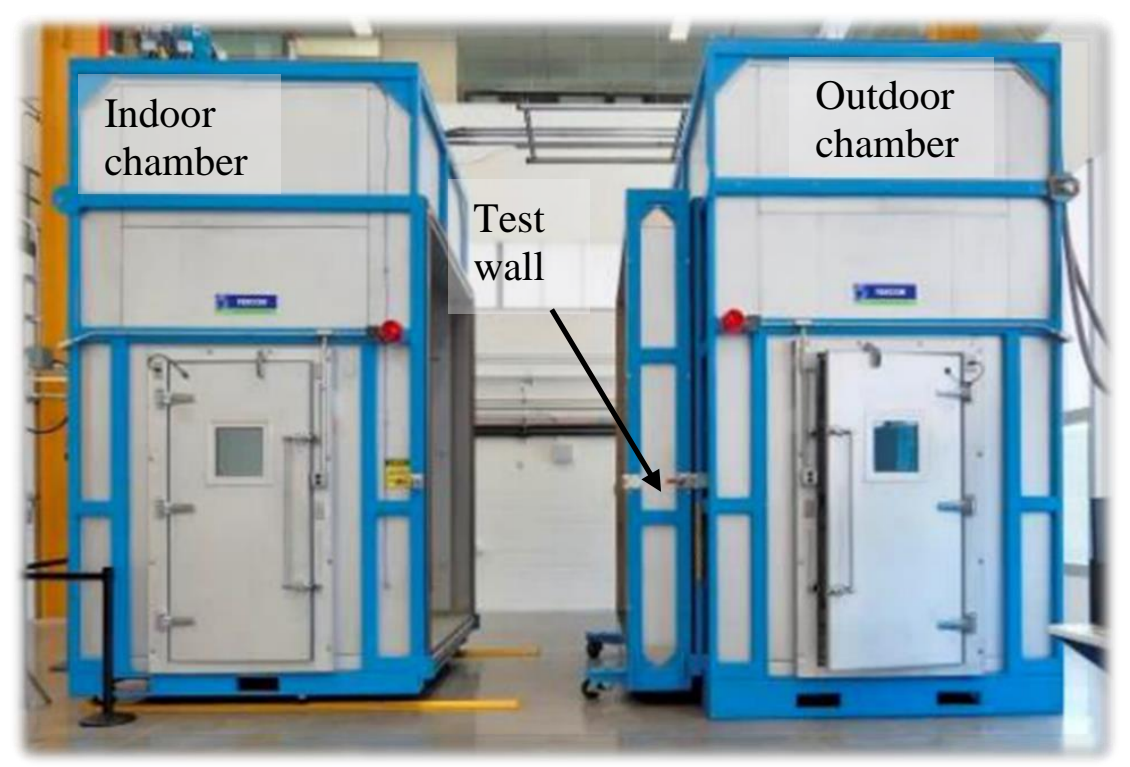

Figure 2. Oak Ridge National Laboratory HAM chamber. The indoor chamber slides so that the test wall can be rolled in and out.

Table 1. HAM chamber specifications.

\begin{tabular}{|l|l|l|}
\hline & \multicolumn{1}{|c|}{ Indoor chamber } & \multicolumn{1}{c|}{ Outdoor chamber } \\
\hline Dry bulb temperature $\left({ }^{\circ} \mathbf{F}\right) *$ & $30-90$ & $0-110($ ramp rate $1-1.5 / \mathrm{min})$ \\
\hline Relative humidity $(\boldsymbol{\%})^{*}$ & $10-90$ & $10-90$ \\
\hline Dew point $\left({ }^{\circ} \mathbf{F}\right)^{*}$ & $7-80$ & $-5-90$ \\
\hline Pressure $\left(\mathbf{w . r . t}\right.$ ambient) $(\mathbf{P a})^{*}$ & $0-75$ (sustained) & $\pm 1,200$ (pulsed), \pm 75 (sustained) \\
\hline Precipitation $\left(\mathbf{f t}^{\mathbf{3}} / \mathbf{m i n}\right)$ & - & $\leq 1$ \\
\hline Precipitation temperature $\left({ }^{\circ} \mathbf{F}\right)$ & - & $40-95$ \\
\hline Solar insolation* $\left(\mathbf{W}_{\mathbf{f}} \mathbf{f t}^{\mathbf{}}\right)$ & - & $\leq 100$ \\
\hline
\end{tabular}

*Steady state and transient—diurnal cycles

The HAM chamber is controlled with custom LabVIEW virtual instruments, which allow the emulation of a diurnal cycle of temperature, relative humidity (RH), differential pressure, and solar insolation in the chamber. The sensors used for feedback control of the interior and exterior chamber air are listed in

Table 2. Table 3 shows other sensors used to measure the temperature, RH, and moisture content inside the test wall and the volumetric airflow through the wall.

Table 2. Sensors used in the feedback control loop of the climate chamber environment.

\begin{tabular}{|l|l|l|l|}
\hline \multicolumn{1}{|c|}{ Sensor } & \multicolumn{1}{c|}{ Model } & \multicolumn{1}{c|}{ Range } & \multicolumn{1}{c|}{ Accuracy } \\
\hline Temperature & Vaisala HMT330 & $-40^{\circ} \mathrm{F}-176^{\circ} \mathrm{F}$ & $\pm 0.36^{\circ} \mathrm{F} @ 68^{\circ} \mathrm{F}$ \\
\hline RH & Vaisala HUMICAP 180 & $0-97 \%$ & $\begin{array}{l} \pm 0.6 \% \mathrm{RH}(0 \% \text { to } 40 \% \mathrm{RH}) @ 68^{\circ} \mathrm{F} \\
\pm 1 \% \mathrm{RH}(40 \% \text { to } 97 \% \mathrm{RH}) @ 68^{\circ} \mathrm{F}\end{array}$ \\
\hline Pressure & Rosemount $2051 \mathrm{CD}$ & $\pm 288,000 \mathrm{lb} / \mathrm{ft}^{2}$ & $\pm 0.075 \%$ Full Scale \\
\hline
\end{tabular}


Table 3. Sensors used to measure the hygrothermal state of the test wall materials and the airflow through the wall.

\begin{tabular}{|l|l|l|l|}
\hline \multicolumn{1}{|c|}{ Sensor } & \multicolumn{1}{c|}{ Model } & \multicolumn{1}{c|}{ Range } & \multicolumn{1}{c|}{ Accuracy } \\
\hline Temperature & Type T Thermocouple & $-380^{\circ} \mathrm{F}-392^{\circ} \mathrm{F}$ & $\pm 1.8^{\circ} \mathrm{F}$ \\
\hline RH $(\%)$ & Honeywell HIH-4000-003 & $0 \%-100 \%$ & $\pm 3.5 \% \mathrm{RH}$ \\
\hline Flowmeter & $\begin{array}{l}\text { EPI } 8732 \text { MPNH-SSS-133- } \\
\text { DC24 }\end{array}$ & $0.16-32 \mathrm{SCFM}$ & $\begin{array}{l} \pm(1 \% \mathrm{RDG}+[0.5 \% \mathrm{FS}+0.02 \% \\
\left.\left.\mathrm{FS} /{ }^{\circ} \mathrm{C}\right]\right)\end{array}$ \\
\hline Moisture content & $\begin{array}{l}\text { Temperature and species- } \\
\text { corrected moisture pins }\end{array}$ & $6 \%-30 \%$ & - \\
\hline
\end{tabular}

\subsection{EXPERIMENTAL PLAN}

Four walls were tested in the HAM chamber in pairs. The first pair uses low-permeance continuous insulation (CI) with a high and low interior side vapor permeance. Shown in Figure 3, these walls were meant to test the performance of low-permeance CI ( 2 in. extruded polystyrene [XPS]) with and without an interior vapor retarder (VR). From the outside to inside layer, the first pair consisted of vinyl siding, a 5/8 in. air gap, 2 in. of XPS CI, $15 \mathrm{lb}$ of felt paper, oriented strand board (OSB) sheathing, a $2 \times 624$ in. on-center wood frame with fiberglass insulation, gypsum board (GB), and latex paint. One wall had a polyethylene sheet as the interior VR between the gypsum and the cavity. The other wall had no interior VR. In both walls, the gypsum, sheathing, and CI had horizontal joints $4 \mathrm{ft}$ from the bottom. In Figure 3 , the blue dots indicate the location of combo probes that measured the RH and dry bulb temperature. The combo probes were located along an imaginary horizontal line a few inches above the centerline of the wall. The green dots indicate the location of moisture content measurements with the associated temperature of the wood. These two walls were built up in a single wall frame so that they could be tested simultaneously. 


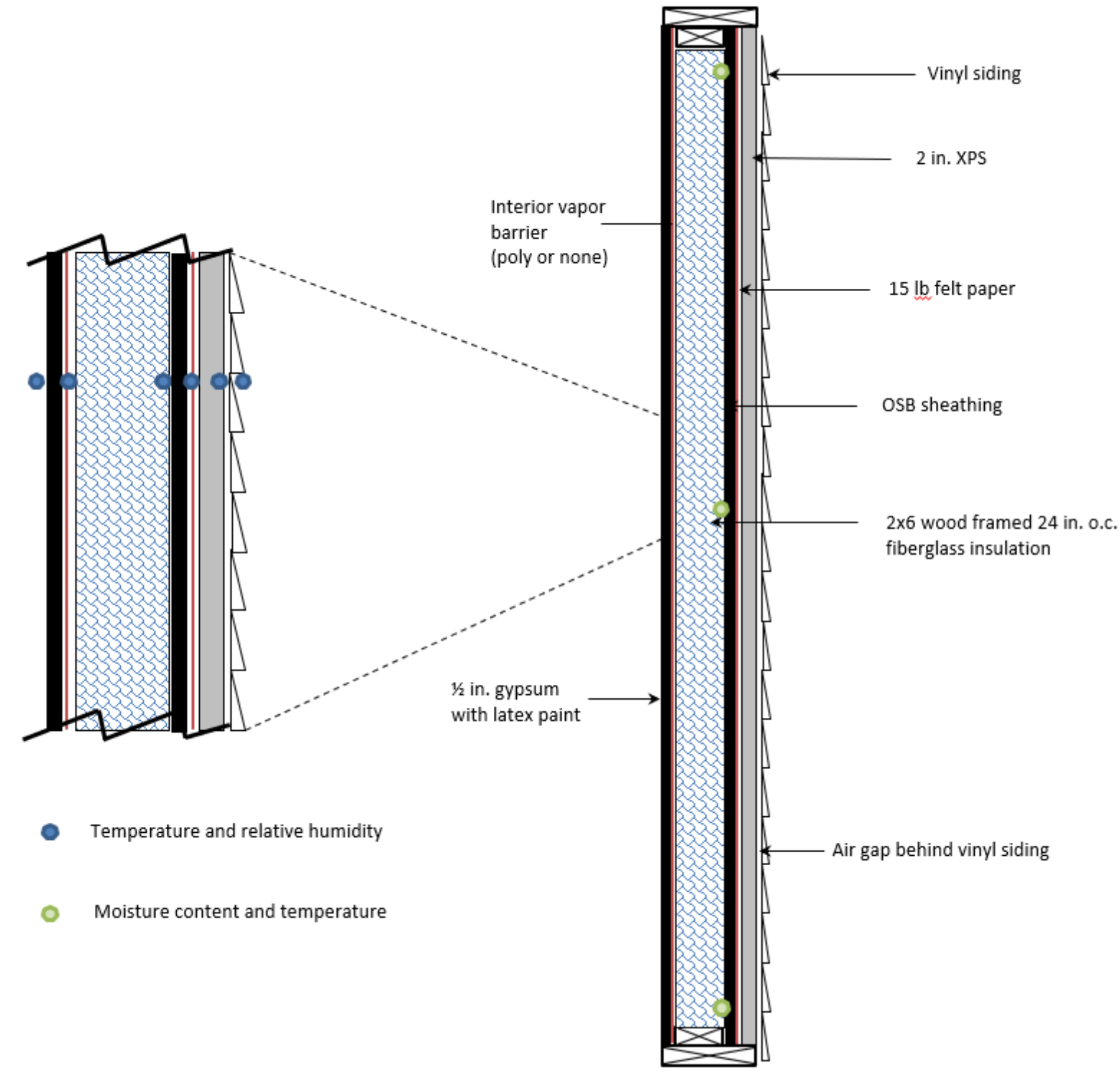

Figure 3. Schematic of the low-permeance CI walls to be tested in the chamber. One wall had a low-permeance interior vapor permeance (polyethylene interior VR) and the other had a high-permeance interior vapor permeance with no interior VR. The blue dots indicate the location of combo probes that measured the RH and dry bulb temperature. The green dots indicate the location of moisture content measurements with the associated temperature of the wood.

The second pair of walls was built to investigate the performance of high-permeance CI ( 3 in. mineral wool) with two different weather resistive barriers (WRBs). One wall had $15 \mathrm{lb}$ of felt paper (Felt) and the other had spun-bonded polyolefin (SBP) as the WRB. There was no interior VR except for the latex paint on the gypsum as shown in Figure 4. 


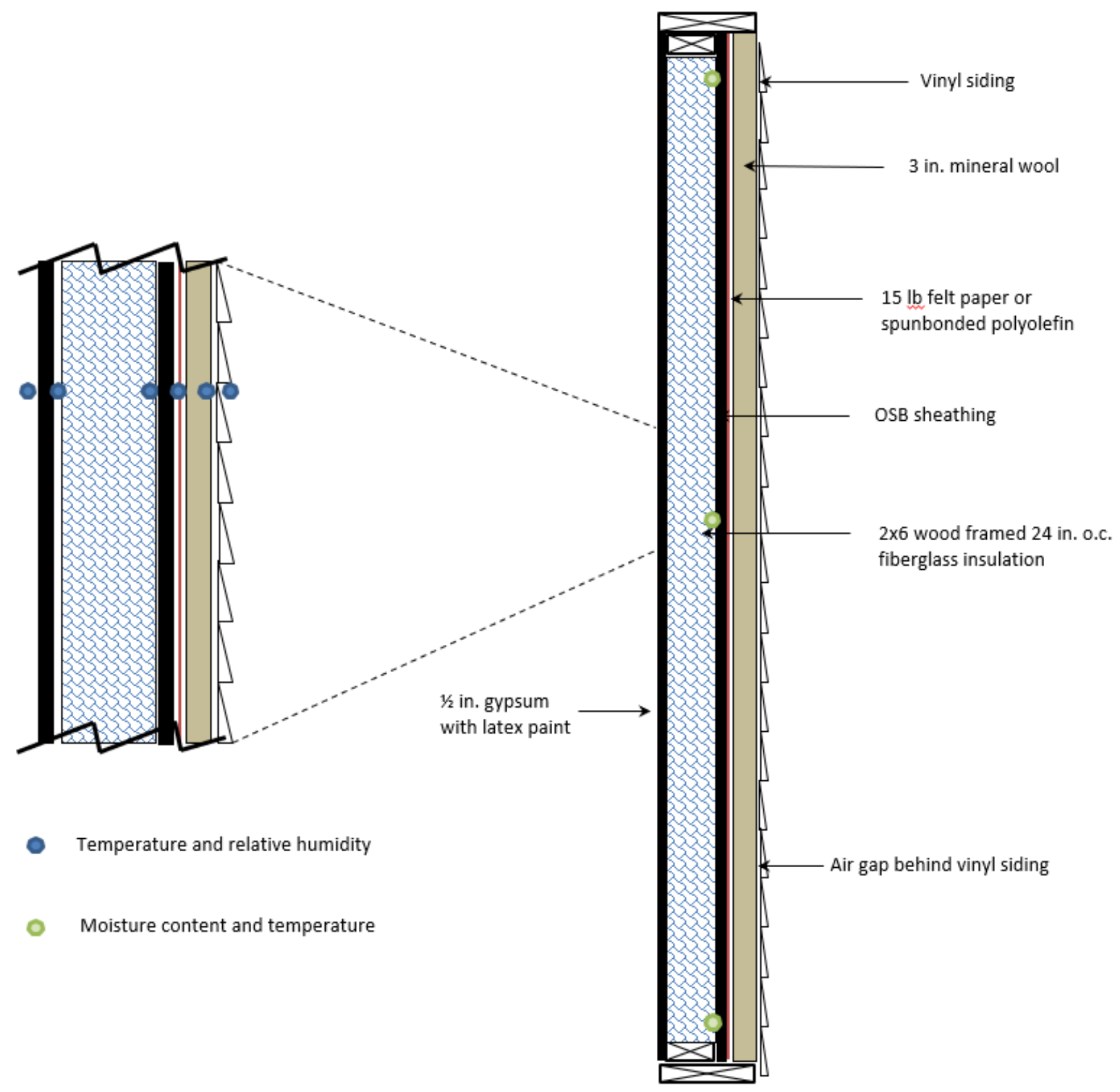

Figure 4. Schematic of the high-permeance CI walls tested in the chamber. Each wall had a different WRB, one used $15 \mathrm{lb}$ of felt building paper, and the other had spun-bonded olefin. The blue dots indicate the location of combo probes that measured the RH and dry bulb temperature. The green dots indicate the location of moisture content measurements with the associated temperature of the wood.

For these long-term tests, winter conditions were emulated in the outdoor room of the chamber. Diurnal temperature and RH data from the Chicago, Illinois cold-year weather conditions from the WUFI meteorological database were used. Figure 5 shows the month-long test targets for the exterior condition that were emulated for the XPS walls (blue square) and the mineral wool walls (red square). A 20-Pa pressure difference was applied across the wall to emulate air-infiltration for a portion of the test period. For the interior boundary condition, the indoor chamber was set to a constant $75^{\circ} \mathrm{F} / 50 \% \mathrm{RH}$ for summer and a constant $68^{\circ} \mathrm{F} / 40 \% \mathrm{RH}$ for winter. 


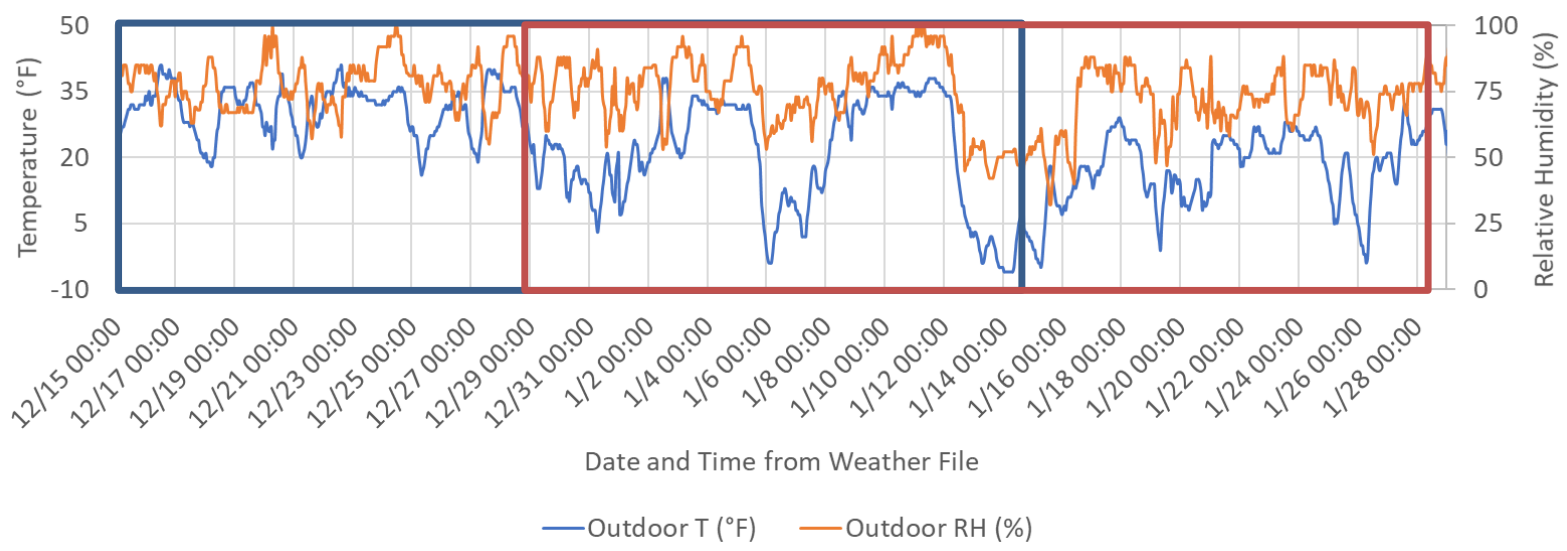

Figure 5. Exterior boundary conditions for the test wall were taken from the cold-year Chicago weather conditions file from WUFI. The blue box indicates the weather conditions that were emulated in the chamber for the walls with XPS ( $\mathrm{T}=$ temperature), and the red box shows the conditions for the walls with mineral wool exterior insulation.

\subsection{CHARACTERIZING WALL INFILTRATION}

The air infiltration was only measured for the mineral wool walls using the ASTM E283 Standard Test Method. To measure the volumetric airflow rate versus pressure differential, a calibrated EPI thermal mass flowmeter was used as described in Table 3. The leakage was characterized as the power law shown in Eq. (1), where $C$ is the flow coefficient and $n$ is the flow exponent, which are both found experimentally; $P$ is the pressure differential across the wall in pascals, and $Q$ is the resulting volumetric airflow through the wall in cubic feet per minute (CFM).

$$
Q=C P^{n}
$$

Figure 7 shows the results of the leakage at various pressure differentials for the entire wall frame, which includes the header and both mineral wool walls and is shown in Figure 6. At the operating pressure of 20 $\mathrm{Pa}$ the leakage through the entire frame is about $1 \mathrm{CFM}$. 

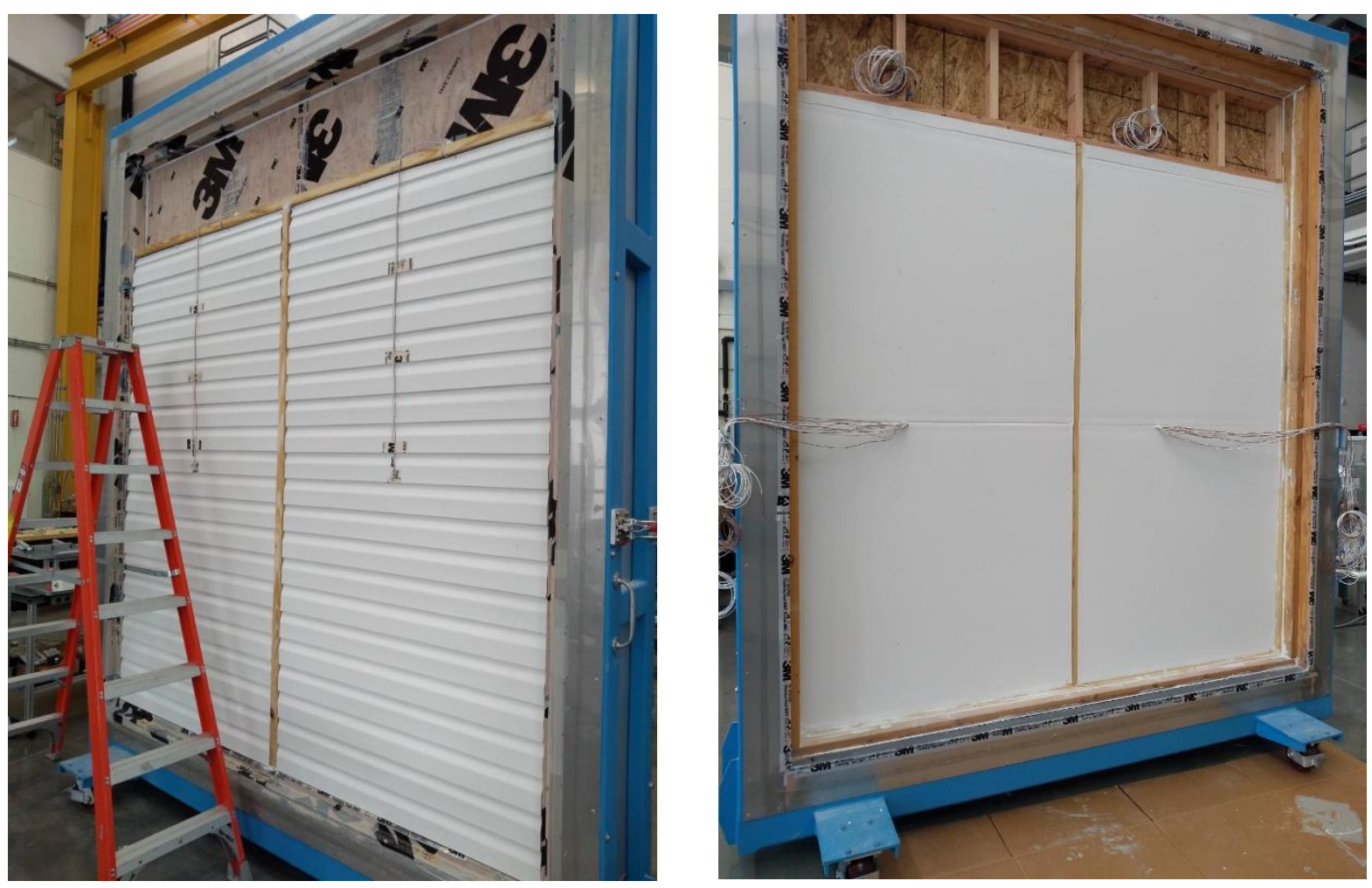

Figure 6. (left) Exterior and (right) interior of the wall frame showing the header and both high-vapor permeance CI (mineral wool) walls.

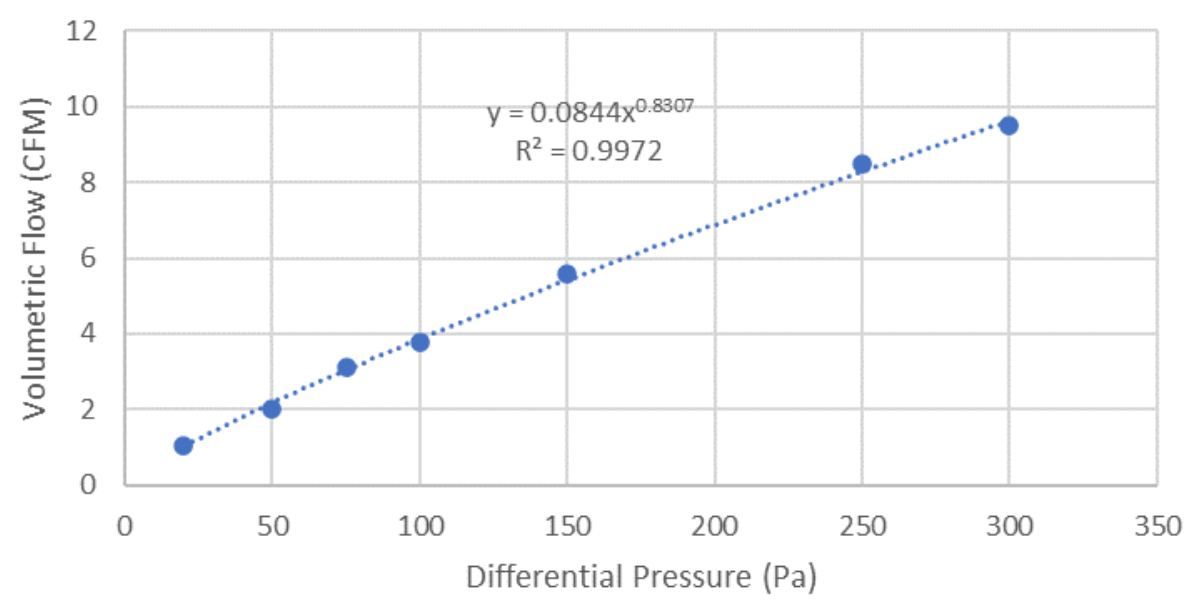

Figure 7. Volumetric leakage versus differential pressure for the whole wall frame for mineral wool walls.

\subsection{HYGROTHERMAL MODEL}

WUFI Pro Version 6.4 was used for modeling the transient, one-dimensional heat and moisture transfer in these walls. For details about this software and how it was used, please see Section 2.4 of the 2019 project report (Boudreaux et al. 2019). 


\subsubsection{Material Properties in Simulations}

The materials for the simulations were taken from the WUFI databases (Table 4). The hygrothermal properties of the actual materials in the test walls were not measured for input into the simulation. All materials are referred to in the WUFI material database.

Table 4. Materials used in hygrothermal simulations and the selected material properties.

\begin{tabular}{|l|l|}
\hline \multicolumn{1}{|c|}{ Layer name } & \multicolumn{1}{c|}{ WUFI database material } \\
\hline Vinyl siding & $\begin{array}{l}\text { Created from polyethylene by } \\
\text { increasing thickness }\end{array}$ \\
\hline Air cavity & $\begin{array}{l}\text { Air layer } 10 \text { mm; without } \\
\text { additional moisture capacity }\end{array}$ \\
\hline WRB & $\begin{array}{l}\text { Bituminous paper (\#15 felt) and } \\
\text { spun bonded polyolefin } \\
\text { membrane }\end{array}$ \\
\hline Mineral fiber insulation & Rockwool Comfortboard 80 \\
\hline XPS, 2 in. & XPS \\
\hline OSB, $7 / 16$ in. & OSB low \\
\hline Fiber glass insulation & $\begin{array}{l}\text { Low-density glass fiber batt } \\
\text { insulation }\end{array}$ \\
\hline Vapor retarder & $\begin{array}{l}\text { Polyethylene membrane (Poly: } \\
0.07 \text { perm) }\end{array}$ \\
\hline Interior gypsum board, $1 / 2$ in. & Gypsum board (USA) \\
\hline
\end{tabular}

\section{DISCUSSION AND RESULTS}

\subsection{XPS WALLS}

The low-permeance CI walls, with 2 in. of XPS, were exposed to 31 days of Chicago winter weather. In the following sections, the chamber weather emulation, hygrothermal performance of the wall, and comparisons to WUFI simulations will be discussed.

\subsubsection{Weather Emulation}

\subsubsection{Indoor side}

Figure 8 shows the temperature and RH in the indoor chamber during the test versus the targets. The indoor chamber temperature stayed very close to the target of $68^{\circ} \mathrm{F}$. However, large spikes could occur daily in the RH, rising $10 \%-20 \%$ above the target of $40 \% \mathrm{RH}$. This occurred when the chamber's steam generator, which provides humidity, underwent a blow-down to help clean out any mineral deposits. Because of limited access to the lab during the COVID-19 pandemic, this was not noticed until the mineral wool walls were put into the chamber. Once noticed, the blow-down feature of the steam generator was turned off. 


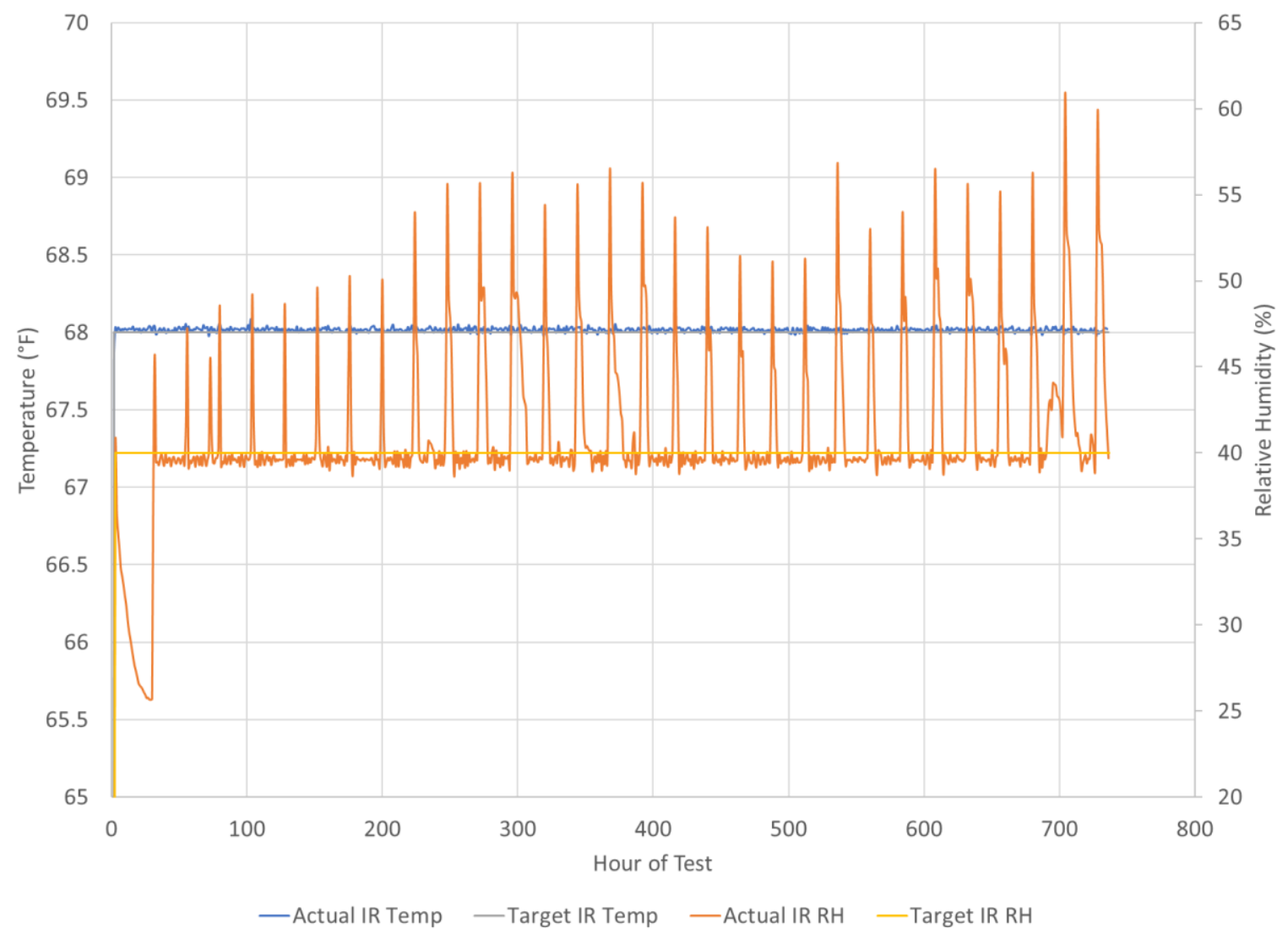

Figure 8. The indoor side of the chamber had targets of $68^{\circ} \mathrm{F}$ and $40 \% \mathrm{RH}$. The daily spikes in indoor RH were due to the indoor room (IR) steam generator blow-down, which helps keep the steam generator from clogging with mineral deposits.

\subsubsection{Outdoor side}

Figure 9 shows the temperature and RH in the outdoor chamber during the test versus the targets, which follow the WUFI Chicago cold-weather file from December 15 to January 11. The temperature and RH stayed close to the targets except at times when the dry bulb temperature was very low for an extended period $\left(<10^{\circ} \mathrm{F}\right.$ for more than a few hours). In these cases, the chamber could not keep the $\mathrm{RH}$ at the low target. The small spikes along the measured temperature and RH were due to the chamber coils undergoing defrost twice a day. 


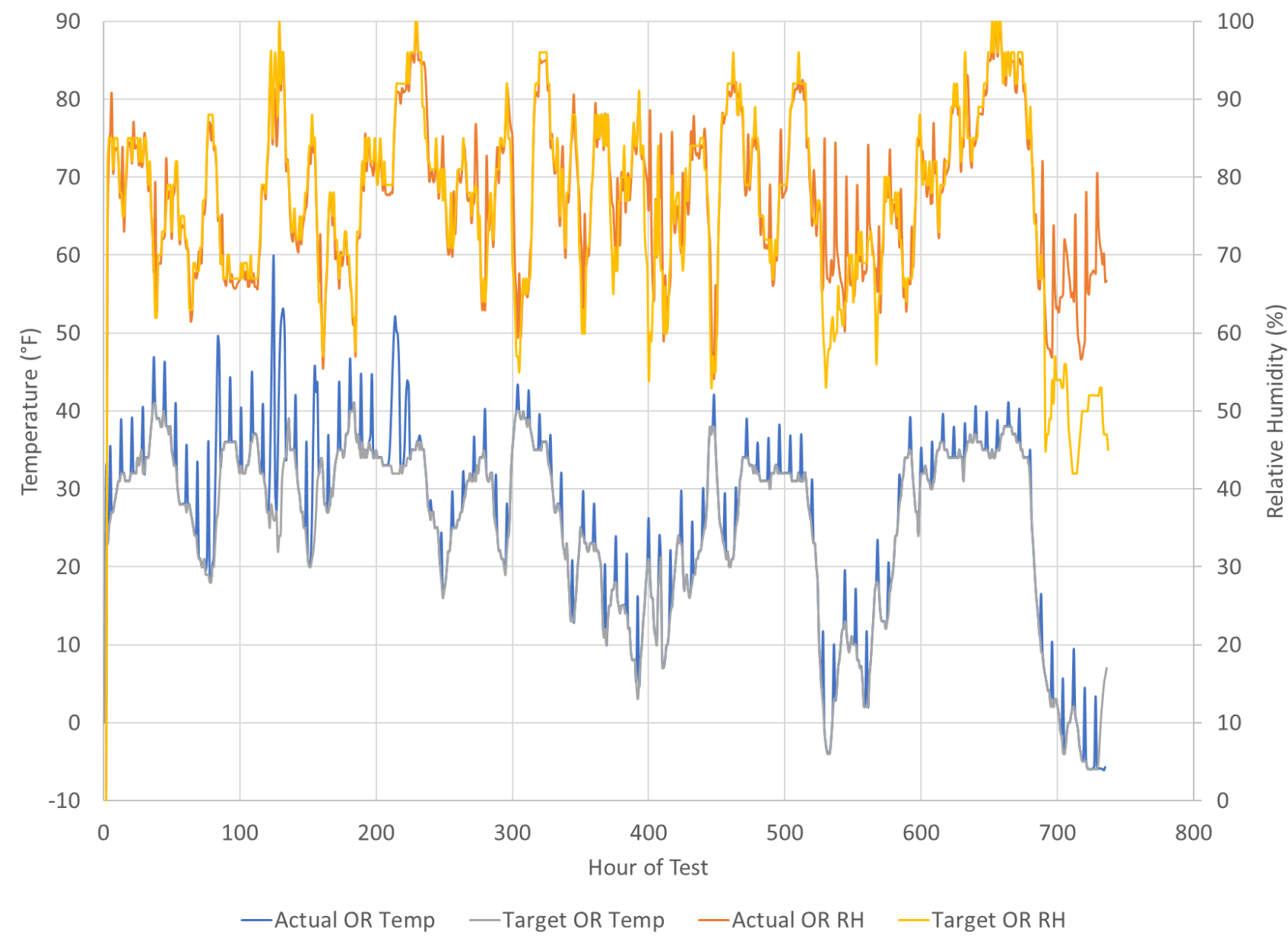

Figure 9. Outdoor chamber temperature and RH change according to the WUFI Chicago weather file. The outdoor room (OR) stayed close to the target, but toward the end of the experiment, the RH was difficult to keep as low as the target because the chamber temperatures were very cold for a significant amount of time.

Figure 10 shows the measured cladding temperature of the vinyl siding during the test in comparison with the target, which was determined using a hygrothermal simulation of the walls being tested and the outdoor conditions of Chicago. Initially, a light rack was used to heat the cladding as it would have been in the field, but we found that the light rack was not needed. After about $200 \mathrm{~h}$ into the experiment, the light rack was shut off and the temperature of the cladding stayed closer to the target. 


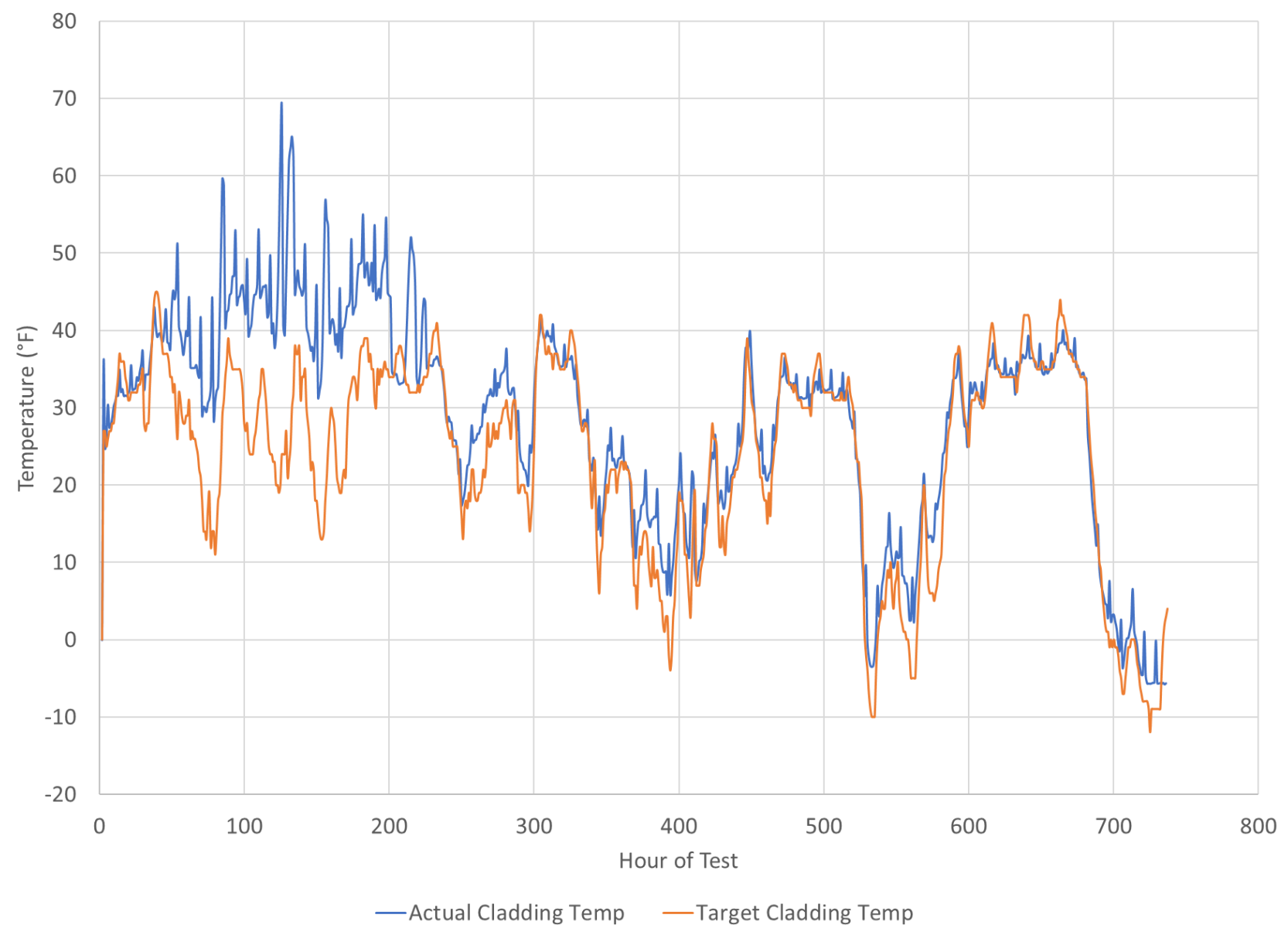

Figure 10. The cladding temperature target changed along with the outdoor weather. Initially, a light rack was used to try to maintain the vinyl siding temperature, but after $\sim 210 \mathrm{~h}$, they were turned off.

\subsubsection{Wall Performance Measurements compared with WUFI Predictions}

\subsubsection{Measured performance of a wall with a polyethylene interior VR}

The following plots show the measured temperature (Figure 11), measured RH (Figure 12), and moisture content (Figure 13) of the OSB sheathing of the wall with the low-vapor permeance interior VR, polyethylene. The moisture content was calculated using a temperature-corrected method for OSB (Boardman, Glass, and Lebow 2017). 


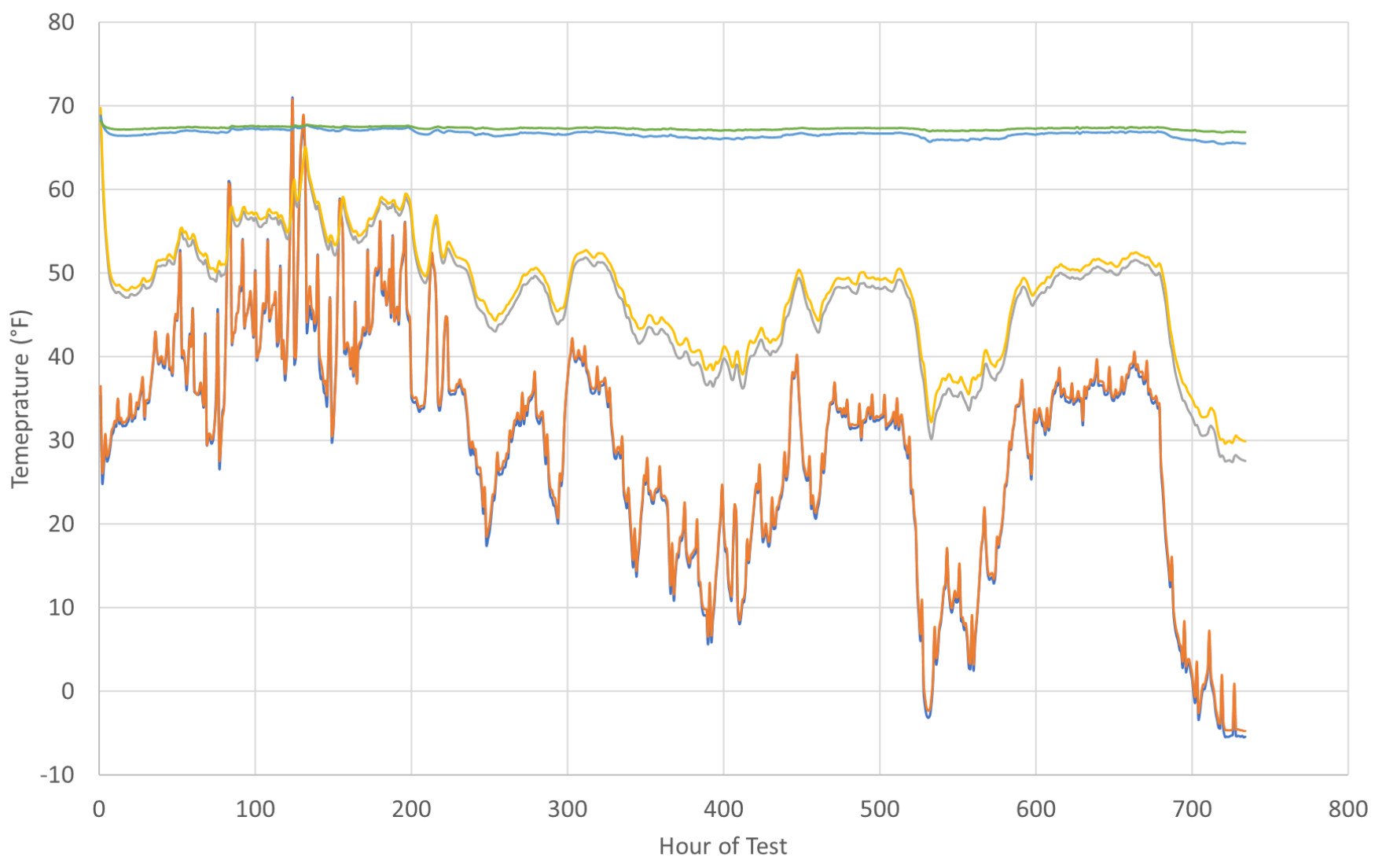

—Wall 1 Exterior Cladding Surface Vinyl Temp —Wall 1 Vinyl Surface Air Space Temp

—Wall 1 OSB Surface Air Space Temp

—Wall 1 OSB Interior Surface Cavity Side Temp

—Wall 1 Gypsum Surface Cavity Side Temp — Wall 1 Gypsum Surface Interior Side Temp

Figure 11. Measured temperature throughout the XPS wall with a polyethylene interior VR. 


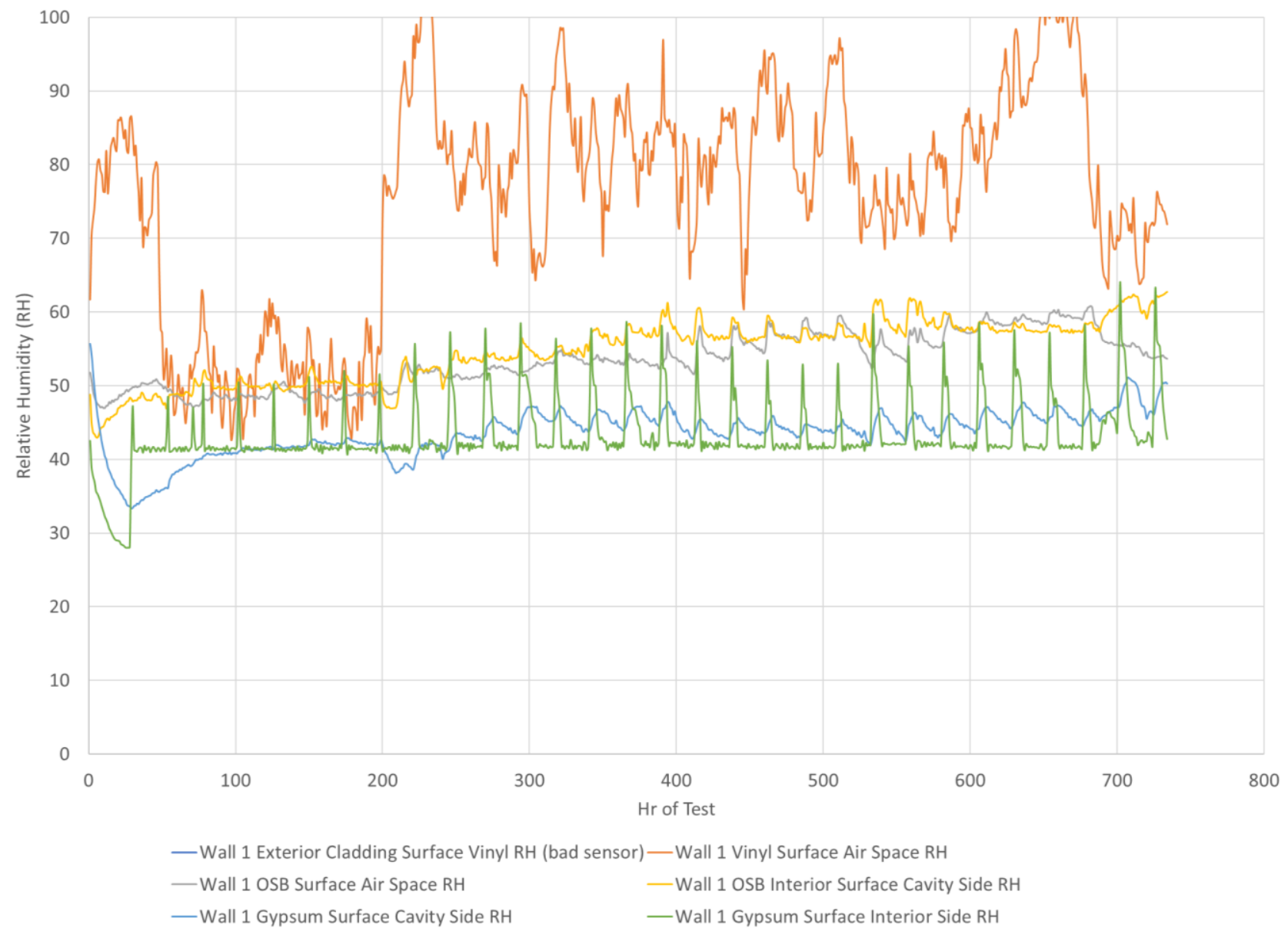

Figure 12. Measured RH throughout the XPS wall with a polyethylene interior VR. 


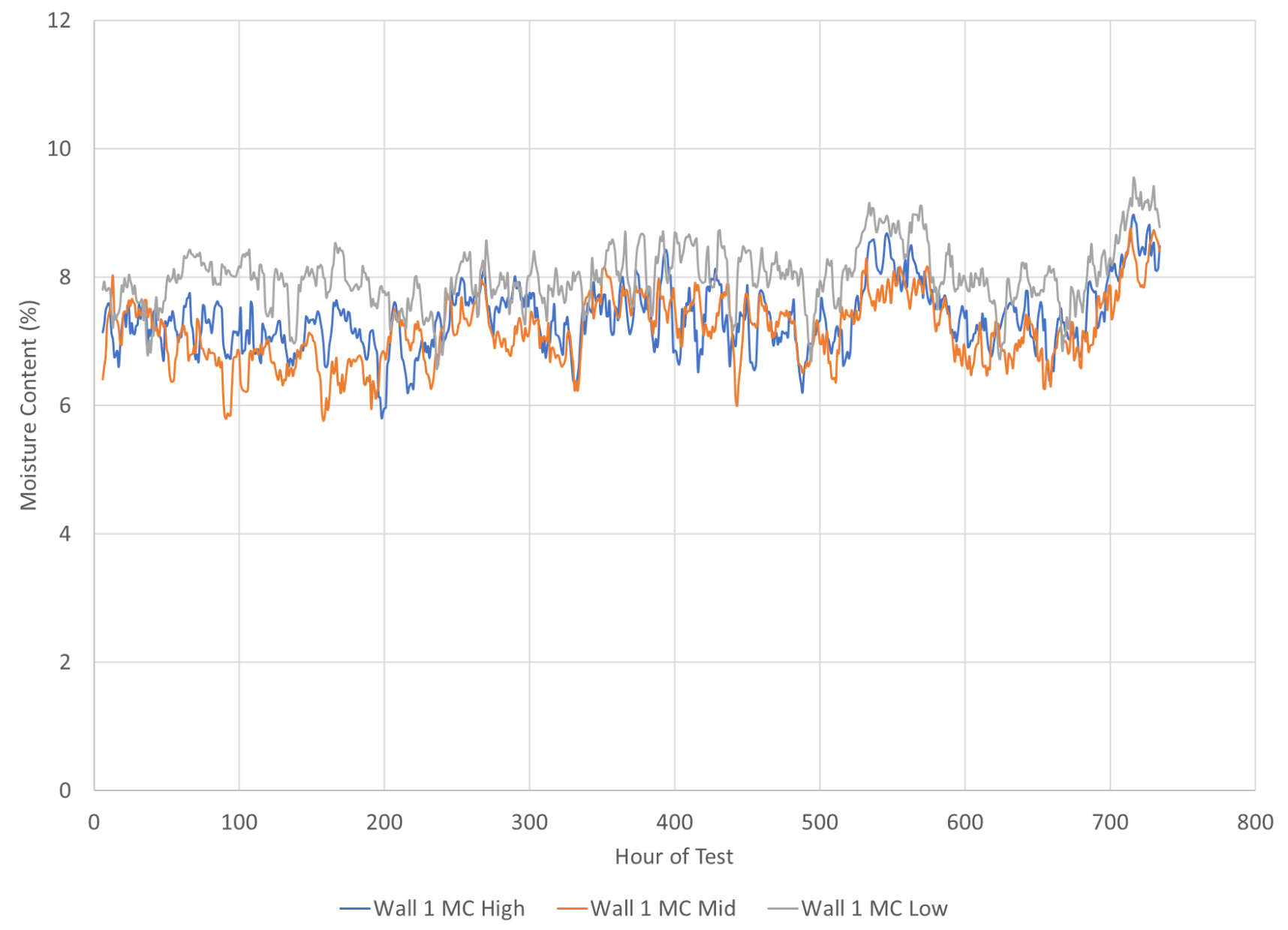

Figure 13. Measured moisture content (MC) at three heights along the cavity side face of the OSB sheathing in the XPS wall with a polyethylene interior VR.

\subsubsection{XPS wall with a polyethylene interior VR - comparison between measured and simulated results}

The XPS wall with a polyethylene interior VR was modeled as shown in Figure 14. The air gap behind the vinyl siding ( $3 / 8$ in.) was ventilated at a constant rate of 20 air changes per hour. The wall was simulated with and without air leakage through the wall. 


\section{Component Assembly}

\section{Case: \#4 2x6 R19+2inXPS+Poly}
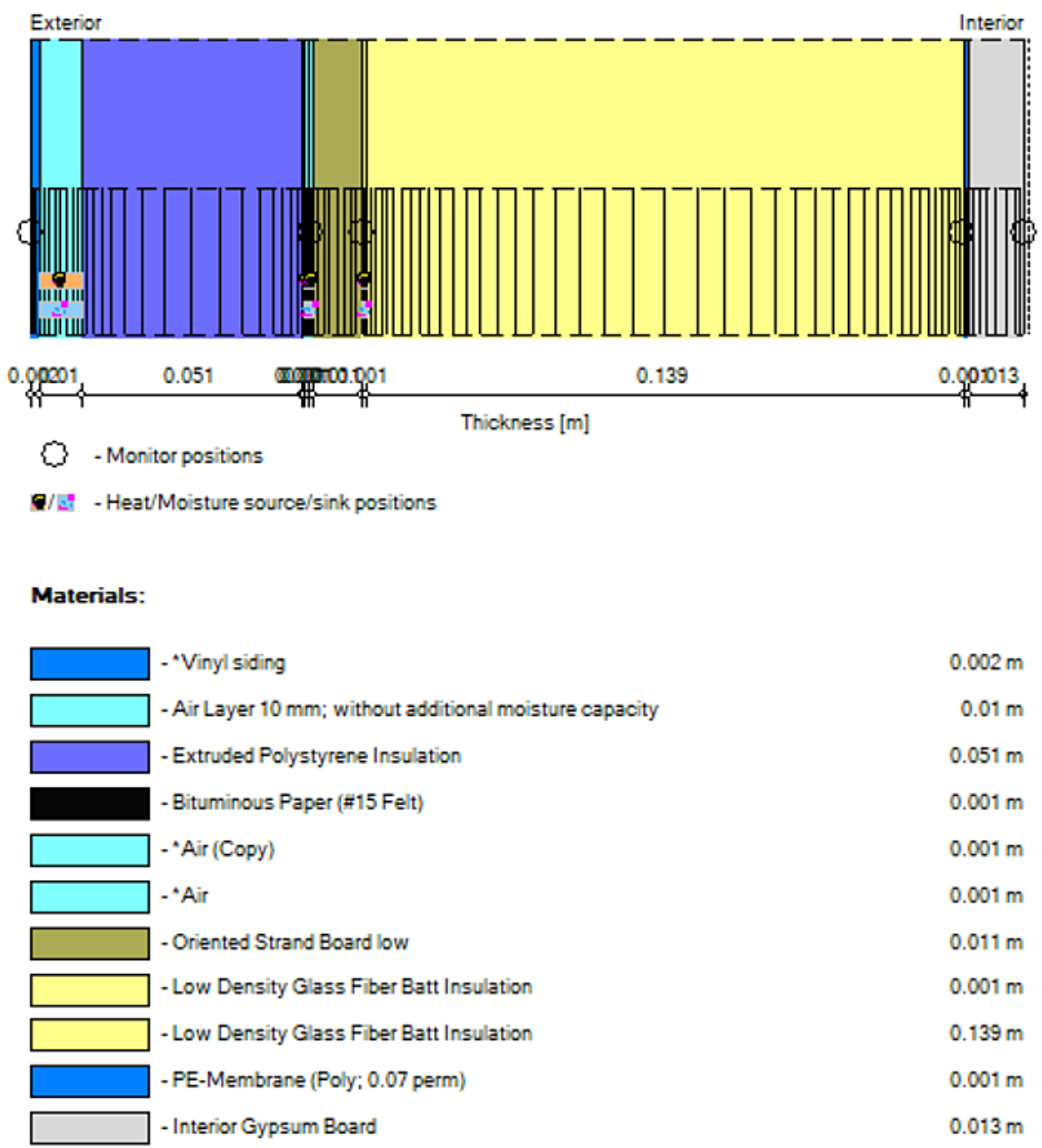

Figure 14. Layers and materials in the simulated WUFI model for the XPS wall with a polyethylene interior $\mathrm{VR}$.

We compared the simulated results to the measurements for the following selected layers in the wall: temperature and RH on the exterior and interior surface of the OSB sheathing and on the indoor side of the cavity insulation, and the moisture content of the OSB sheathing. The initial conditions were assumed to be $50 \% \mathrm{RH}$ and $68^{\circ} \mathrm{F}$ in all the layers.

Air leakage through the walls was estimated based on the overall air leakage of the whole assembly, shown in Figure 7, as a function of differential pressure across the wall. The air leakage through the wall cavity affected the temperatures and moisture in the wall differently depending on how and where the air moved through it. In one-dimensional simulations, and specifically in the WUFI Pro model, the air leakage can be considered as a source term. We did not have individual air leakage measurements for the pairs of the walls, and instead, the air leakage rates were estimated based on the total air leakage. In the simulations, we separated the two walls to leaky and airtight. The wall with the polyethylene as a vapor barrier was considered to have half the leakage of the wall with no VR. The air leakage through the wall was set as a source of air from either outdoor weather or indoor air depending on the pressure difference 
flowing to the insulated cavity and to the air gap between the exterior sheathing (OSB) and the WRB. The air leakage was calculated based on the airtightness of the walls and the measured pressure difference between the indoor and outdoor climate chambers. Two air layers were created to model exfiltration and infiltration: one to allow an air source from the outdoor chamber and one to allow an air source from the indoor chamber. The air leakage model in the hygrothermal model can only take one source location (i.e., outdoor or indoor air) per air leakage, and each location in a layer can only take one source (i.e., overlapping sources are not allowed). The air leakage path was not known, and in one-dimensional modeling, the impact of the path cannot be well considered. We assigned half of the air leaks to the exterior side of the OSB and half of the air leaks to the wall cavity.

Figure 15 indicates the locations of the monitoring points used in comparing the simulated and measured results. Figure 16 compares the measured and simulated temperatures in the polyethylene vapor barrier wall when the walls were simulated with air leakage through the wall. The simulated temperatures matched the measured results very well.

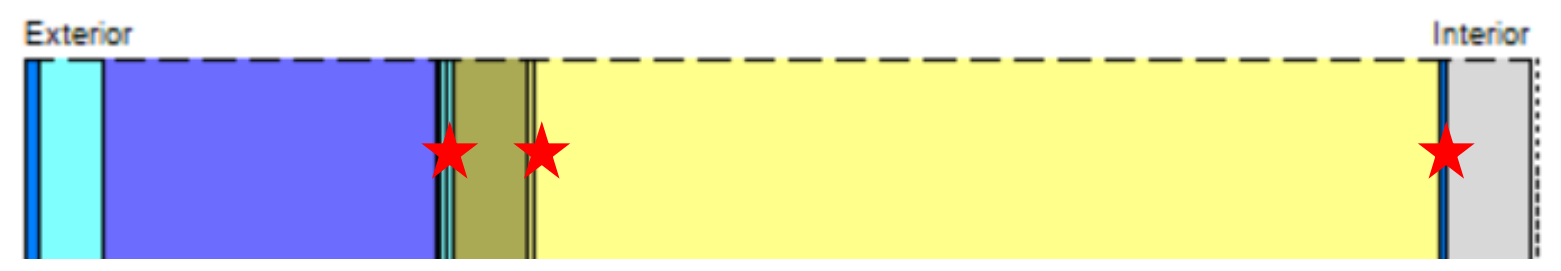

Figure 15. Monitoring points used in comparing the measured and simulated results. 


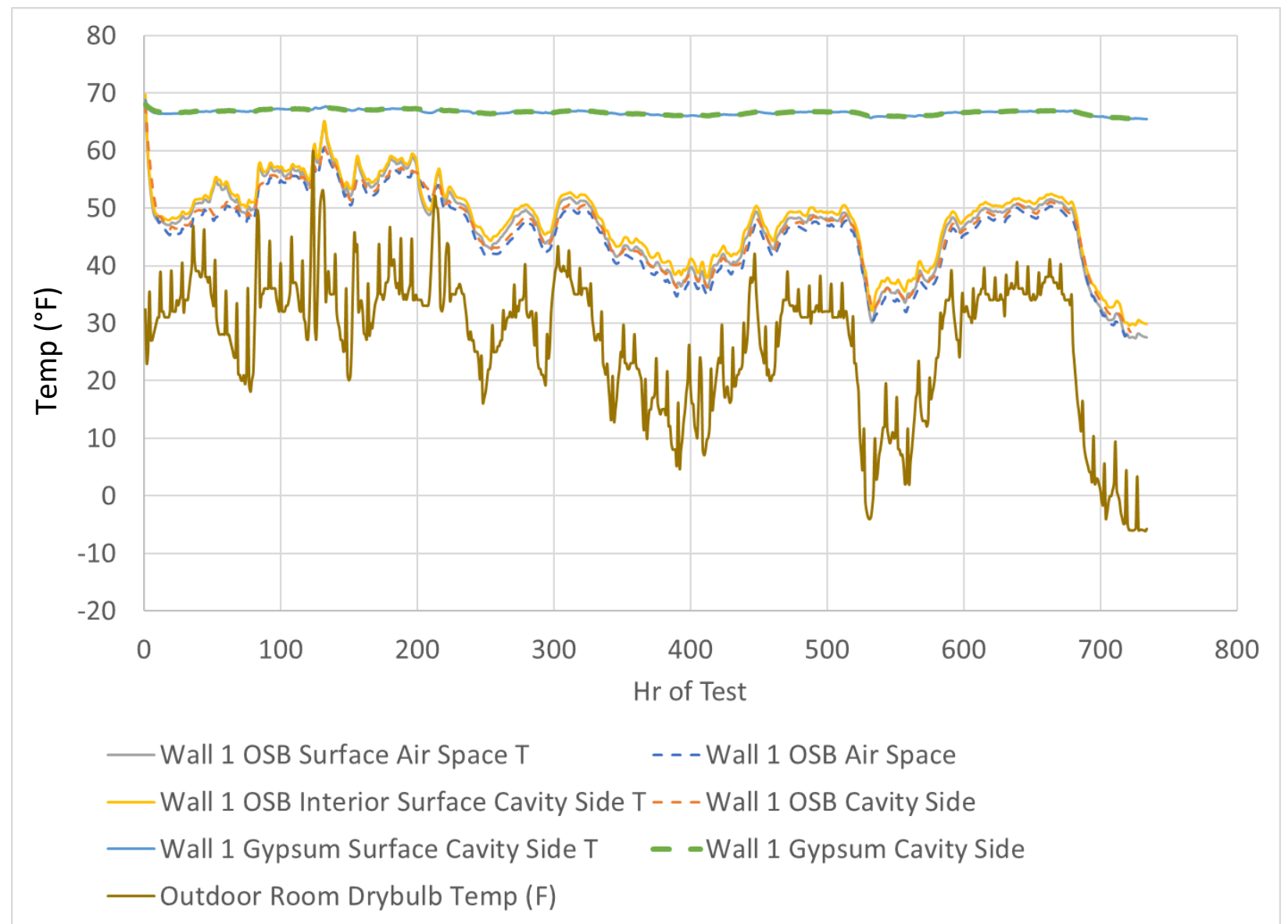

Figure 16. Comparison of measured and simulated temperature (T) in the XPS wall with a polyethylene interior VR with air leakage through the wall. The solid lines are measured data and the dashed lines are simulated data.

The air leakage through the wall did not affect the temperatures noticeably, so only the results with air leakage are reported for the temperatures. However, the impact of the air leaks was significant regarding the humidity as shown in Figure 17 (without air leaks) and Figure 18 (with air leaks). 


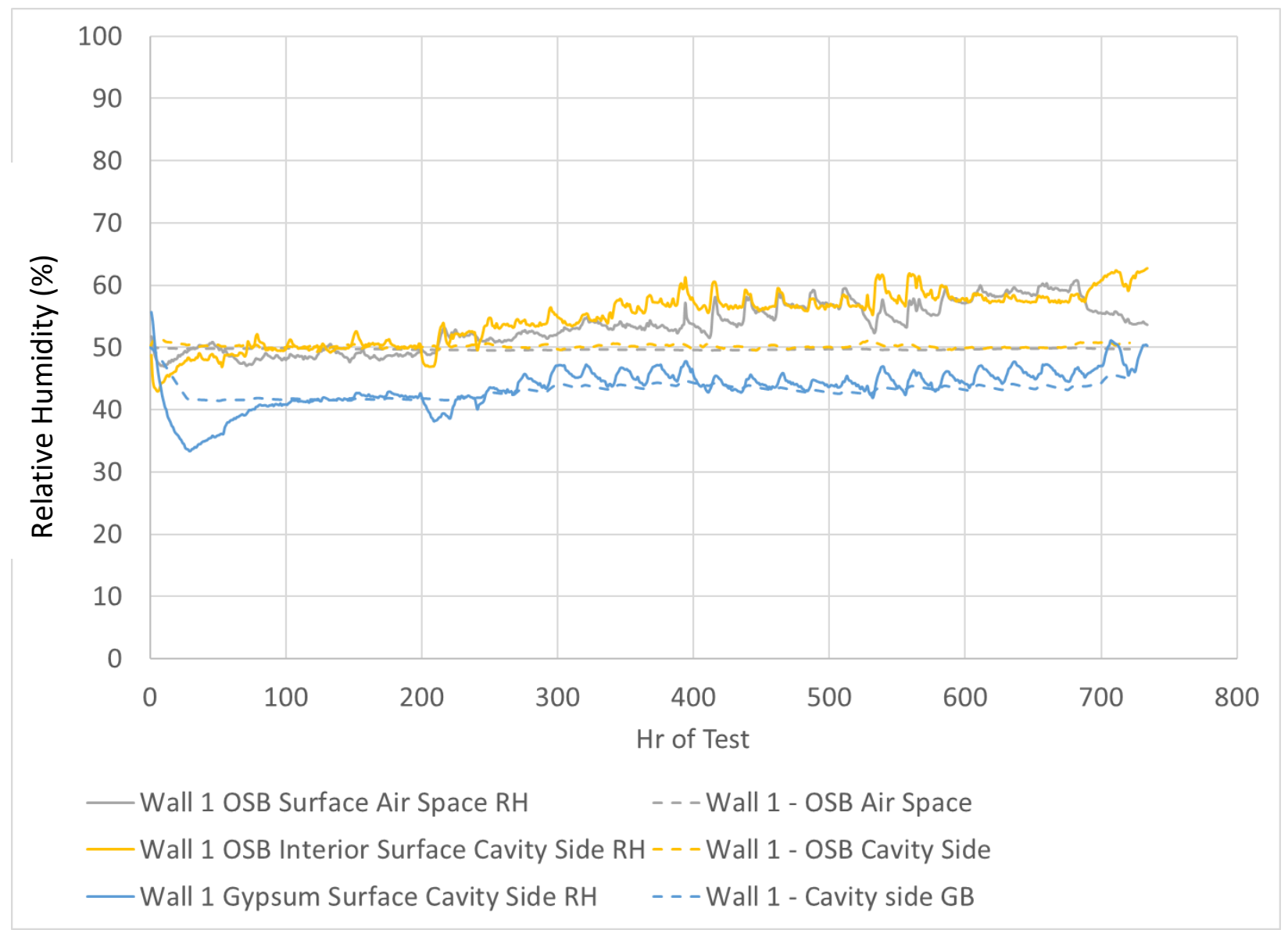

Figure 17. Comparison of measured and simulated relative humidity in the XPS wall with a polyethylene interior VR without air leakage through the wall. The solid lines are measured data and the dashed lines are simulated data. 


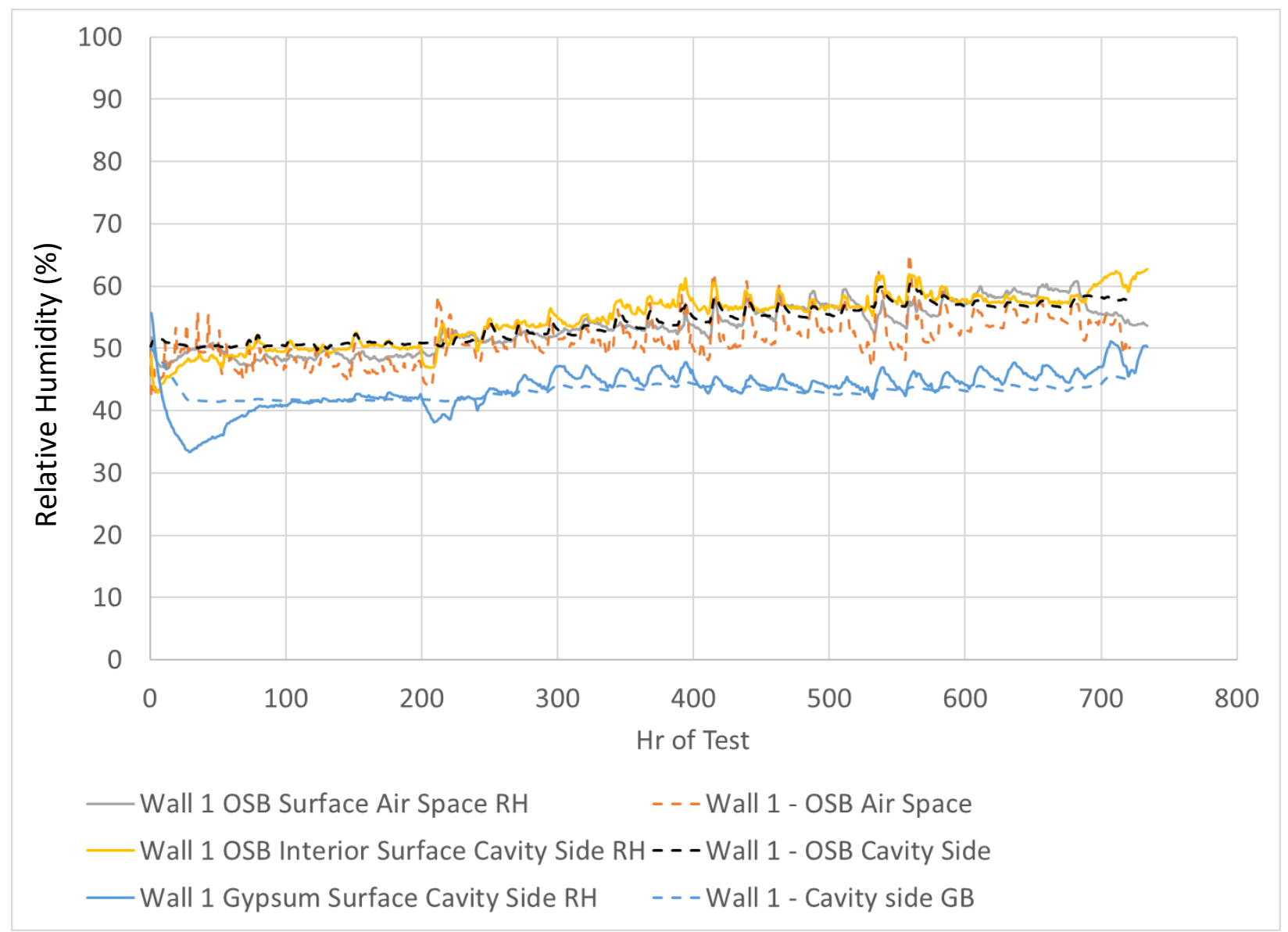

Figure 18. Comparison of measured and simulated relative humidity in the XPS wall with a polyethylene interior VR with air leakage through the wall. The solid lines are measured data and the dashed lines are simulated data.

The simulated RH on the exterior surface of the OSB (Wall 1: OSB air space) without air leaks did not agree well with the measured results (Wall 1 OSB surface air space RH) (Figure 17), and the simulated humidity showed almost no change through the month. The polyethylene VR effectively blocked diffusion. When air leaks are added to the simulations, it becomes clear that the air leaks carried moisture into the wall (Figure 18) and that the daily spikes in the humidity are caused by the fluctuations of the pressure difference across the wall.

Figure 19 shows the measured moisture content of the exterior sheathing as a function of time. The level of moisture content is overall low and at the low credible limit of moisture pins. The difference between the measured and simulated results, approximately $2 \%$ moisture content, can be caused by the equation that correlates the resistance of moisture pins to the moisture content in the material. The moisture content was calculated based on an equation using measured resistance and temperature for OSB (Boardman, Glass, and Lebow 2017) with a root mean square error (RMSE) of $0.726 \%$ moisture content. 


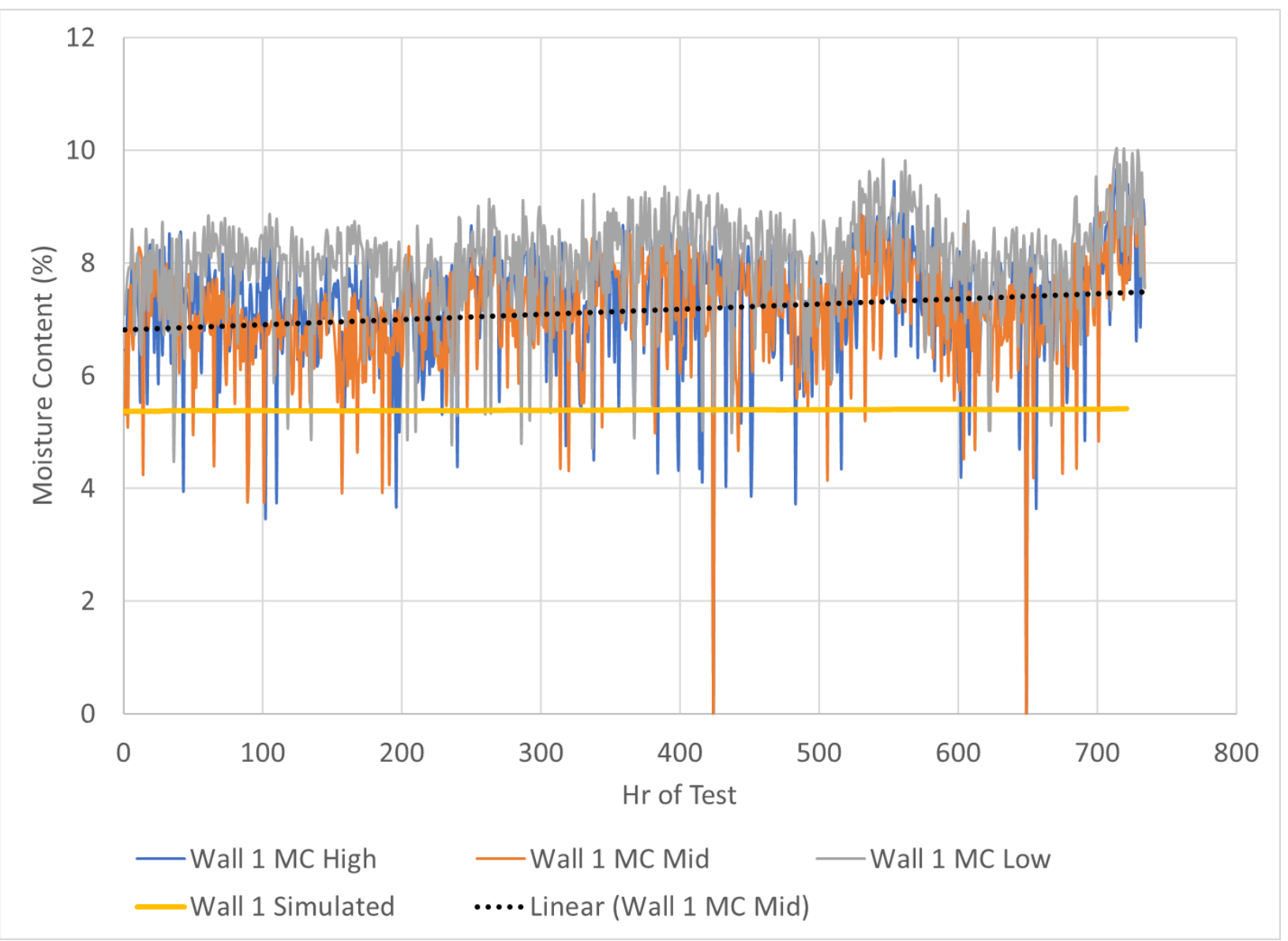

Figure 19. Comparison of measured and simulated moisture content of the exterior sheathing (OSB) in the XPS wall with a polyethylene interior VR with air leakage through the wall.

The calculated RMSE between the measured and simulated values of temperature and RH for this wall is in Table 5 both with and without air leaks in the model. When are leaks are added, the RH predicted by the model is closer to the measured RH as shown by the lower RMSE.

Table 5. RMSE between the measured and simulated temperature (T) and relative humidity in the XPS wall with a polyethylene interior VR.

\begin{tabular}{|l|r|r|r|r|r|r|}
\hline \multicolumn{1}{|c|}{ RMSE } & $\begin{array}{c}\text { T OSB air } \\
\text { space }\left({ }^{\circ} \mathbf{F}\right)\end{array}$ & $\begin{array}{c}\text { T OSB } \\
\text { cavity side } \\
\left({ }^{\circ} \mathbf{F}\right)\end{array}$ & $\begin{array}{c}\text { T gypsum } \\
\text { cavity side } \\
\left({ }^{\circ} \mathbf{F}\right)\end{array}$ & $\begin{array}{c}\text { RH OSB air } \\
\text { space } \\
(\% \text { RH })\end{array}$ & $\begin{array}{c}\text { RH OSB } \\
\text { cavity side } \\
(\% \mathbf{R H})\end{array}$ & $\begin{array}{l}\text { RH gypsum } \\
\text { cavity side } \\
(\% \text { RH })\end{array}$ \\
\hline $\begin{array}{l}\text { XPS/poly wall } \\
\text { without air leaks }\end{array}$ & 1.9 & 2.1 & 0.1 & 5.2 & 6.0 & 2.5 \\
\hline $\begin{array}{l}\text { XPS/poly wall } \\
\text { with air leaks }\end{array}$ & 1.8 & 2.0 & 0.1 & 3.0 & 2.0 & 2.5 \\
\hline
\end{tabular}

\subsubsection{Performance of wall with no interior VR}

The following plots show the measured temperature (Figure 20), RH (Figure 21), and moisture content (Figure 22) of the OSB sheathing of the XPS wall with no interior VR. 


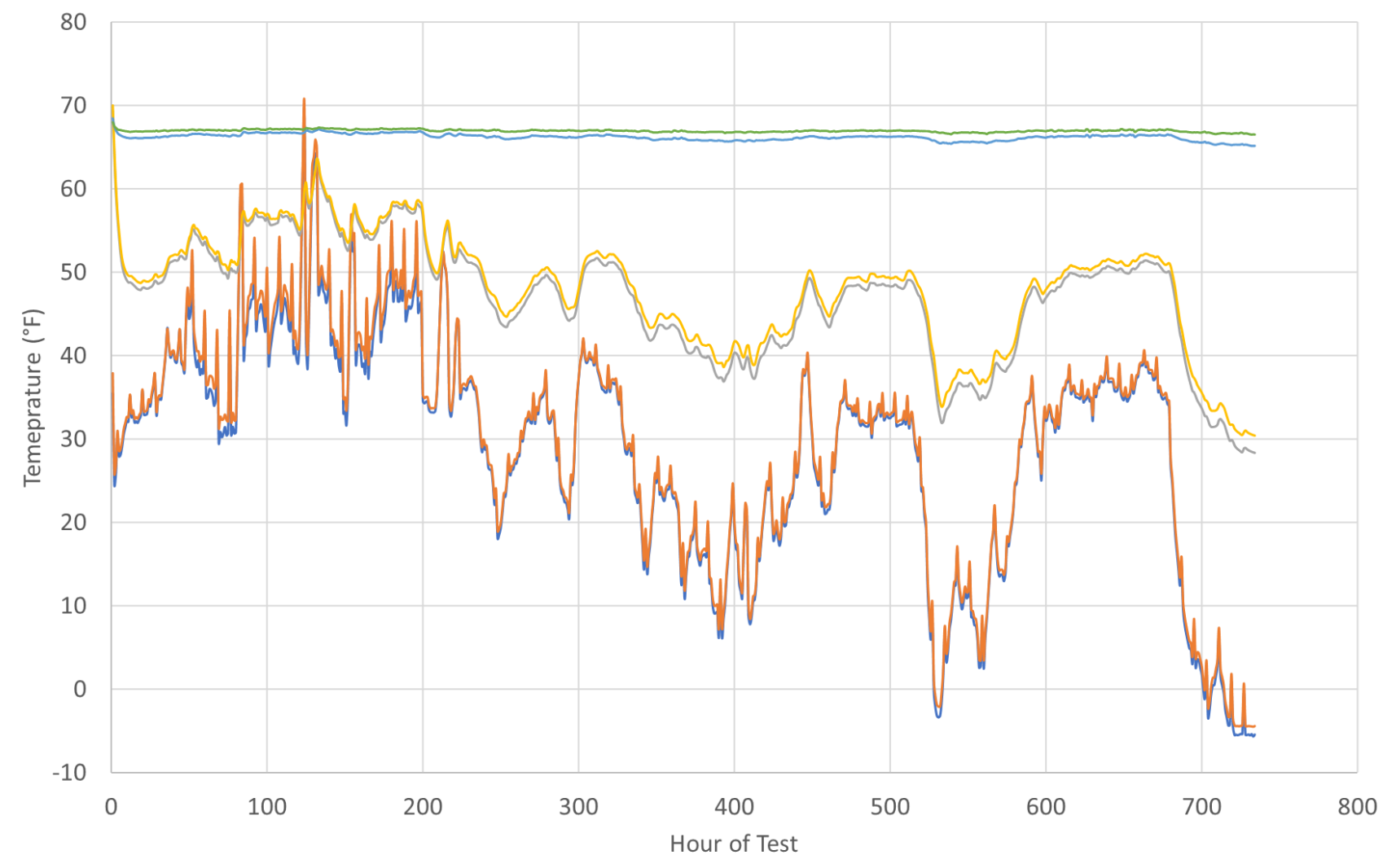

—Wall 2 Exterior Cladding Surface Vinyl Temp —Wall 2 Vinyl Surface Air Space Temp

-Wall 2 OSB Surface Air Space Temp — -Wall 2 OSB Interior Surface Cavity Side Temp

—Wall 2 Gypsum Surface Cavity Side Temp _-Wall 2 Gypsum Surface Interior Side Temp

Figure 20. Measured temperature (T) throughout the XPS wall with no interior VR. 


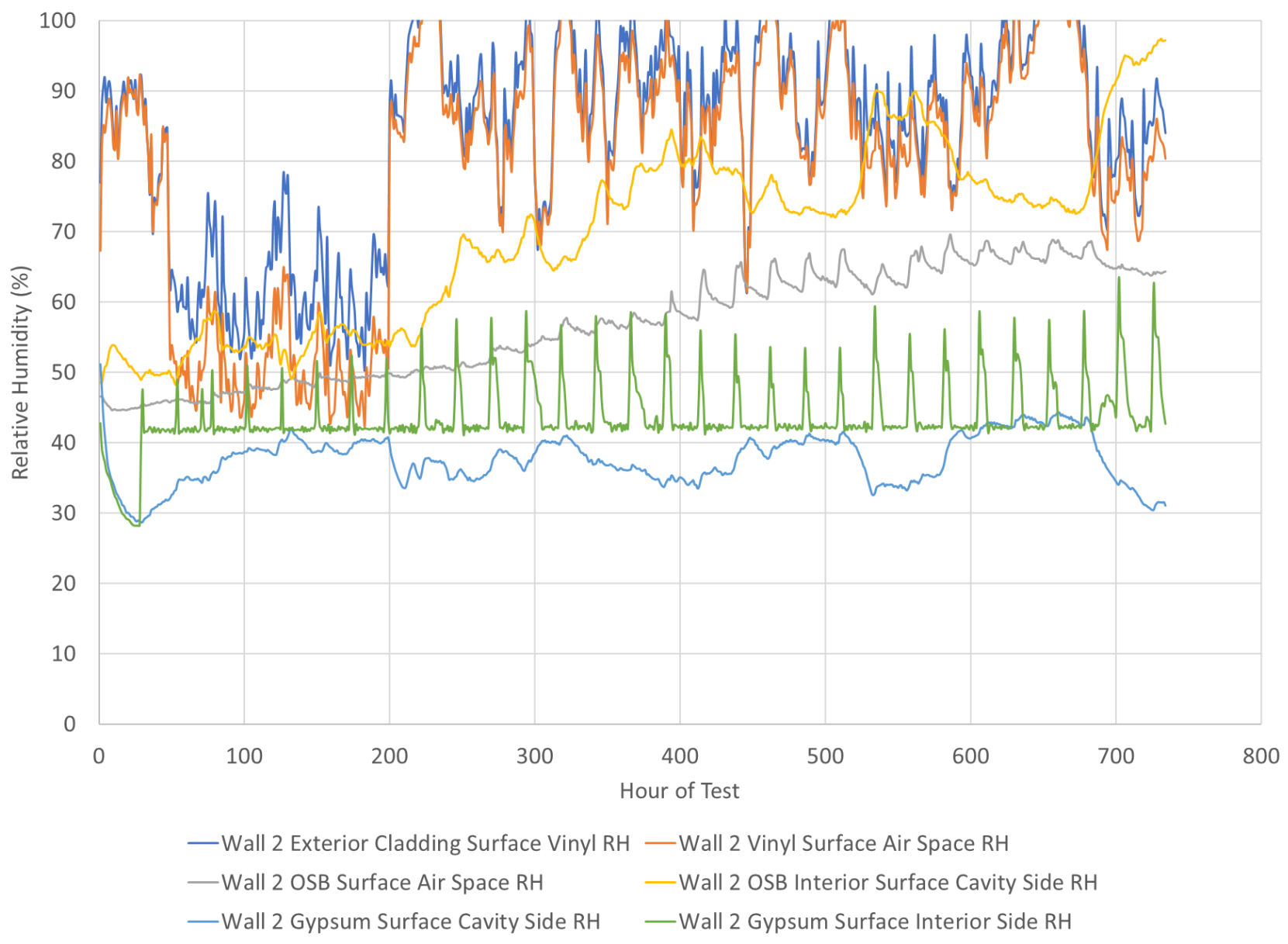

Figure 21. Measured RH throughout the XPS wall with no interior VR. 


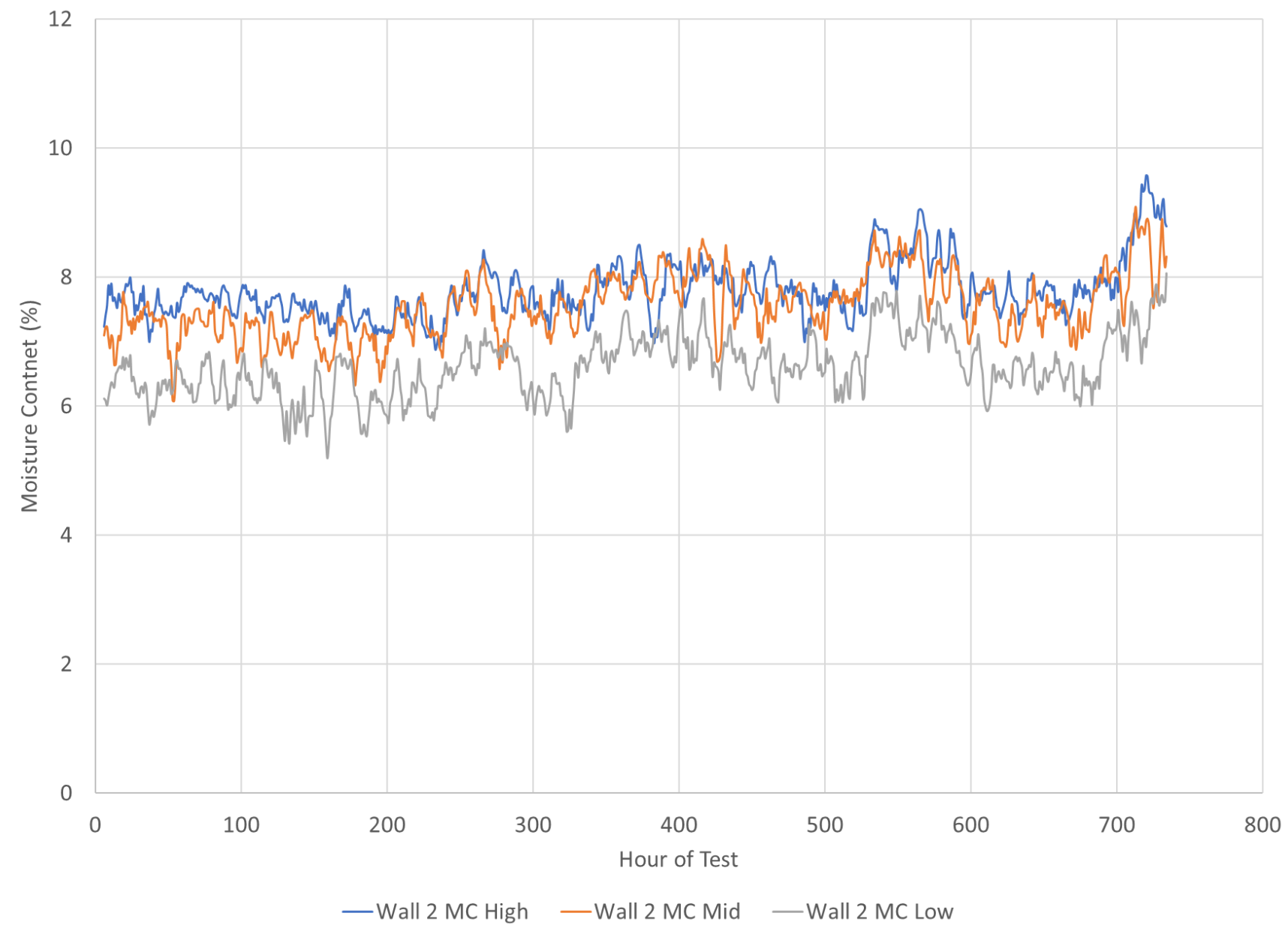

Figure 22. Measured moisture content (MC) at three heights along the cavity side face of the OSB sheathing in the XPS wall with no interior VR.

\subsubsection{XPS wall with no interior VR-comparison between measured and simulated results}

The XPS wall with no interior VR was modeled as shown in Figure 23. The air gap behind the vinyl siding $(10 \mathrm{~mm} / 3 / 8 \mathrm{in}$.) was ventilated at a constant rate of $20 \mathrm{l} / \mathrm{h}$. The wall was simulated with and without air leakage through the wall. 
Component Assembly

Case: \#3 2x6 R19+2inXPS

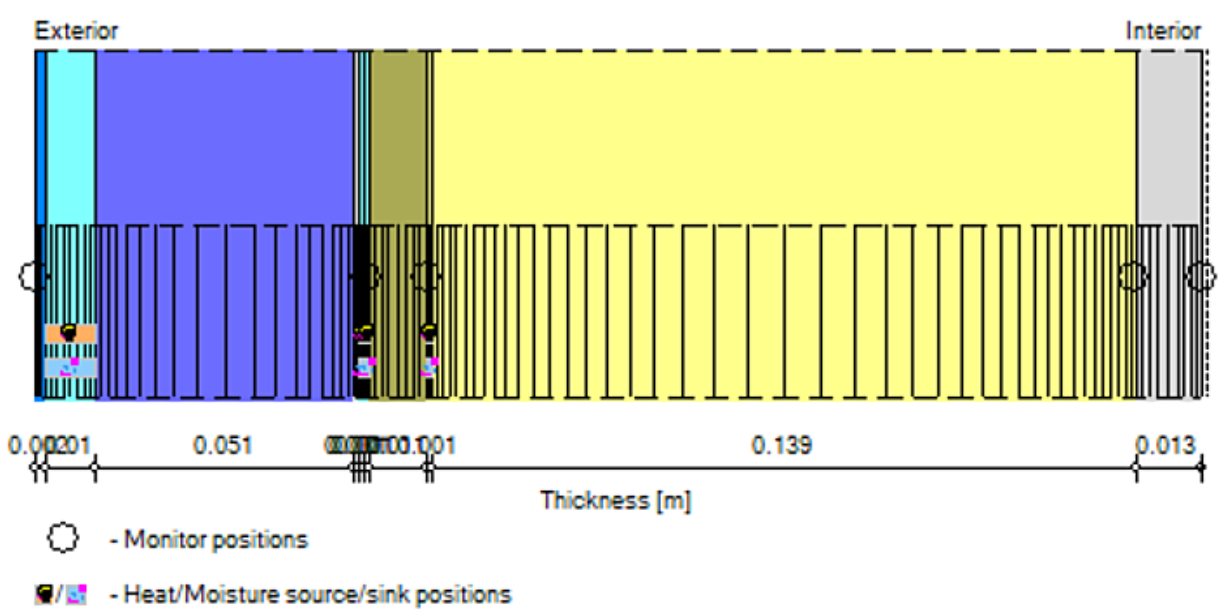

Materials:

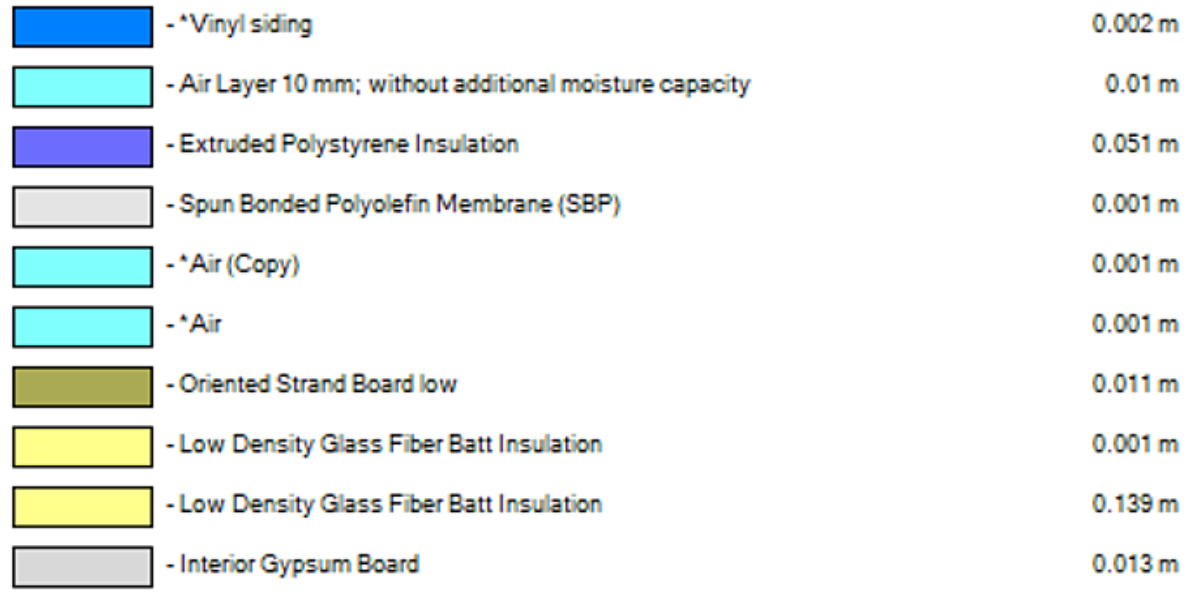

Figure 23. Layers and materials in the simulated WUFI model for the XPS wall with no interior VR.

We compared the simulated results to the measurements for the following selected layers in the wall: temperature and RH on the exterior and interior surface of the OSB sheathing and on the indoor side of cavity insulation, and the moisture content of the OSB sheathing. The initial conditions were assumed to be $50 \% \mathrm{RH}$ and $68^{\circ} \mathrm{F}$ in all the layers. Figure 24 compares the measured and simulated temperatures in the wall. 


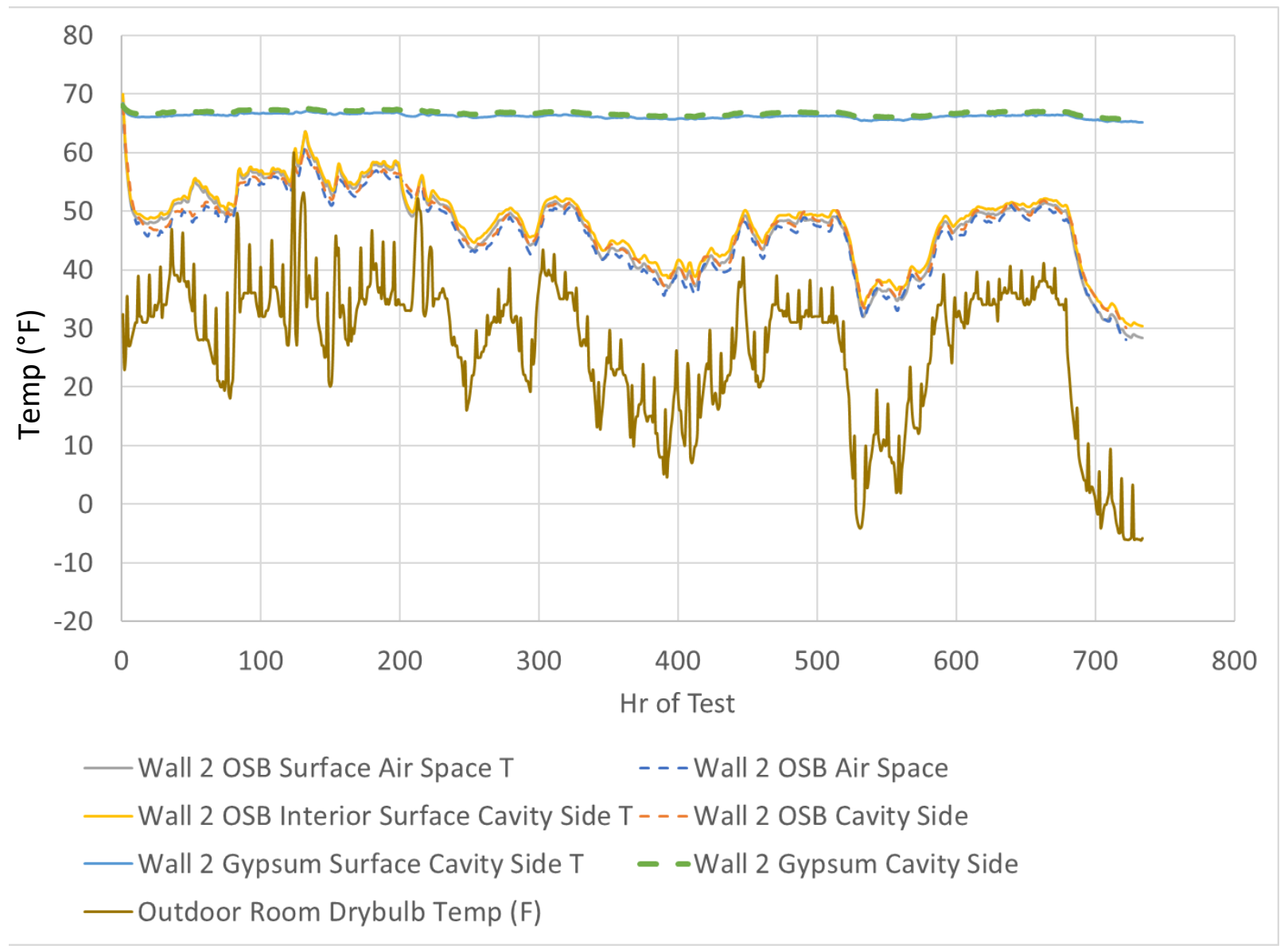

Figure 24. Comparison of measured and simulated temperature (T) in the XPS wall with no interior VR with air leakage through the wall. The solid lines are measured data and the dashed lines are simulated data.

The air leakage through the wall did not affect the temperatures noticeably, so only one figure is reported for temperatures. However, similarly to for the polyethylene VR wall, the humidity conditions in the wall show the impact of air leaks. The simulated results with air leaks through this wall without an interior vapor barrier show a significant increase in RH due to air leakage. The air leaks were a function of pressure difference across the wall.

Figure 25 includes the comparison of the measured and simulated $\mathrm{RH}$ for the wall when no air leaks were present in the simulations. Similar to in the polyethylene VR wall, the RH on the interior and exterior side of the OSB did not match the measured values very well. However, when air leaks - even with assumed path and magnitude - were added to the simulations, the results were significantly better (Figure 26). 


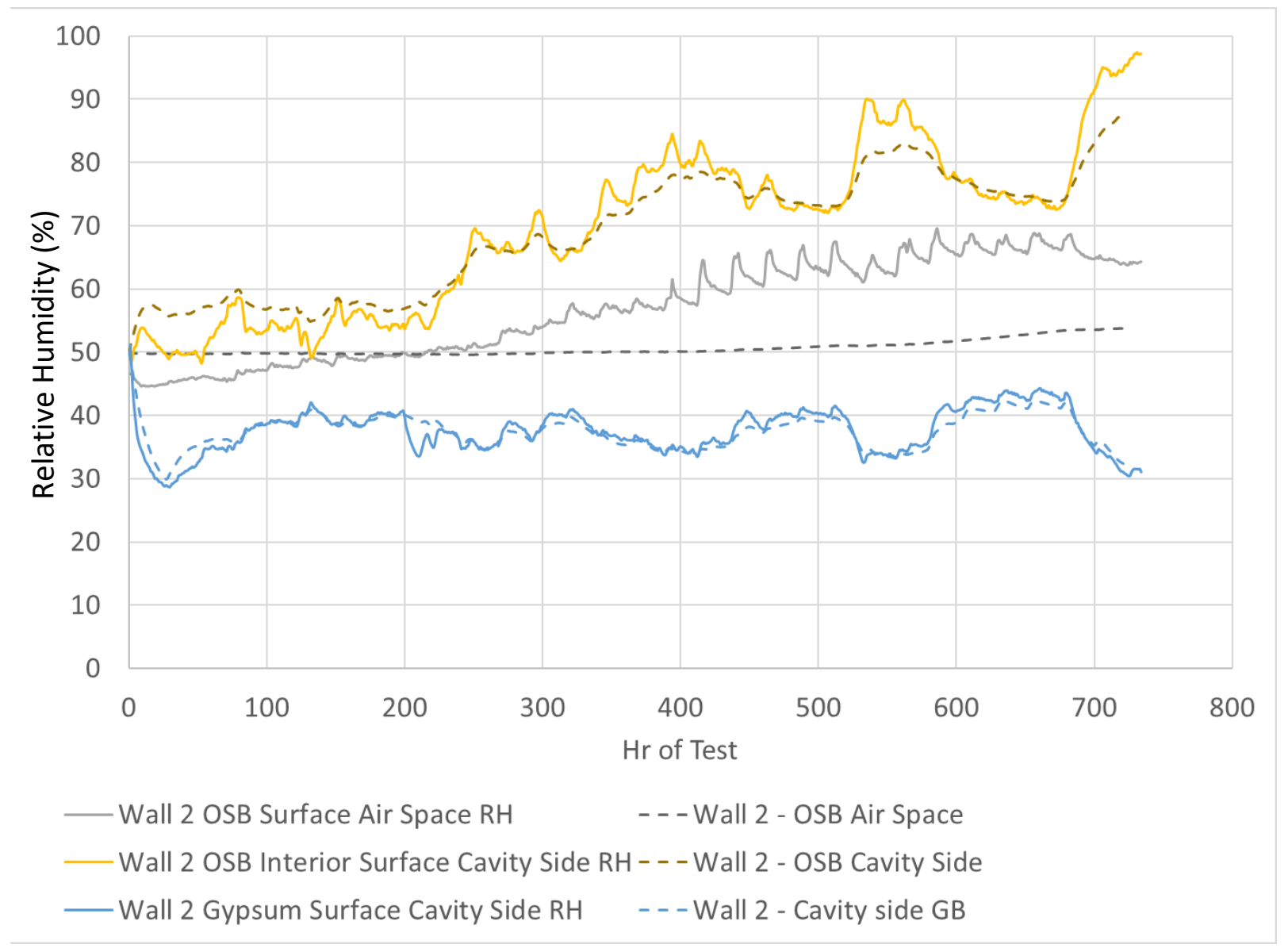

Figure 25. Comparison of measured and simulated relative humidity in the XPS wall with no interior VR without air leakage through the wall. The solid lines are measured data and the dashed lines are simulated data. 


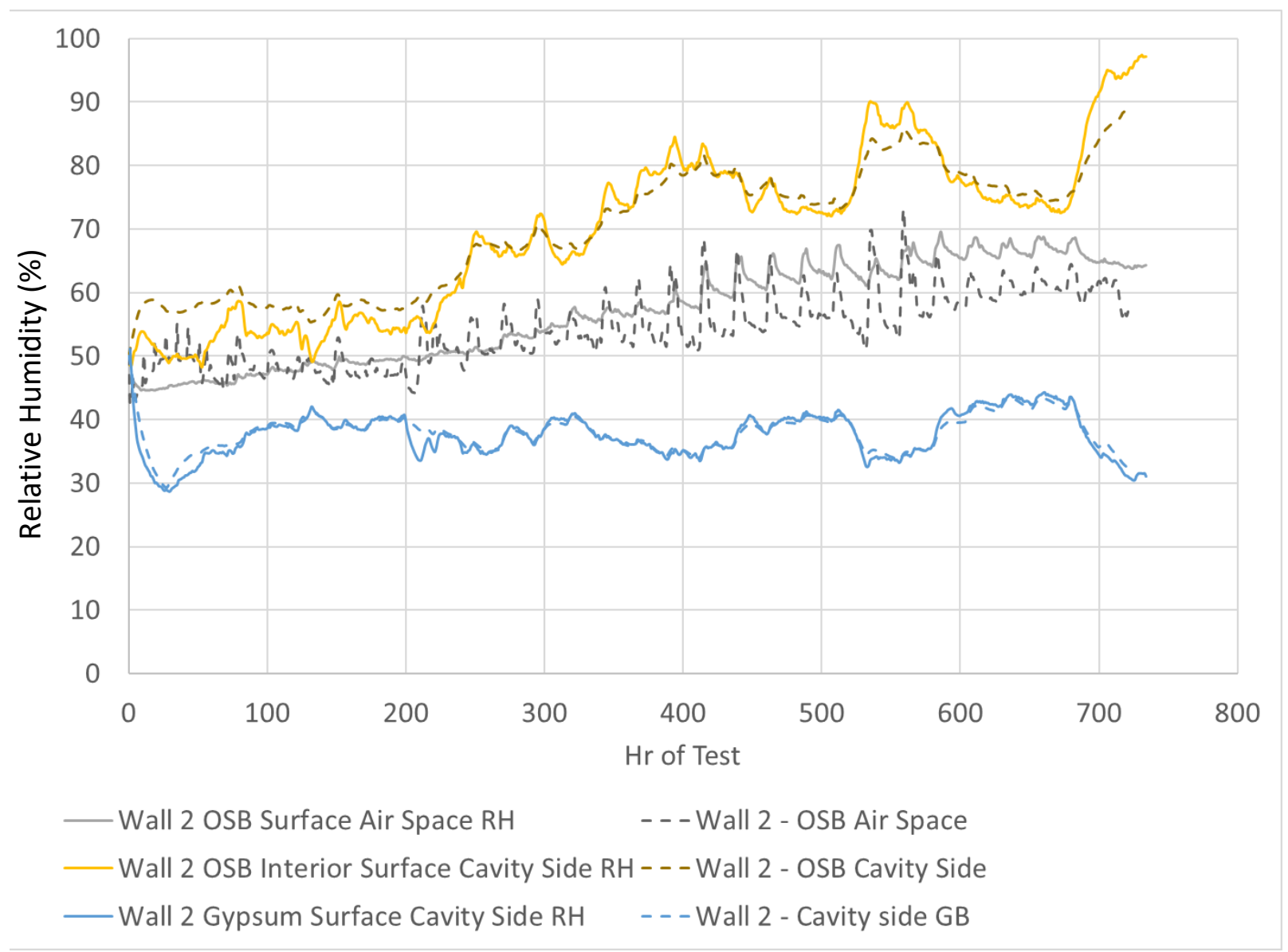

Figure 26. Comparison of measured and simulated relative humidity in the XPS wall with no interior VR with air leakage through the wall. The solid lines are measured data and the dashed lines are simulated data.

Figure 27 shows the measured and simulated moisture content of the exterior sheathing (OSB) as a function of time. At such a low moisture content, the high electrical resistance makes this measurement more uncertain. This uncertainty is likely the cause of the magnitude difference in the measured and simulated moisture content. The increase in moisture content, however, is very similar in the measurements and simulations. 


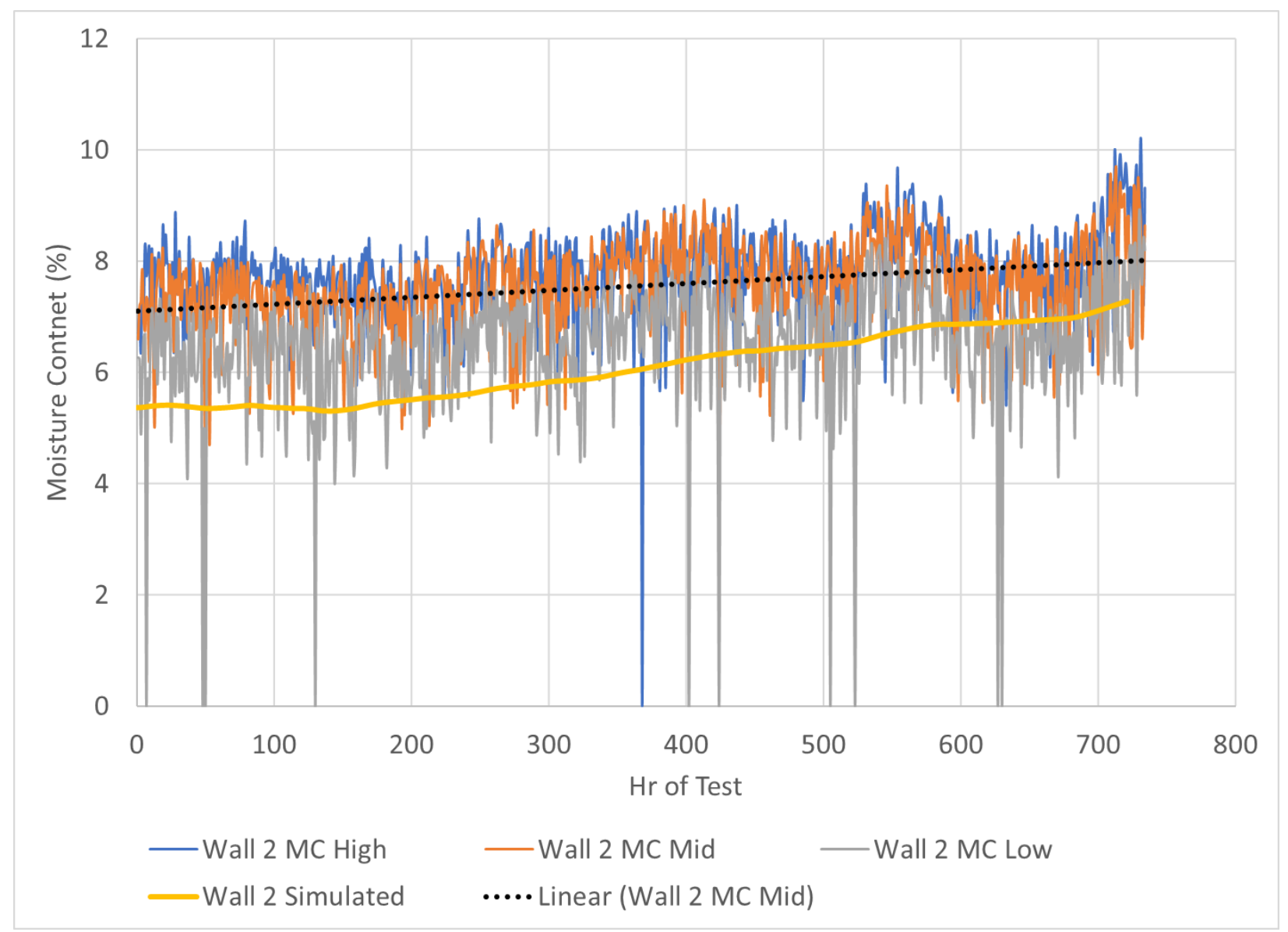

Figure 27. Comparison of measured and simulated moisture content of the exterior sheathing (OSB) in the XPS wall with no VR with air leakage through the wall.

The calculated RMSE between the measured and simulated values for the XPS wall with no interior VR is in Table 6. Notice when air leaks are modeled and simulated the RMSE gets smaller when comparing the simulated and measured RHs.

Table 6. RMSE between the measured and simulated temperature $(T)$ and relative humidity in the wall with no VR.

\begin{tabular}{|l|r|r|r|r|r|r|}
\hline \multicolumn{1}{|c|}{ RMSE } & $\begin{array}{c}\text { T OSB air } \\
\text { space }\left({ }^{\circ} \mathbf{F}\right)\end{array}$ & $\begin{array}{c}\text { T OSB cavity } \\
\text { side }\left({ }^{\circ} \mathbf{F}\right)\end{array}$ & $\begin{array}{c}\text { T gypsum } \\
\text { cavity side } \\
\left({ }^{\circ} \mathbf{F}\right)\end{array}$ & $\begin{array}{c}\text { RH OSB air } \\
\text { space } \\
(\% \mathbf{R H})\end{array}$ & $\begin{array}{c}\text { RH OSB } \\
\text { cavity side } \\
(\% \mathbf{R H})\end{array}$ & $\begin{array}{c}\text { RH gypsum } \\
\text { cavity side } \\
(\% \mathbf{R H})\end{array}$ \\
\hline $\begin{array}{l}\text { XPS/no VR } \\
\text { without air leaks }\end{array}$ & 1.5 & 1.6 & 0.5 & 9.2 & 3.6 & 1.6 \\
\hline $\begin{array}{l}\text { XPS/no VR with } \\
\text { air leaks }\end{array}$ & 1.4 & 1.4 & 0.5 & 4.7 & 3.5 & 1.2 \\
\hline
\end{tabular}




\subsection{MINERAL WOOL WALLS}

\subsubsection{Weather Emulation}

For the next two walls that were tested, instead of starting the weather on December 15 of the WUFI coldweather Chicago file, the chamber was started on December 27 of the weather file. Therefore, the $x$-axis starts at approximately the 300th hour, which corresponds to the 300th hour of the weather file, which starts on December 15.

\subsubsection{Indoor side}

Figure 28 shows the temperature and RH in the indoor chamber during the test versus the targets. The indoor chamber temperature stayed very close to the target of $68^{\circ} \mathrm{F}$. However, large spikes occurred daily in the RH, rising $\sim 10 \%$ above the target of $40 \% \mathrm{RH}$. This occurred when the chamber's steam generator, which provides humidity, underwent a blow-down to help clean out any mineral deposits. The blow-down feature was disabled toward the end of the experiment.

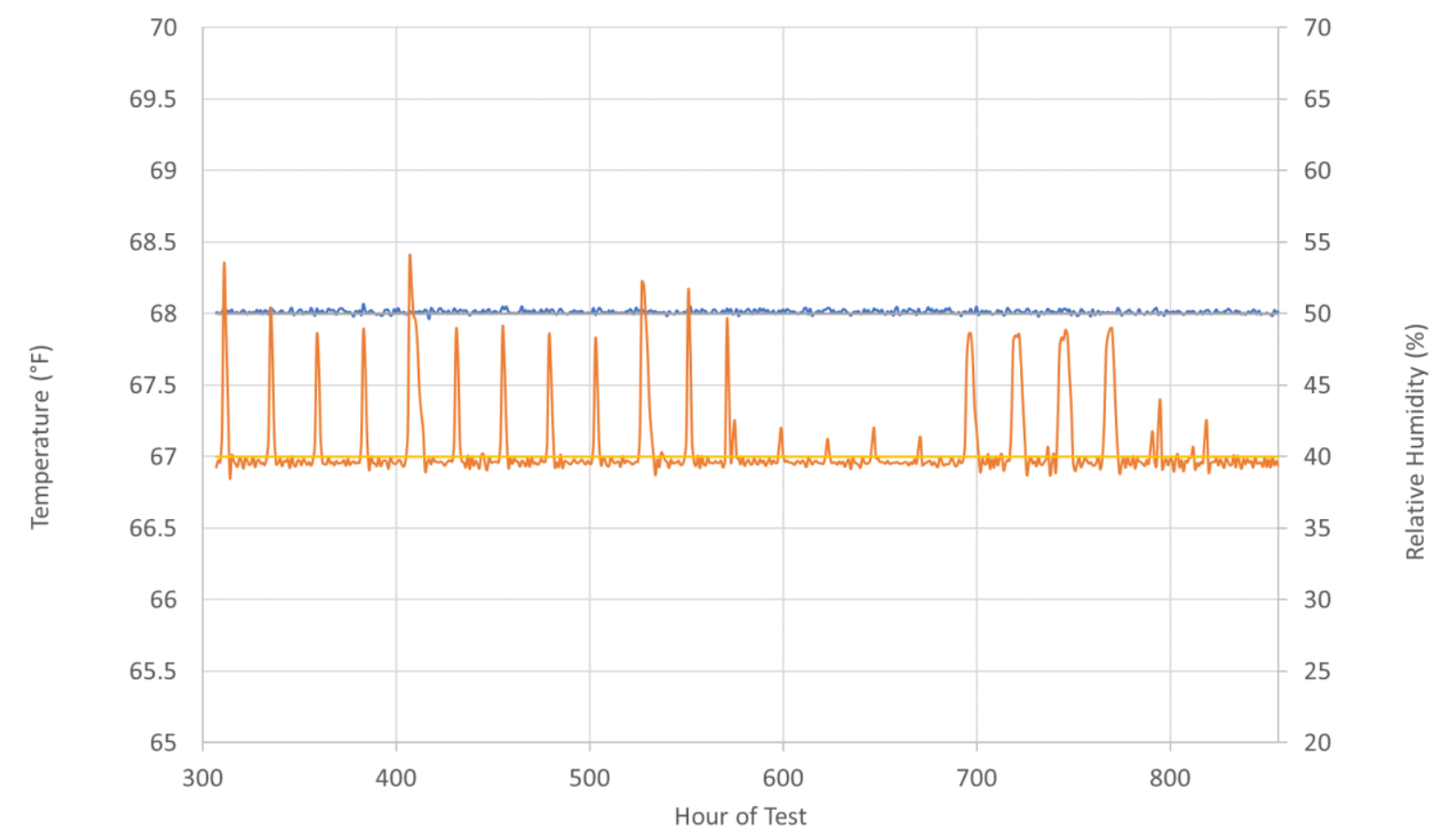

- Indoor Room Temp - - Indoor Room Temp Target _ - Indoor Room RH - Indoor Room RH Target

Figure 28. The indoor side of the chamber had targets of $68^{\circ} \mathrm{F}$ and $40 \% \mathrm{RH}$. The daily spikes in indoor RH were due to the indoor steam generator blow-down, which helps keep the steam generator from clogging with mineral deposits. Toward the end of the test period, the blow-down was deactivated.

\subsubsection{Outdoor side}

Figure 29 shows the temperature and RH in the outdoor chamber during the test versus the targets. The temperature and RH stayed close to the targets except at times when the dry bulb temperature was very 
low for a long time $\left(<10^{\circ} \mathrm{F}\right.$ for more than a few hours). In these cases, the chamber could not keep the RH at the low target. The small spikes along the measured temperature and RH were due to the chamber coils undergoing defrost twice a day.

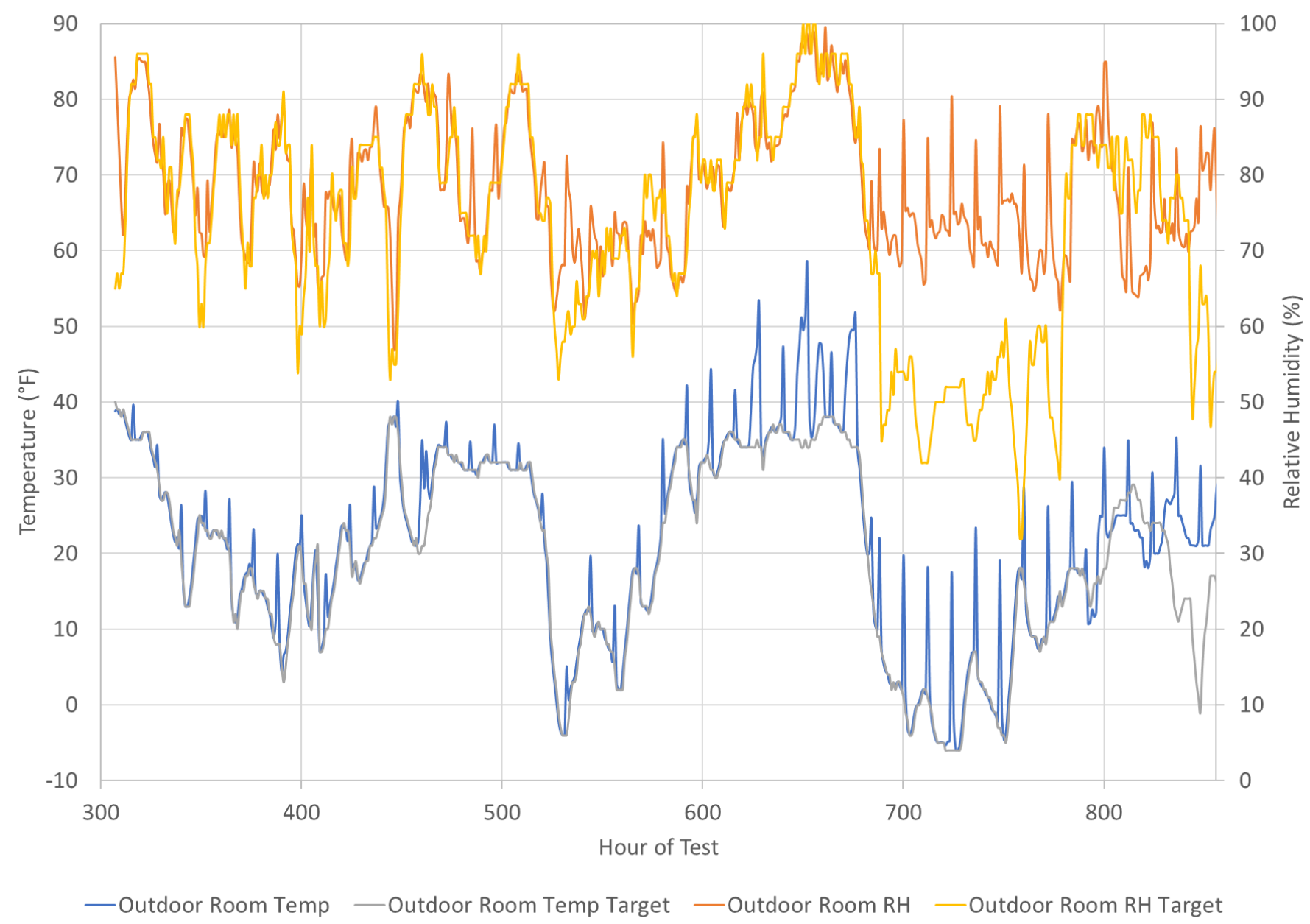

Figure 29. Outdoor chamber temperature and RH change according to the WUFI Chicago weather file. The outdoor chamber stayed close to the target, but between hours 700 and 800, the RH was difficult to keep as low as the target because of the chamber temperatures being very cold for a significant amount of time.

Figure 30 shows the measured cladding temperature of the vinyl siding during the test in comparison with the target, which was determined using a hygrothermal simulation of the walls being tested and the outdoor conditions of Chicago. No active means were used to try to maintain the cladding temperature close to the target. 


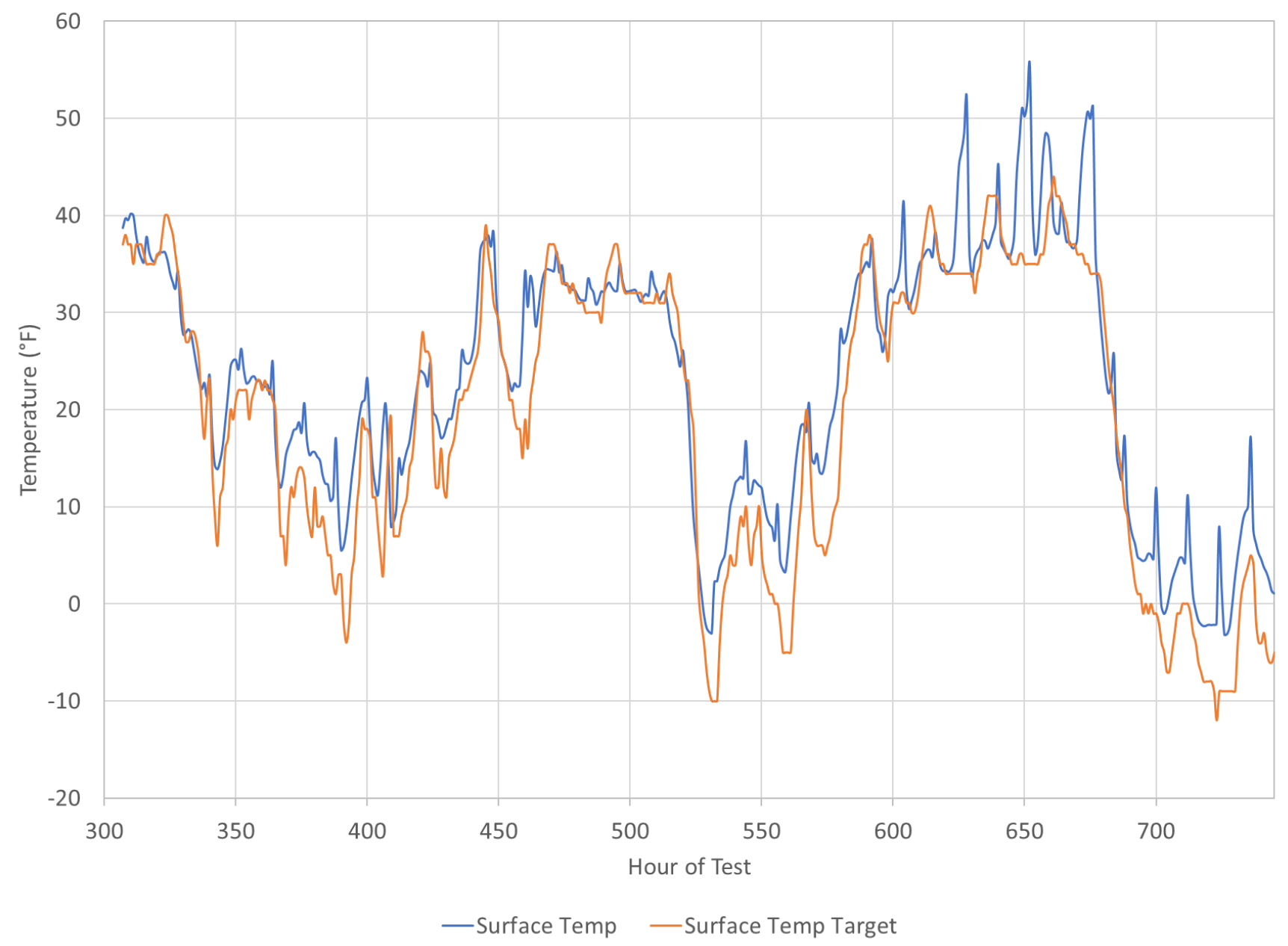

Figure 30. The cladding temperature target changed along with the outdoor weather.

Figure 31 shows the pressure differential between the outdoor and indoor sides. For the first half of the test, the pressure differential stayed around $0 \mathrm{~Pa}$, but for the second half of the experiment, the pressure difference between the outdoor room and indoor room was maintained at $20 \mathrm{~Pa}$, providing infiltration through the wall. 


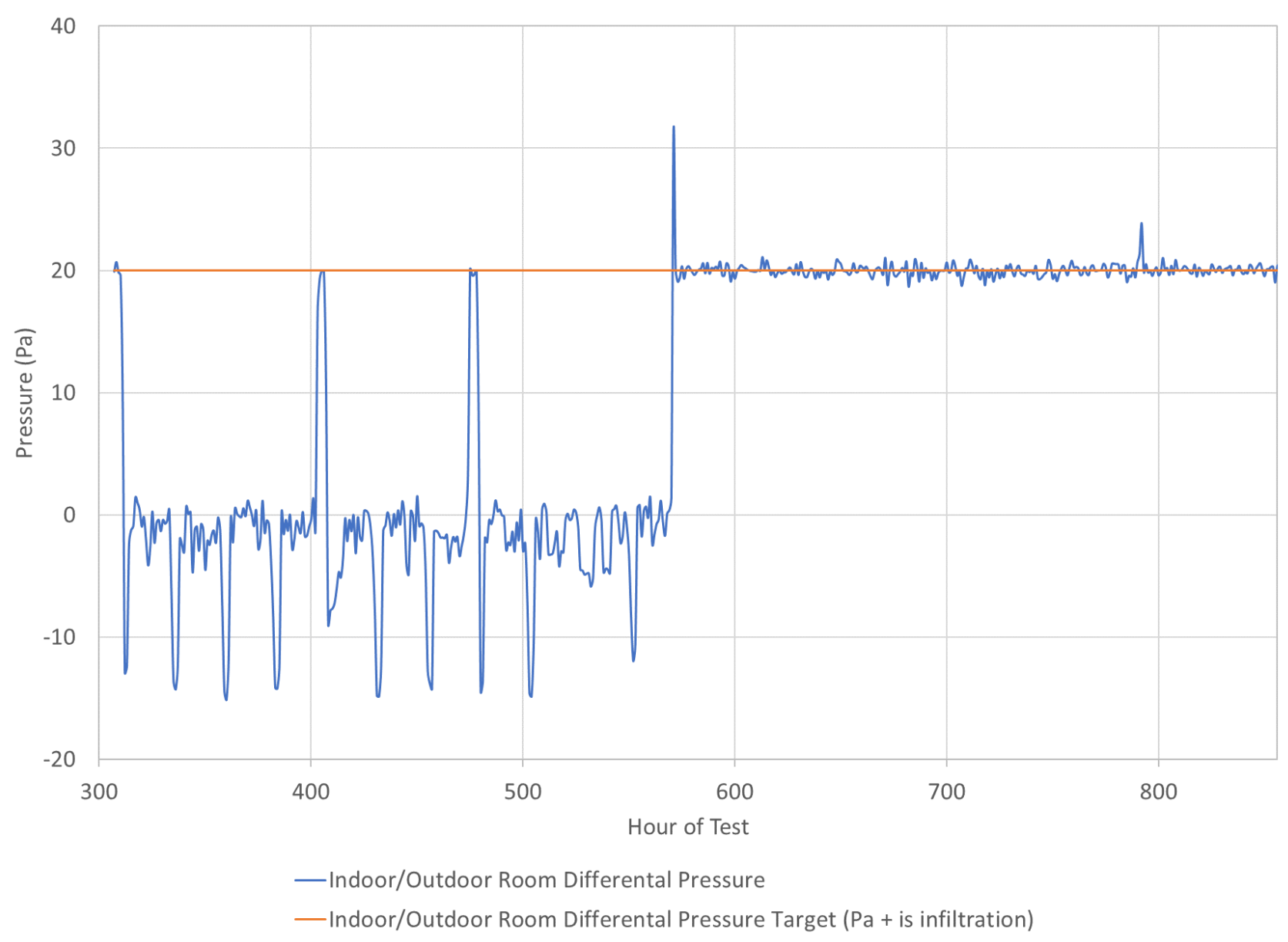

Figure 31. Measured pressure differential across the test wall.

\subsubsection{Wall Performance Measurements compared with WUFI Predictions}

\subsubsection{Measured performance of mineral wool wall with a $15 \mathrm{lb}$ felt WRB}

Figure 32 shows the measured temperature on the layer surfaces, Figure 33 shows the RH, and Figure 34 shows the OSB sheathing moisture content for this wall. 


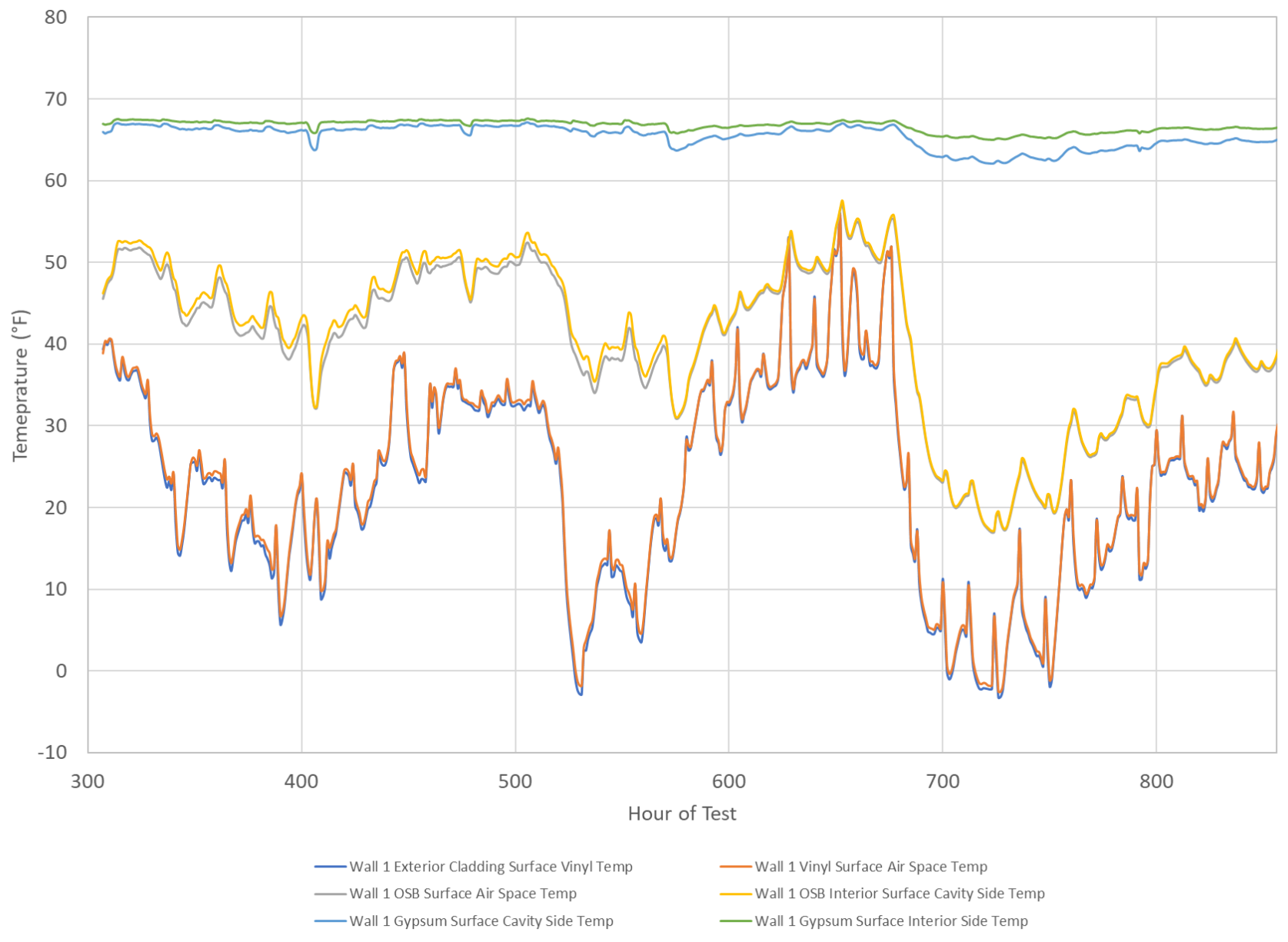

Figure 32. Measured temperature throughout the wall with mineral wool CI and a felt paper WRB. 


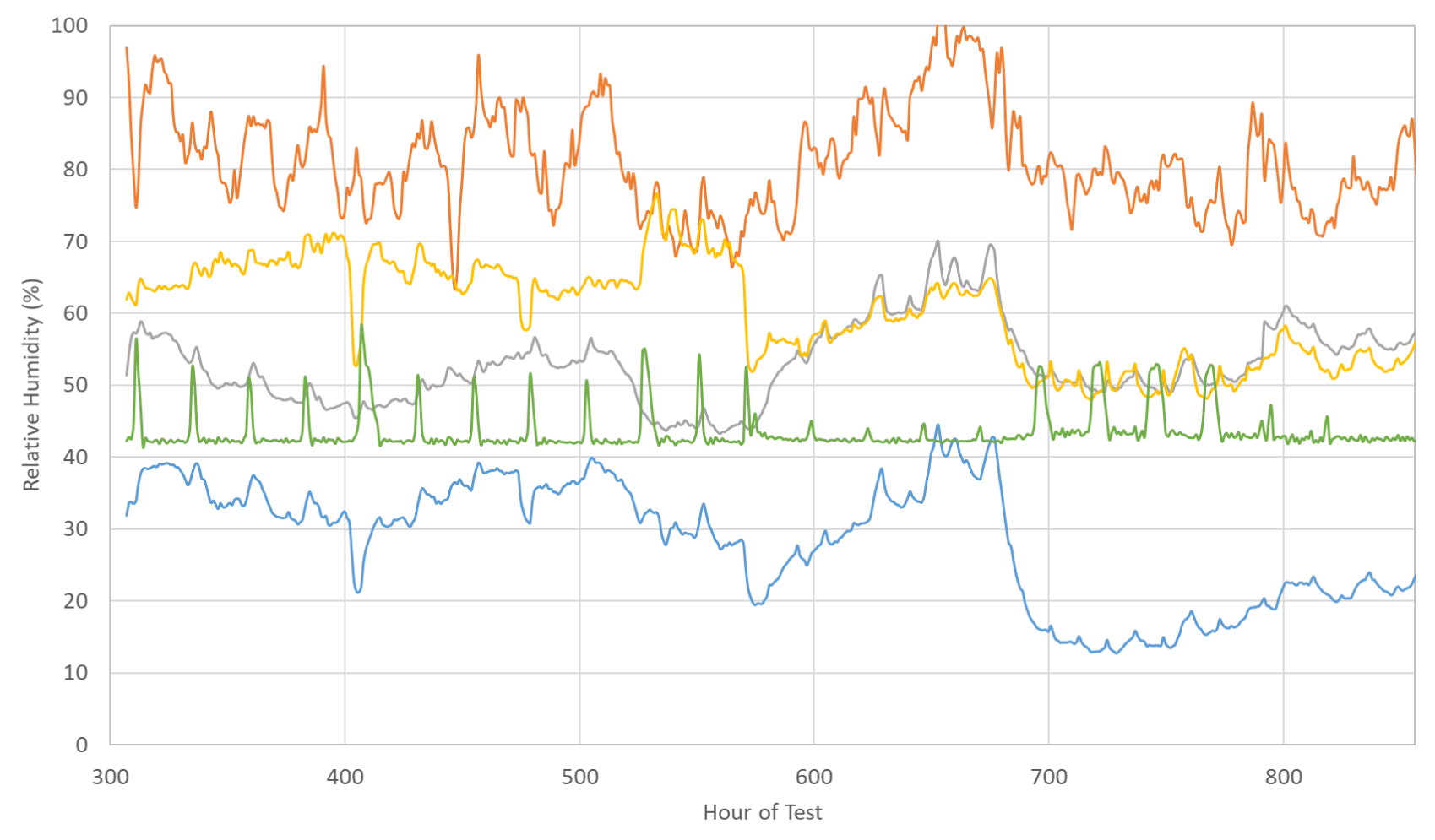

$\begin{array}{lll}\text { —Wall } 1 \text { Exterior Cladding Surface Vinyl RH (bad sensor) } & \text { — Wall } 1 \text { Vinyl Surface Air Space RH } & \text { Wall } 1 \text { OSB Surface Air Space RH } \\ \text { W Wall } 1 \text { OSB Interior Surface Cavity Side RH } & \text { — Wall } 1 \text { Gypsum Surface Cavity Side RH } & \text { Wall } 1 \text { Gypsum Surface Interior Side RH }\end{array}$

Figure 33. Measured RH throughout the wall with mineral wool CI and a felt paper WRB. 


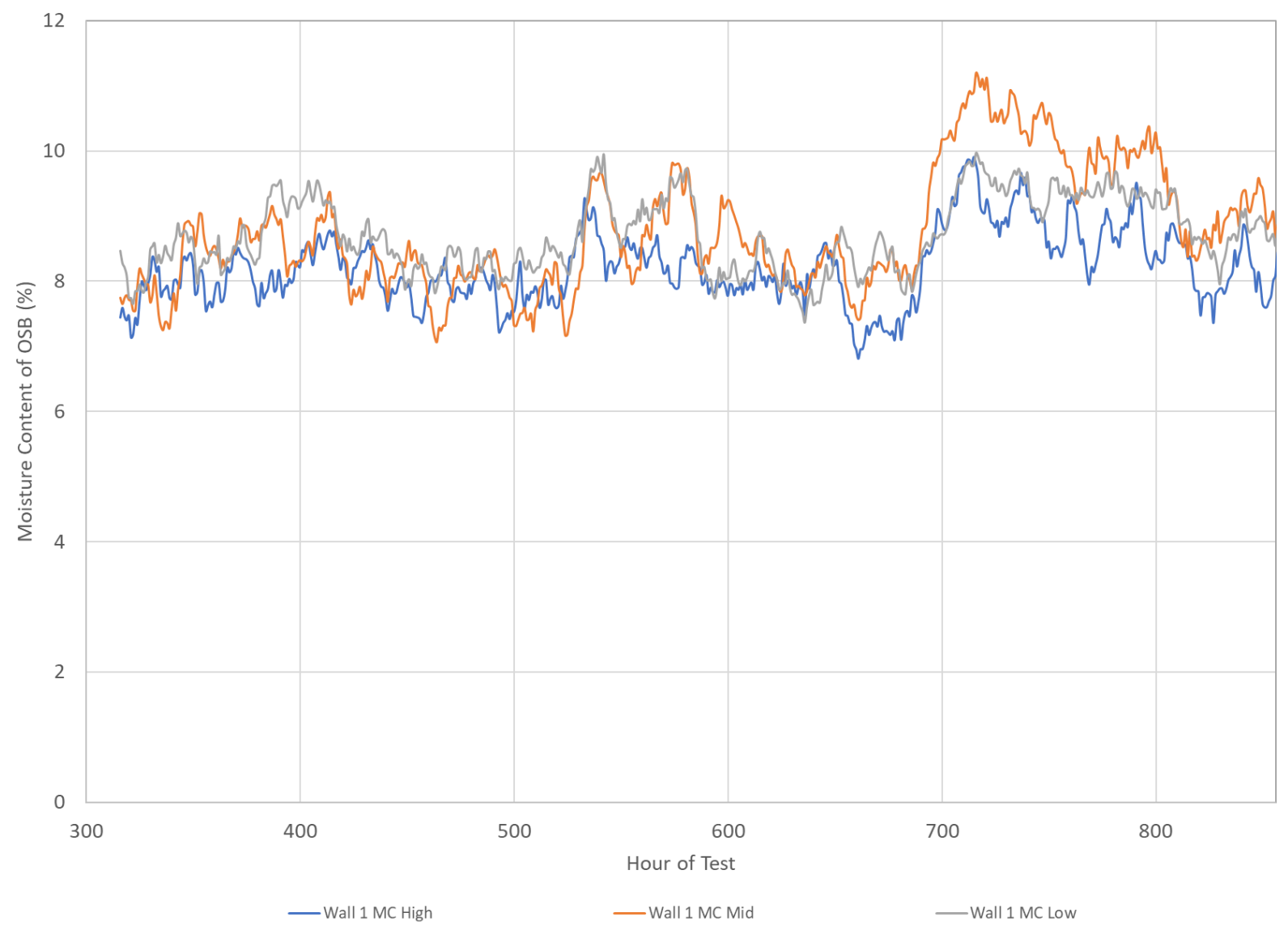

Figure 34. Measured moisture content throughout the wall with mineral wool CI and a felt paper WRB.

\subsubsection{Mineral wool/felt — comparison between measured and simulated results}

The wall was modeled as shown in Figure 35. The air gap behind the vinyl siding $(10 \mathrm{~mm} / 3 / 8 \mathrm{in}$.) was ventilated at a constant rate of $20 \mathrm{1} / \mathrm{h}$. The air leakage through the wall was modeled using a ventilation source term in the insulation in the framed cavity (low-density fiberglass) after hour 569 at a constant rate of $4.41 / \mathrm{h}$ for the whole insulation layer. 

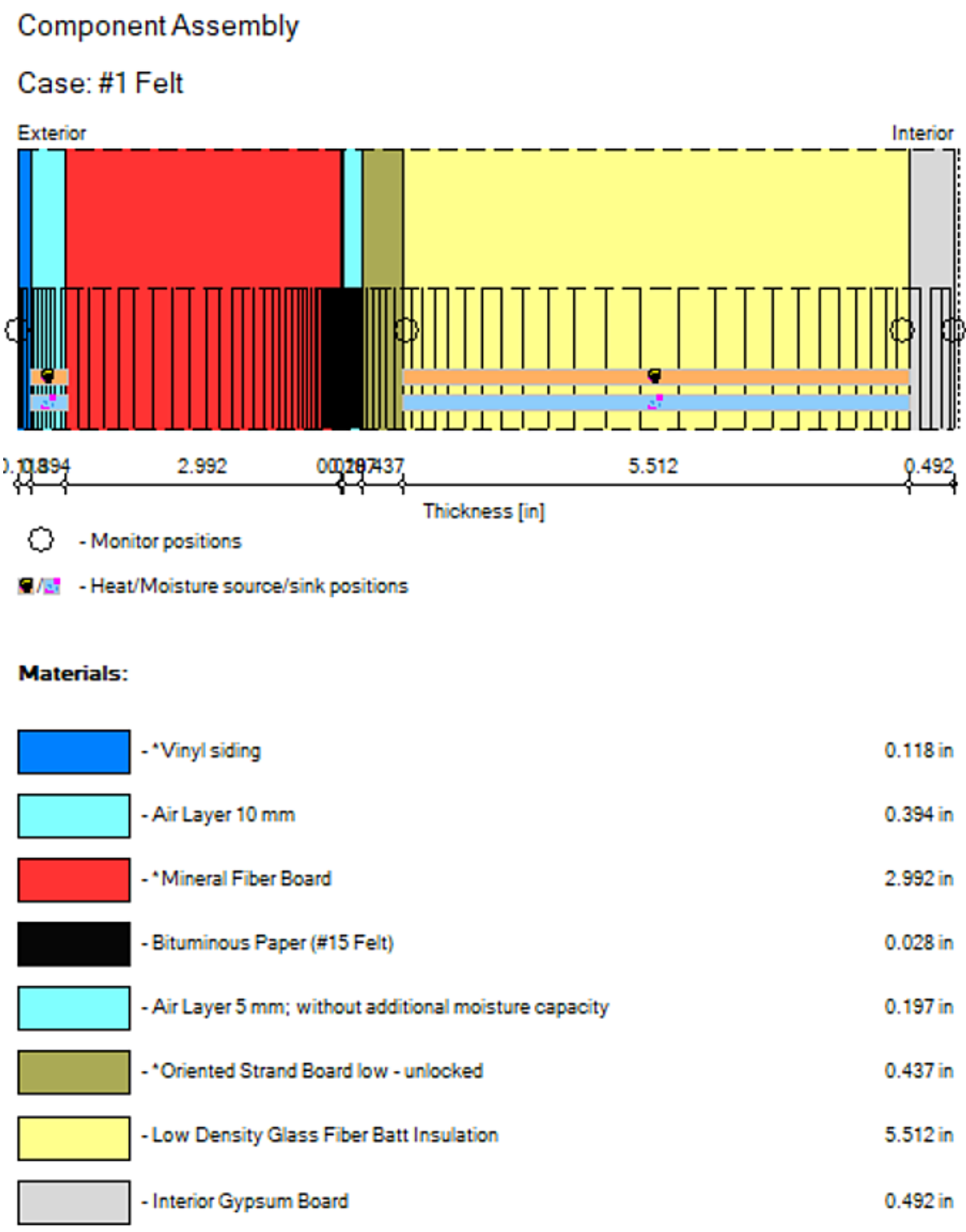

Figure 35. Layers and materials in the simulated WUFI model for the wall with mineral wool CI and a felt paper WRB.

Next, we compared the simulated results to the measurements for the following selected layers in the wall: temperature and $\mathrm{RH}$ on the exterior and interior surface of the OSB sheathing and on the indoor side of cavity insulation (exterior side of gypsum board with no VR in the wall), and the moisture content of the OSB sheathing. The initial conditions were assumed to be $60 \% \mathrm{RH}$ and $68^{\circ} \mathrm{F}$ in all the layers.

Air leakage through the walls was estimated based on the overall air leakage of the whole assembly, which is shown in Figure 7 as a function of pressure differential across the wall. In the simulations, the mineral wool wall with felt exhibited lower temperatures than the wall with spun-bonded polyolefin when the pressure difference between the outdoors and indoors changed from 0 to $20 \mathrm{~Pa}$ (airflow from outdoors to indoors). The air leakage through the wall cavity affected the temperatures and moisture in the wall differently depending on how and where the air moved through the wall. In one-dimensional simulations, and specifically in the WUFI Pro model, the air leakage can be considered as a source term. In the 
simulations, we separated the two walls to leaky and airtight. The wall with felt as a water-resistive barrier was considered to have all the air leakage. The wall with spun-bonded polyolefin was assumed to be airtight. The air leakage through the felt WRB wall (1 CFM) was set as a source of air from outdoor weather flowing to the insulated cavity. The air leakage started at hour 569 in the plots. $1 \mathrm{CFM}$ of airflow resulted in 4.4 air changes per hour in the insulated cavity for the $4 \times 8 \mathrm{ft}$ wall.

The measured and simulated temperatures - measured with thermocouple sensors (TC) - followed the same pattern very well (Figure 36). Figure 37 compares the measured and simulated relative humidity. The measured and simulated moisture content of OSB is shown in Figure 38. The simulated results had less variation between hours in temperature, relative humidity and moisture content.

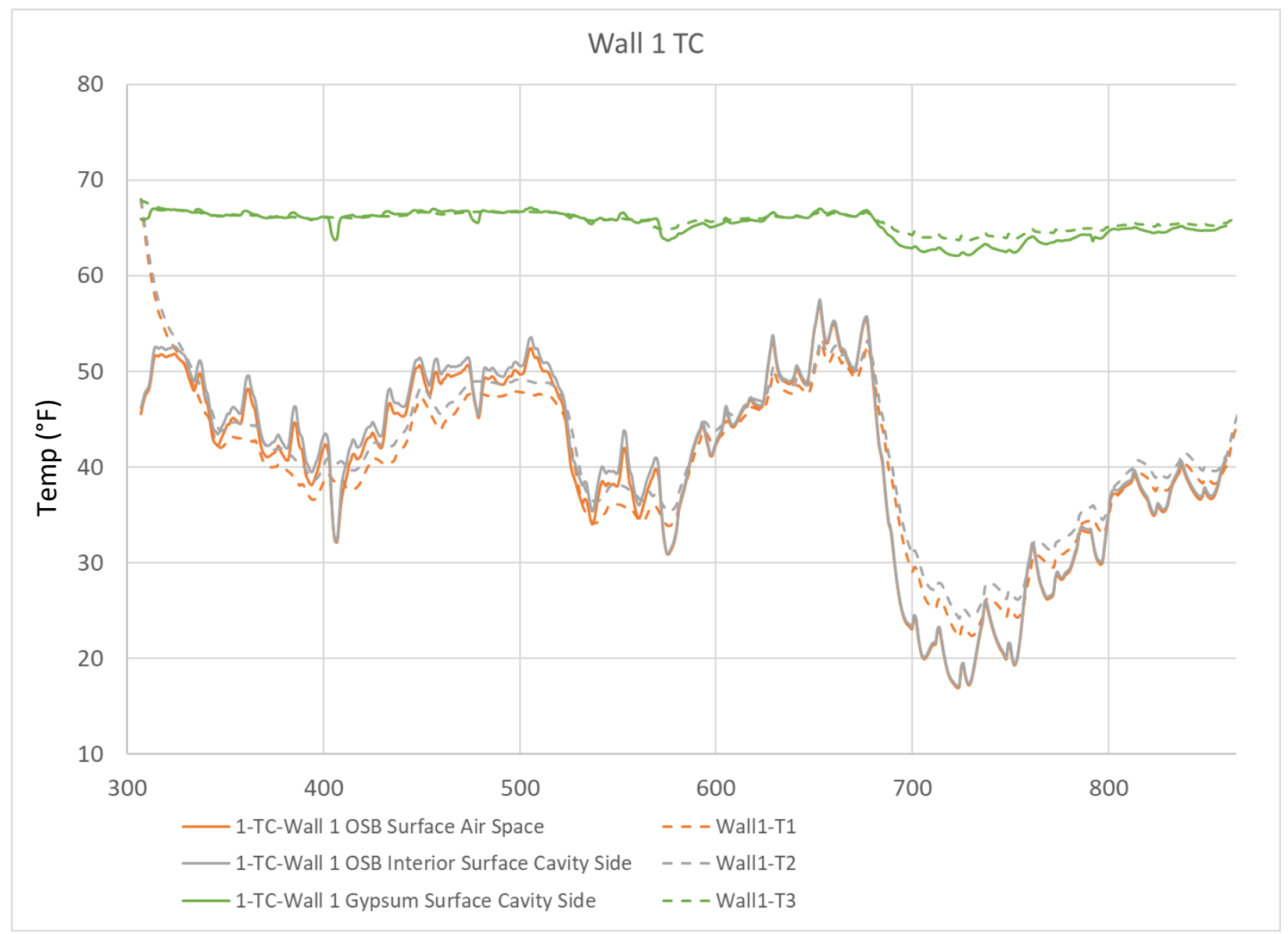

Figure 36. Comparison of measured and simulated temperature in felt WRB wall. The solid lines are measured data and the dashed lines are simulated data. 


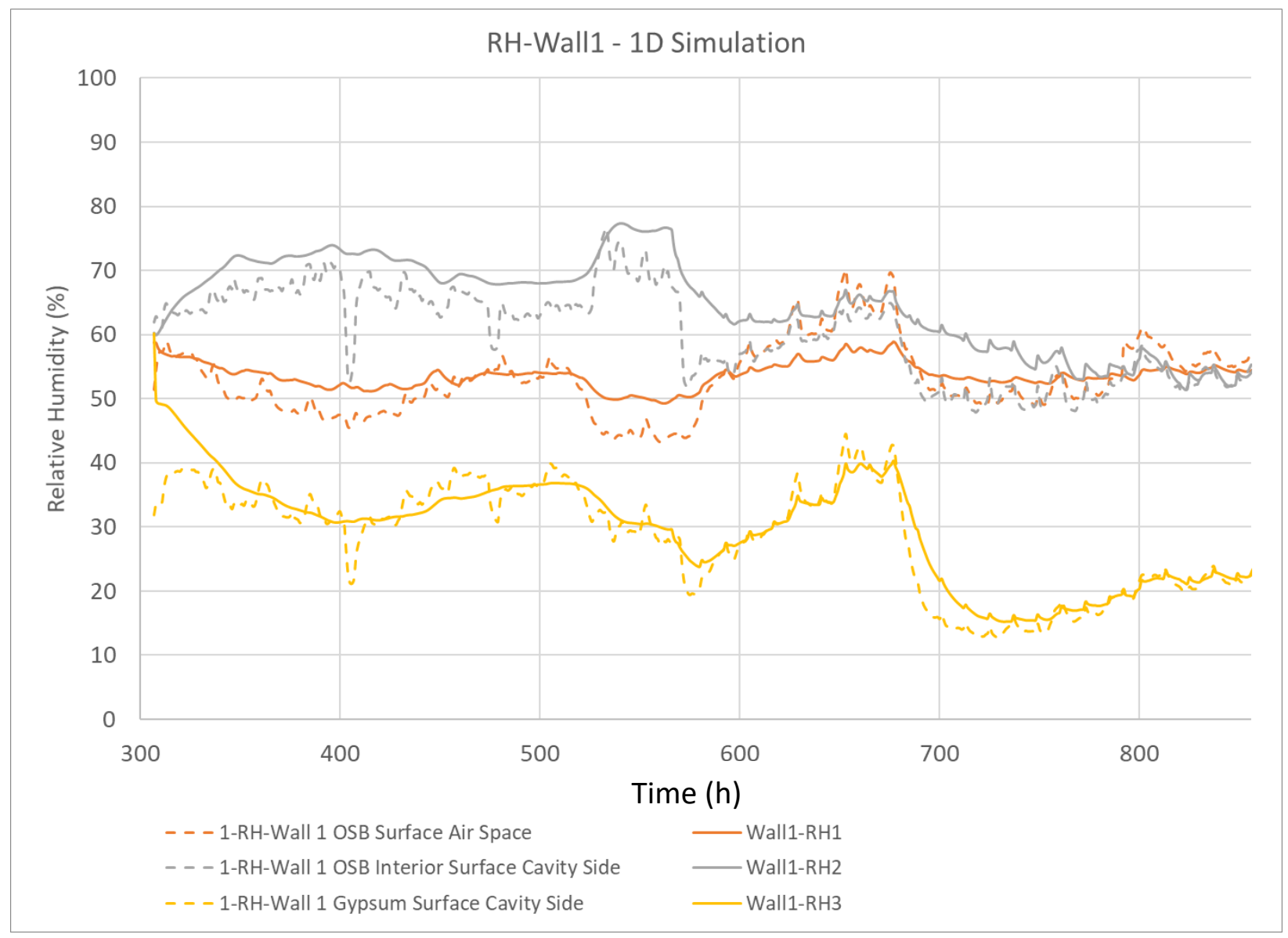

Figure 37. Comparison of measured and simulated RH in the wall with mineral wool CI and a felt WRB. The solid lines are measured data and the dashed lines are simulated data. 


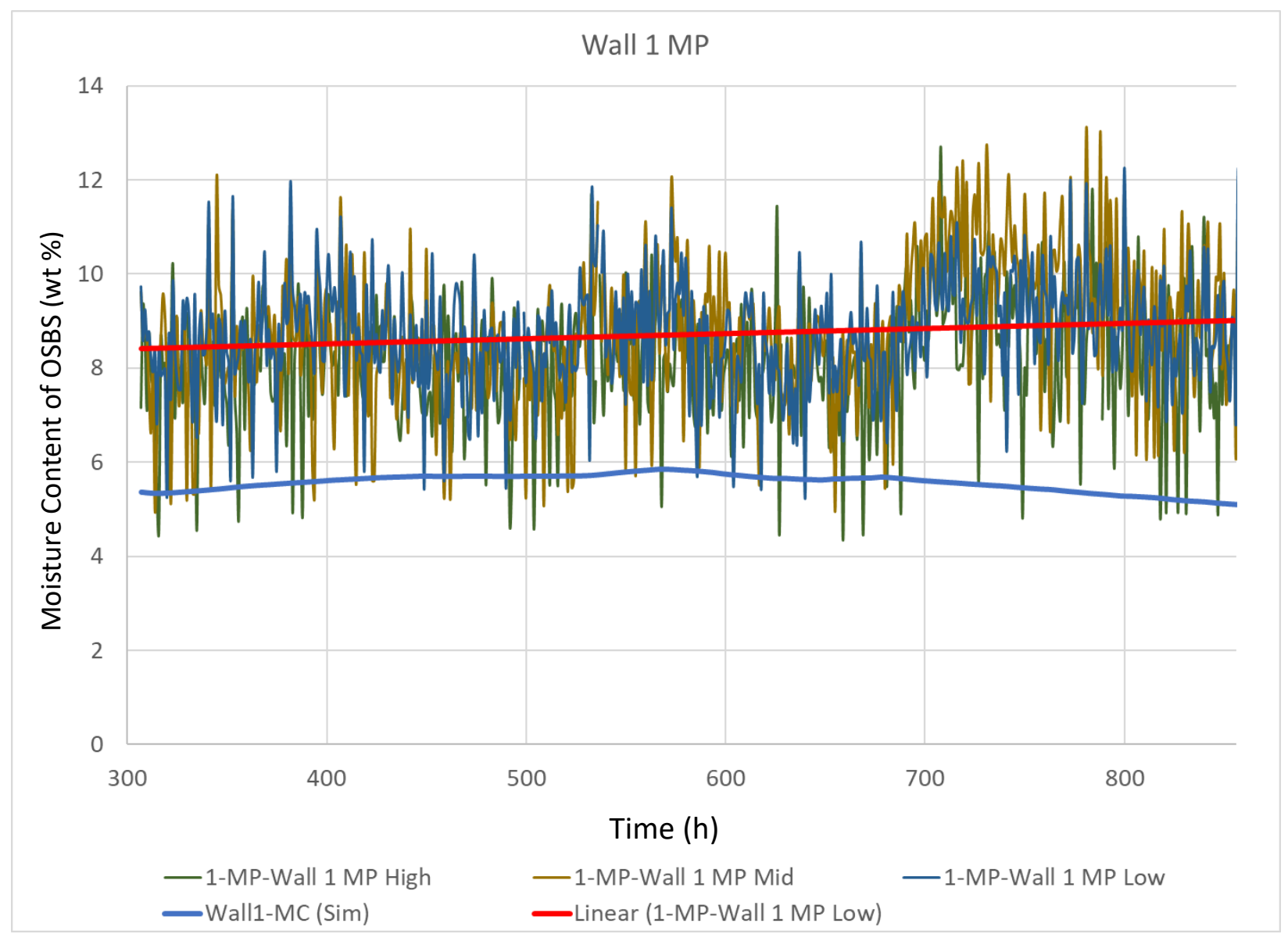

Figure 38. Comparison of measured and simulated moisture content of the OSB (wt \%) in the wall with mineral wool CI and a felt WRB.

\subsubsection{Measured performance of mineral wool wall with a spun-bonded polyolefin WRB}

Figure 39 shows the measured temperature on the layer surfaces, Figure 40 shows the RH, and Figure 41 shows the OSB sheathing moisture content for this wall. 


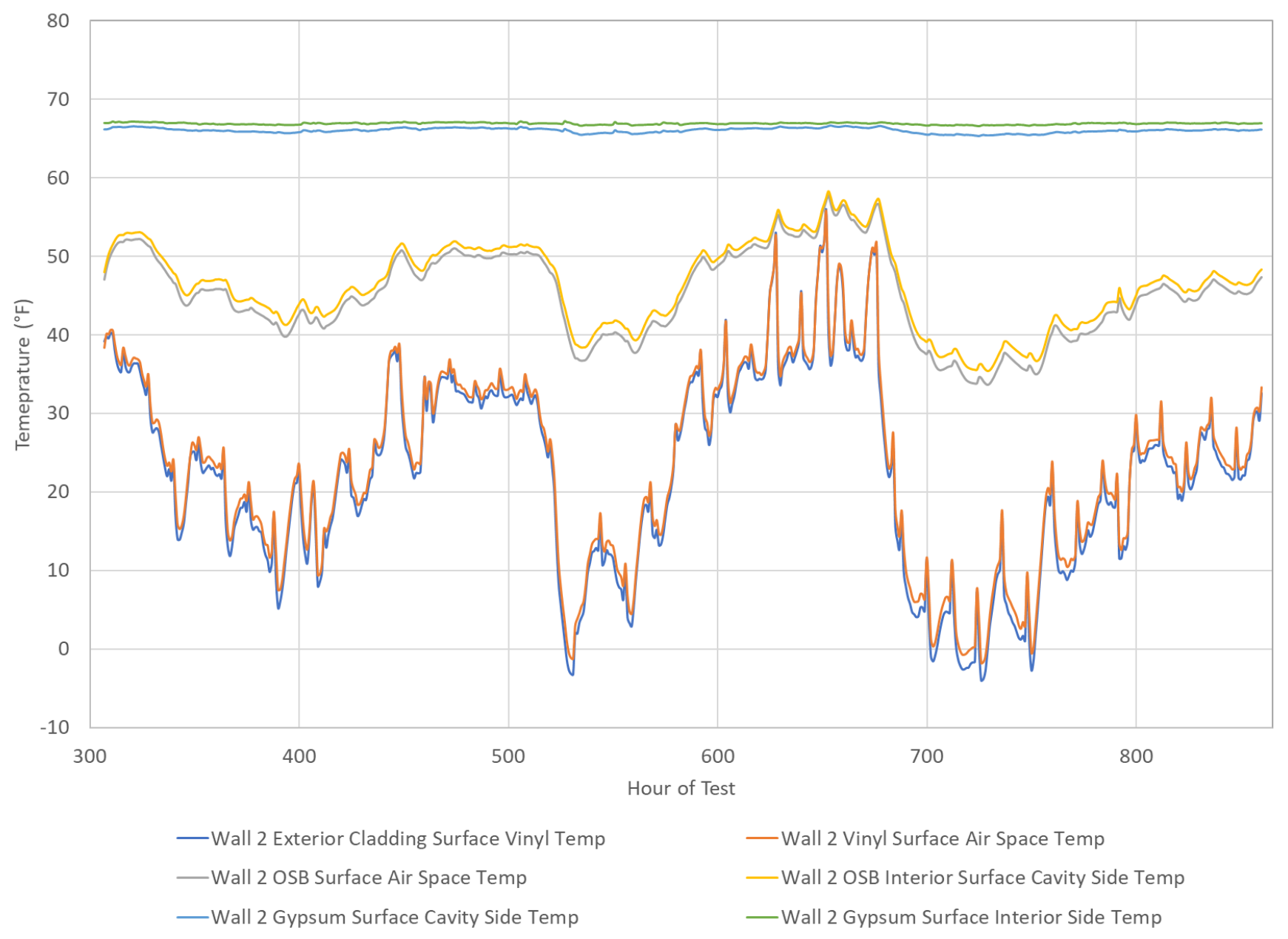

Figure 39. Measured temperature throughout wall with mineral wool CI and a spun-bonded polyolefin WRB. 


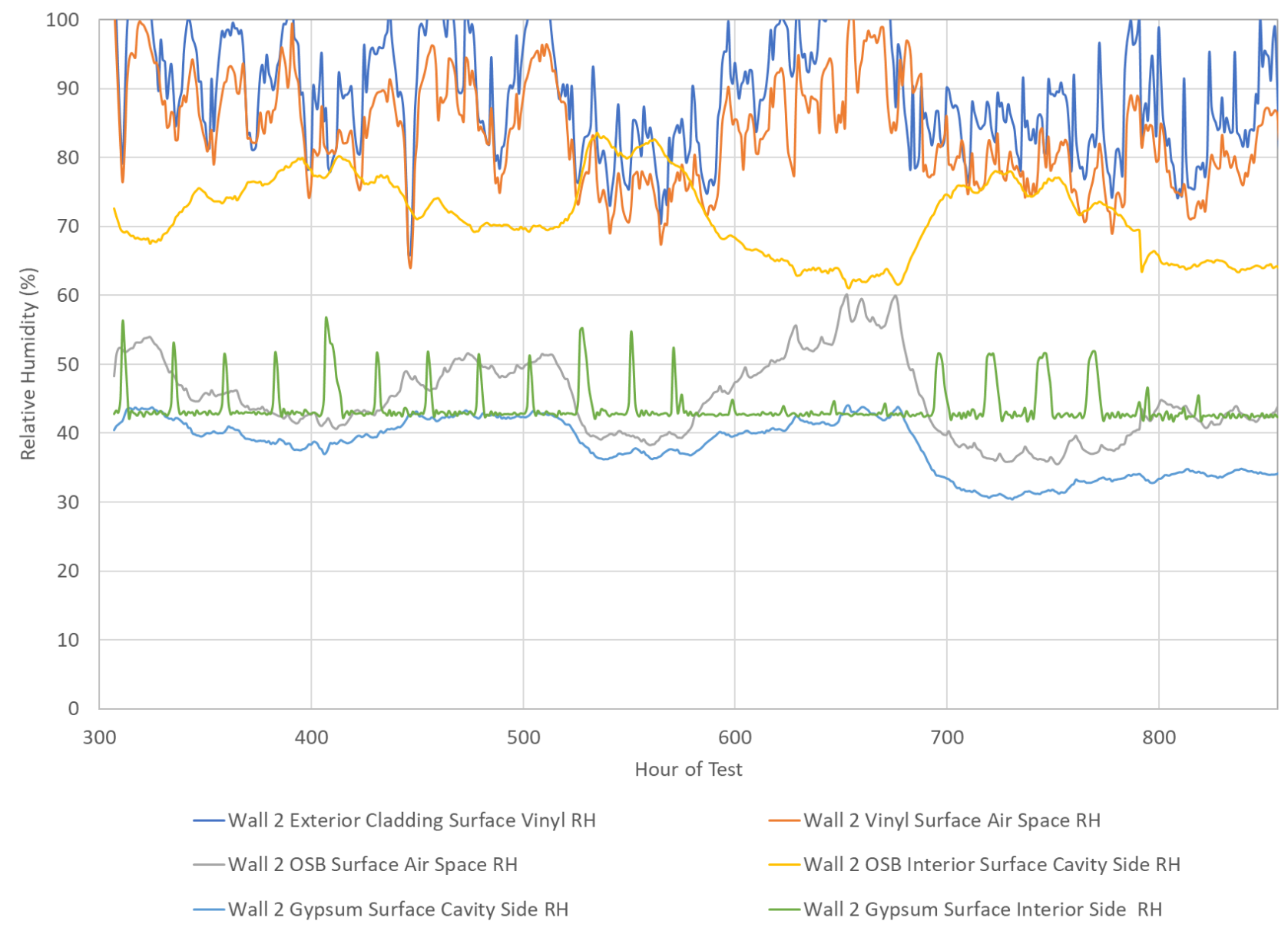

Figure 40. Measured RH throughout the wall with mineral wool CI and a spun-bonded polyolefin WRB. 


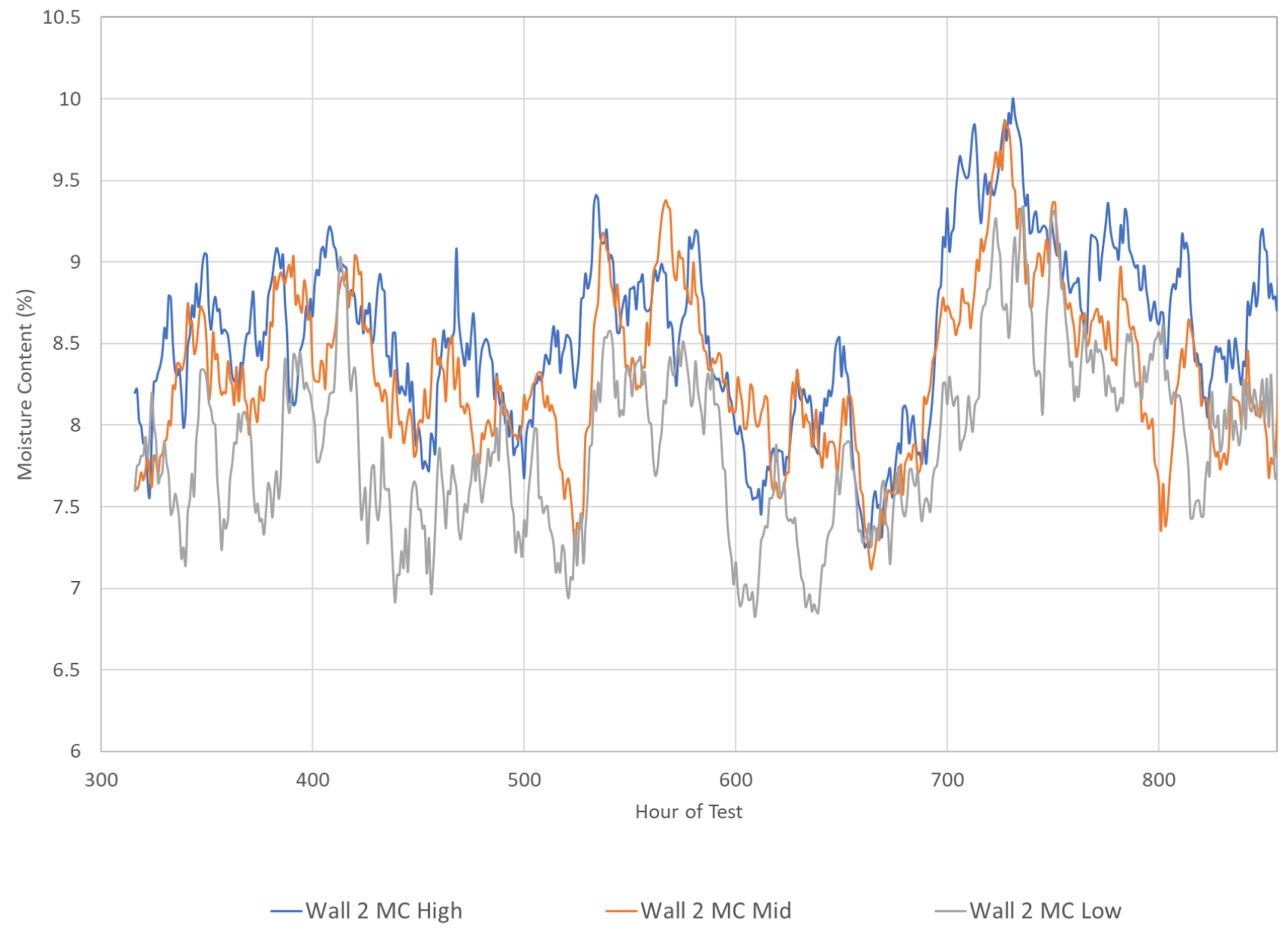

Figure 41. Measured moisture content throughout the wall with mineral wool CI and a spun-bonded polyolefin WRB.

\subsubsection{Mineral wool/spun-bonded polyolefin — comparison between measured and simulated results}

The wall with spun-bonded polyolefin WRB was modeled as shown in Figure 42. The air gap behind the vinyl siding $(10 \mathrm{~mm} / 3 / 8 \mathrm{in}$.) was ventilated at a constant rate of $201 / \mathrm{h}$. The wall was assumed to be airtight, i.e., no air leakage occurred through the wall. 
Component Assembly

Case: \#2 SBP

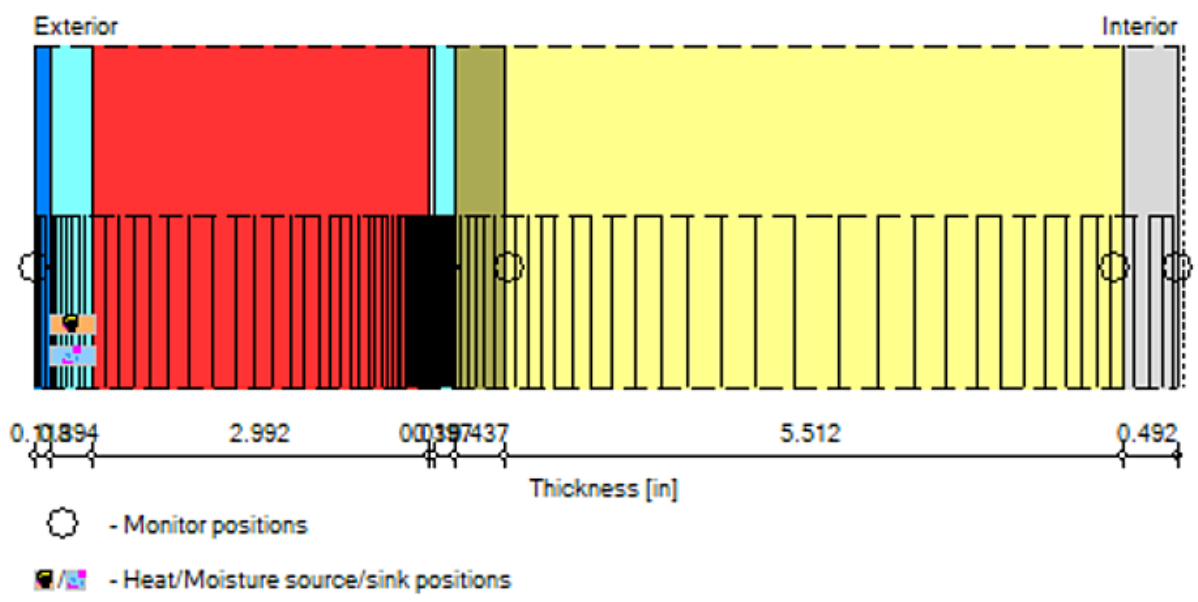

Materials:

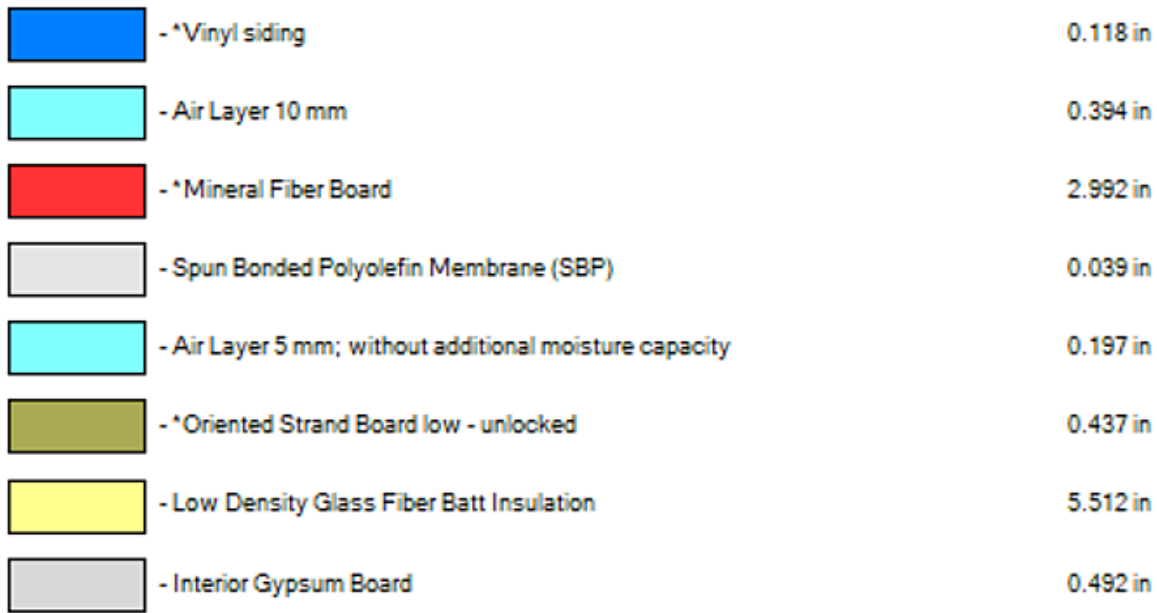

Figure 42. Layers and materials in the simulated WUFI model for the wall with mineral wool CI and a spunbonded polyolefin WRB.

Next, we compared the simulated results to the measurements for the following selected layers in the wall: temperature and RH (Figure 43 and Figure 44) on the exterior and interior surface of the OSB sheathing and on the indoor side of cavity insulation (exterior side of gypsum board with no VR in the wall), and the moisture content of the OSB sheathing. The initial conditions were assumed to be $60 \% \mathrm{RH}$ and $68^{\circ} \mathrm{F}$ in all the layers. 


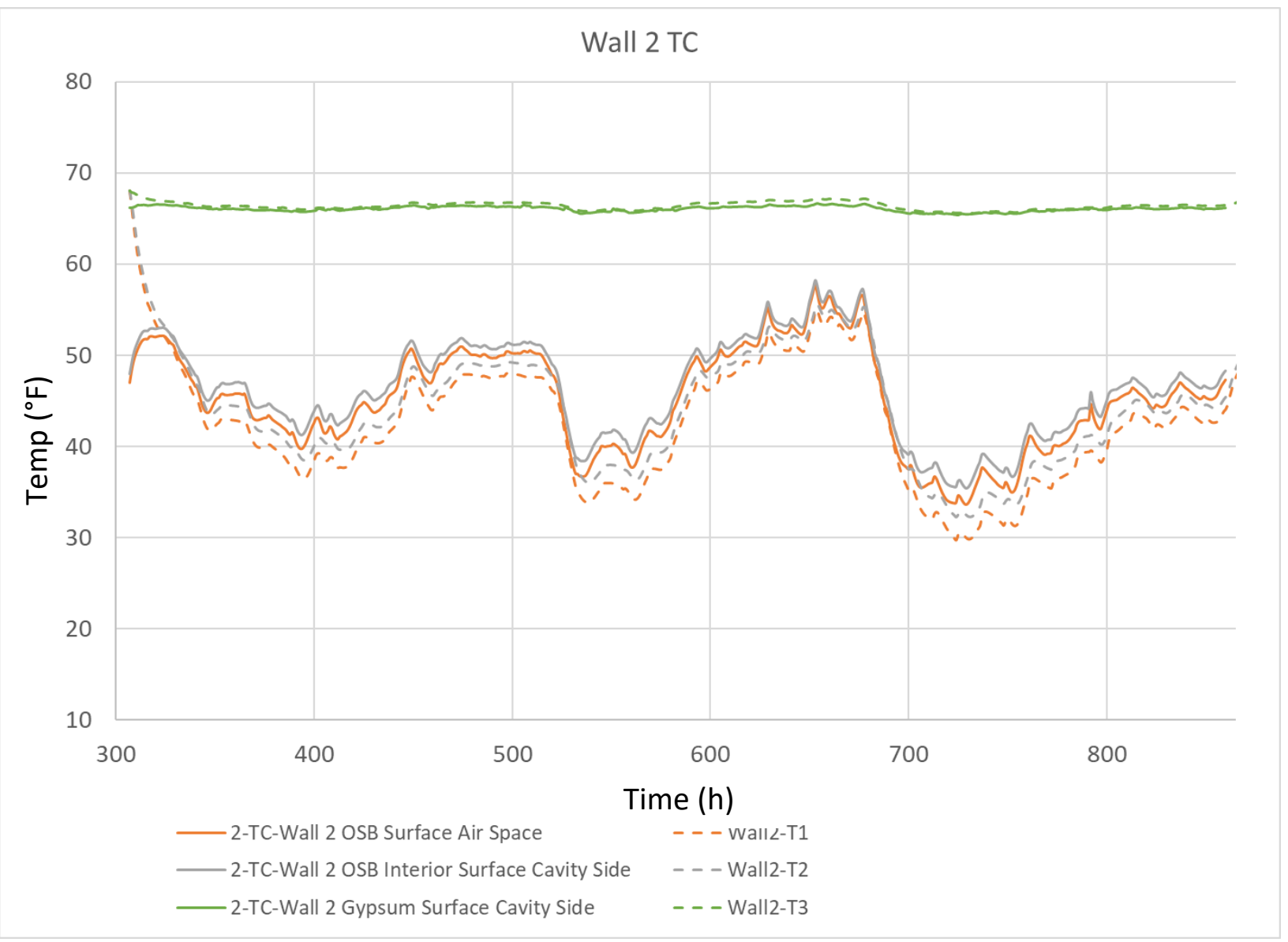

Figure 43. Comparison of measured and simulated temperature in Wall 2 of Pair 2. The solid lines are measured data and the dashed lines are simulated data. 


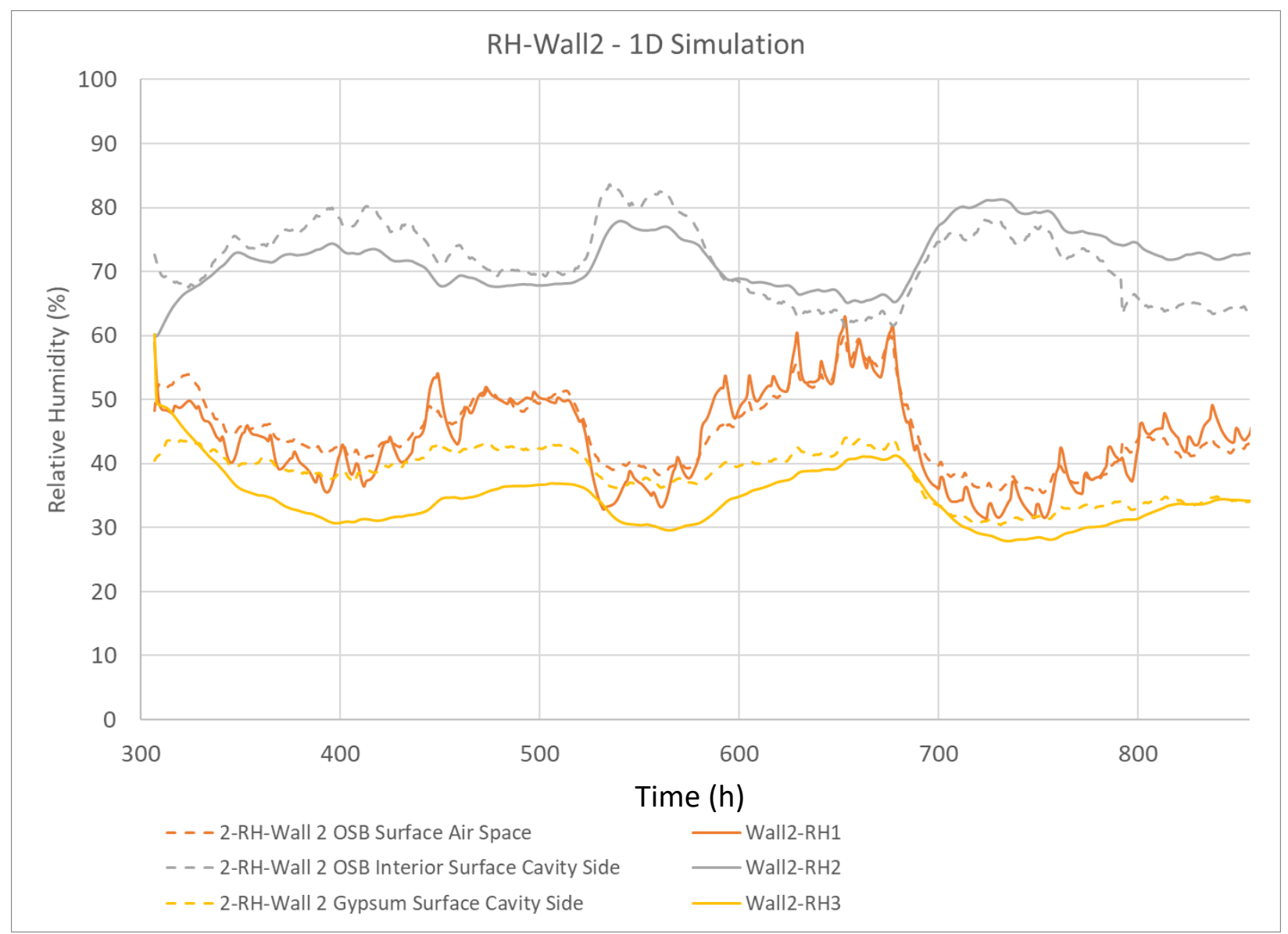

Figure 44. Comparison of measured and simulated RH in Wall 2 of Pair 2. The solid lines are measured data and the dashed lines are simulated data.

Air leakage through the walls was estimated based on the overall air leakage of the whole assembly, which, based on Figure 7, was approximately $1 \mathrm{CFM}$ at $20 \mathrm{~Pa}$. In the simulations, Wall 1 exhibited lower temperatures than Wall 2 when the pressure difference between the outdoors and indoors changed from 0 to $20 \mathrm{~Pa}$ (airflow from outdoors to indoors). The air leakage through the wall cavity affected the temperatures and moisture in the wall differently depending on how and where the air moved through it. In one-dimensional simulations, specifically in the WUFI Pro model, the air leakage can be considered as a source term. In the simulations, we separated the two walls to leaky and airtight. Wall 1, which has felt as a water-resistive barrier, was considered to have all the air leakage. Wall 2, with spun-bonded polyolefin, was assumed to be airtight.

In the wall with spun-bonded polyolefin (Figure 43), the simulated temperatures on the exterior and interior sides of the OSB (Wall2-T1 and Wall2-T2, respectively) were consistently lower than the measured values. This could be caused by differing R-values in the simulations and the measurements for the cavity and the CI. The material properties in the simulations were taken from the WUFI database (i.e., the materials were not tested for thermal resistance).

Figure 45 shows that the simulated moisture content agrees well with the trend in the measured moisture content. The simulated moisture content shows very little hourly variations unlike the measured one. 


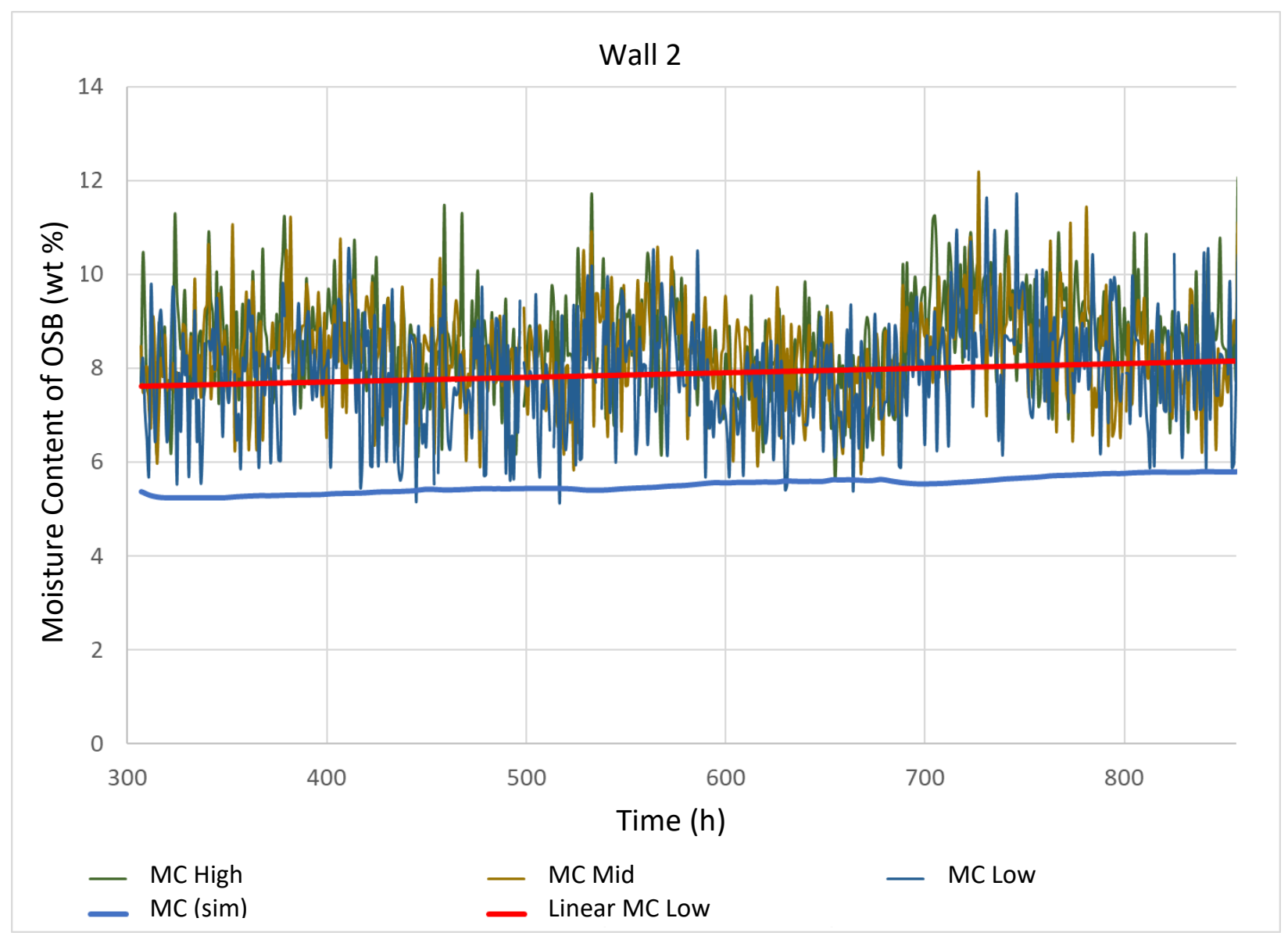

Figure 45. Measured and simulated moisture content of the OSB in Wall 2 for Pair 2.

The RMSE of Wall 1 and Wall 2 of Pair 2 is listed in Table 7.

Table 7. RMSE for Wall 1 and Wall 2 of Pair 2 for temperature (T) and RH. ext = exterior; int = interior.

\begin{tabular}{|l|r|r|r|r|r|r|}
\hline \multicolumn{1}{|c|}{ RMSE } & \multicolumn{1}{c|}{$\begin{array}{c}\text { T ext } \\
\text { OSB }\end{array}$} & \multicolumn{1}{c|}{$\begin{array}{c}\text { T int } \\
\text { OSB }\end{array}$} & \multicolumn{1}{c|}{$\begin{array}{c}\text { T ext } \\
\text { GB }\end{array}$} & \multicolumn{1}{c|}{$\begin{array}{c}\text { RH ext } \\
\text { OSB }\end{array}$} & \multicolumn{1}{c|}{$\begin{array}{c}\text { RH int } \\
\text { OSB }\end{array}$} & \multicolumn{1}{c|}{$\begin{array}{c}\text { RH ext } \\
\text { GB }\end{array}$} \\
\hline Wall 1 & 3.4 & 3.8 & 0.7 & 3.9 & 5.6 & 3.5 \\
\hline Wall 2 & 3.4 & 3.1 & 0.4 & 2.8 & 4.6 & 4.9 \\
\hline
\end{tabular}

\section{ANNUAL SIMULATIONS OF THE RETROFIT WALLS}

The wall sets were simulated in the Chicago climate for 3 to 5 years to evaluate the long-term performance and the possibility of mold growth or high moisture content over the years. The following assumptions and input selections were made:

- The moisture design weather file YEAR2 for Chicago as per ASHRAE Standard 160 was used.

- Medium moisture loads +5\% RH as defined by EN15026 in WUFI-1D was used to create the indoor temperature and $\mathrm{RH}$. 
○ Moisture load due to air leakage through the wall was as follows: air infiltration model IBP option A $\left(1 \mathrm{~m}^{3} / \mathrm{m}^{2}, \mathrm{~h}\right.$ at $50 \mathrm{~Pa}$ pressure difference) matches the airtightness of this wall.

- The orientation was north.

The first wall set, Pair 1, was simulated for 5 years until the increasing trend in moisture content in the wall leveled out to a steady annual cycle. The second wall set, Pair 2, reached steady annual cycling in 3 years.

\subsection{SIMULATION RESULTS}

\subsubsection{XPS Walls}

Figure 46 and Figure 47 show the conditions on the wall cavity side on the exterior sheathing (OSB) for Wall 1 of Pair 1 with Polyethylene or Kraft vapor retarder, respectively. The walls has 2 in. of XPS as CI and a $15 \mathrm{lb}$ felt water-resistive barrier. The annual cycling of the relative humidity on the indoor side of OSB settles to the same level on both walls. The wall with polyethylene vapor retarder takes longer to reach the steady annual cycle which is due to polyethylene's lower water vapor permeance that slows down the diffusion of indoor moisture through the vapor retarder.

Wall 2 has spun-bonded polyolefin as a water-resistive barrier and no VR. Figure 48 shows the results for Wall 2 with a SBP water-resistive barrier and without a vapor retarder (no VR). The permeance of the VR made a significant difference in moisture performance. The "no VR" case allowed for vapor drive from the indoor climate to the wall, which increased the OSB moisture content to levels that could enable mold growth. The polyethylene vapor barrier and the Kraft vapor retarder limited the vapor drive to reduce the risk of mold growth significantly. The modeled comparison of mold growth on the sheathing for each vapor barrier scenario is shown in Figure 49. 


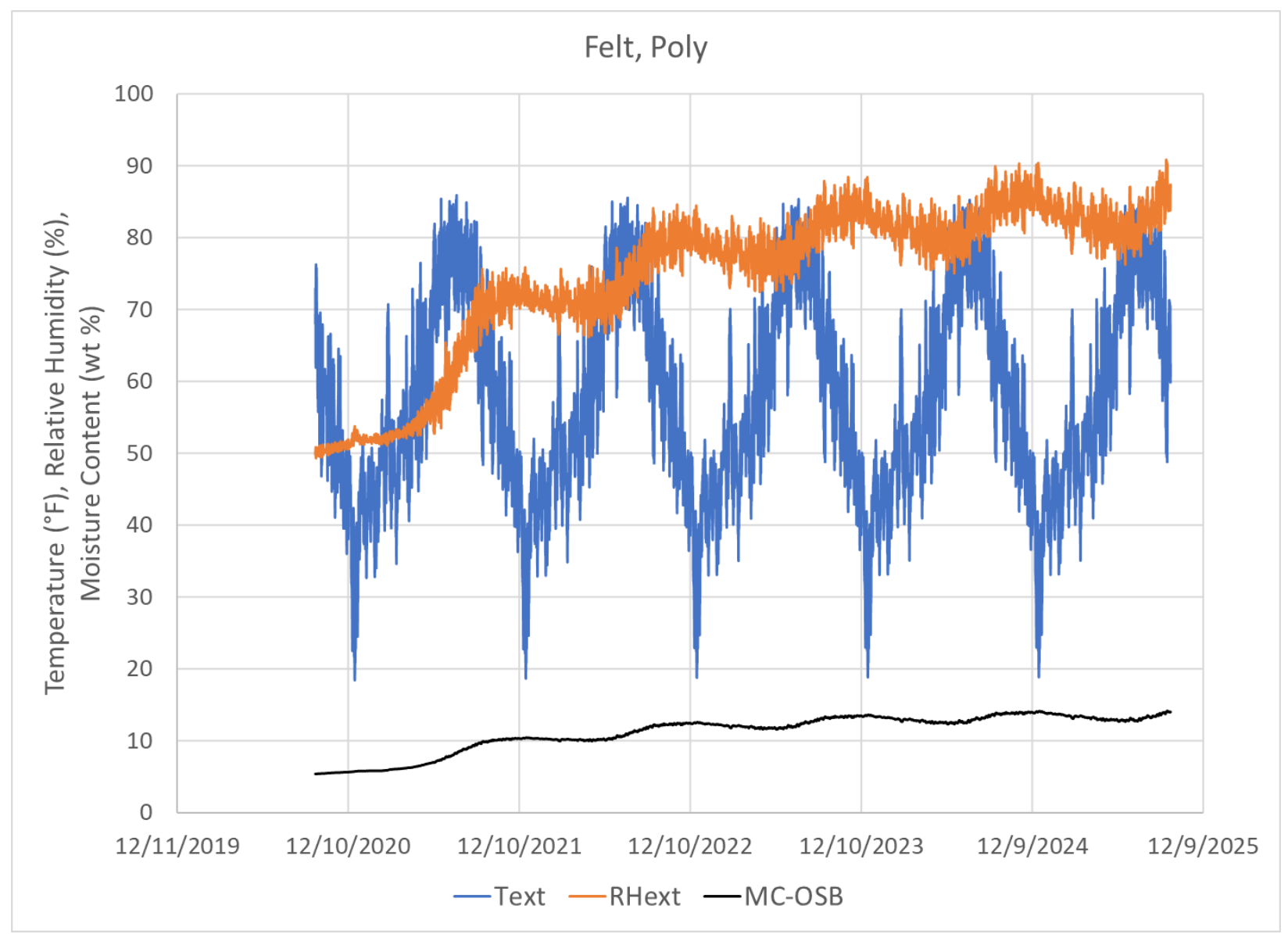

Figure 46. Annual simulation results for Wall 1 of Pair 1. Temperature $\left({ }^{\circ} \mathrm{F}\right)$ and $\mathrm{RH}(\%)$ on the exterior side of the cavity insulation, and the moisture content (MC) of the exterior sheathing (wt \%). 


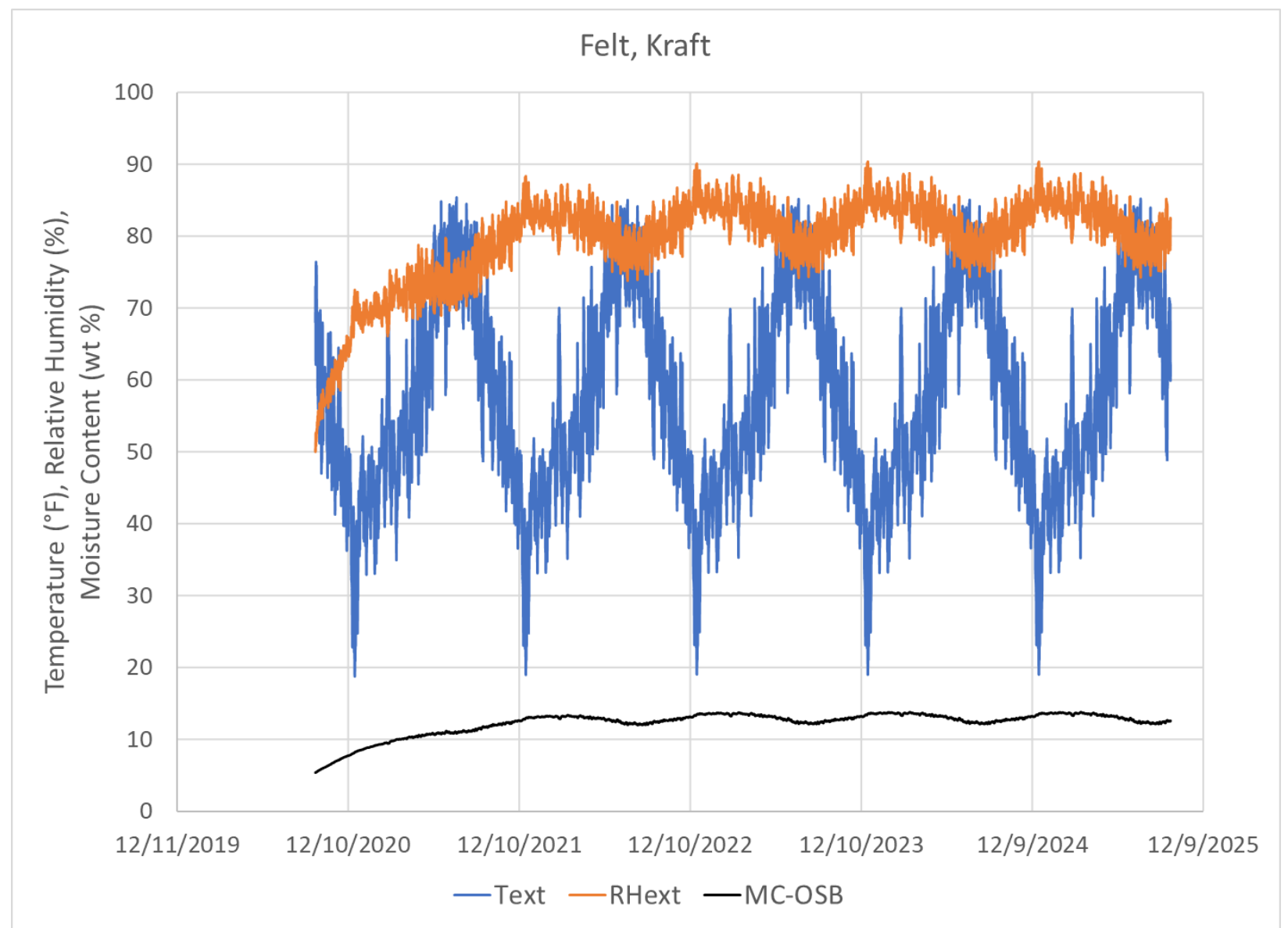

Figure 47. Annual simulation results for Wall 1 of Pair 1 with a Kraft VR instead of polyethylene.

Temperature (Text) $\left({ }^{\circ} \mathrm{F}\right)$ and Relative Humidity (RHext) (\%) on the exterior side of the cavity insulation, and the moisture content (MC) of the exterior sheathing (wt \%). 


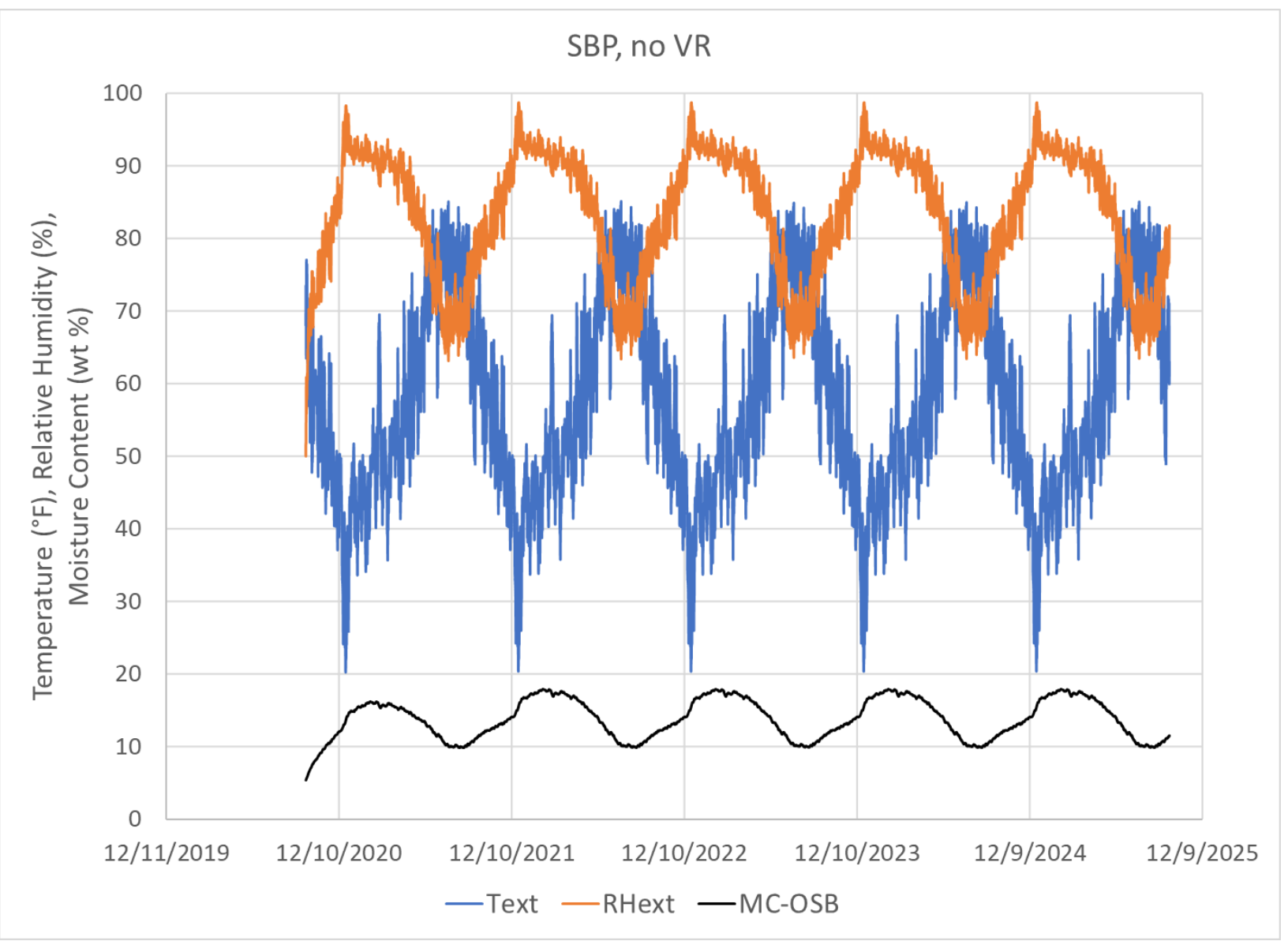

Figure 48. Annual simulation results for Wall 2 of Pair 1. Temperature $\left({ }^{\circ} \mathrm{F}\right)$ and $\mathrm{RH}(\%)$ on the exterior side of the cavity insulation, and the moisture content (MC) of the exterior sheathing (wt \%). 


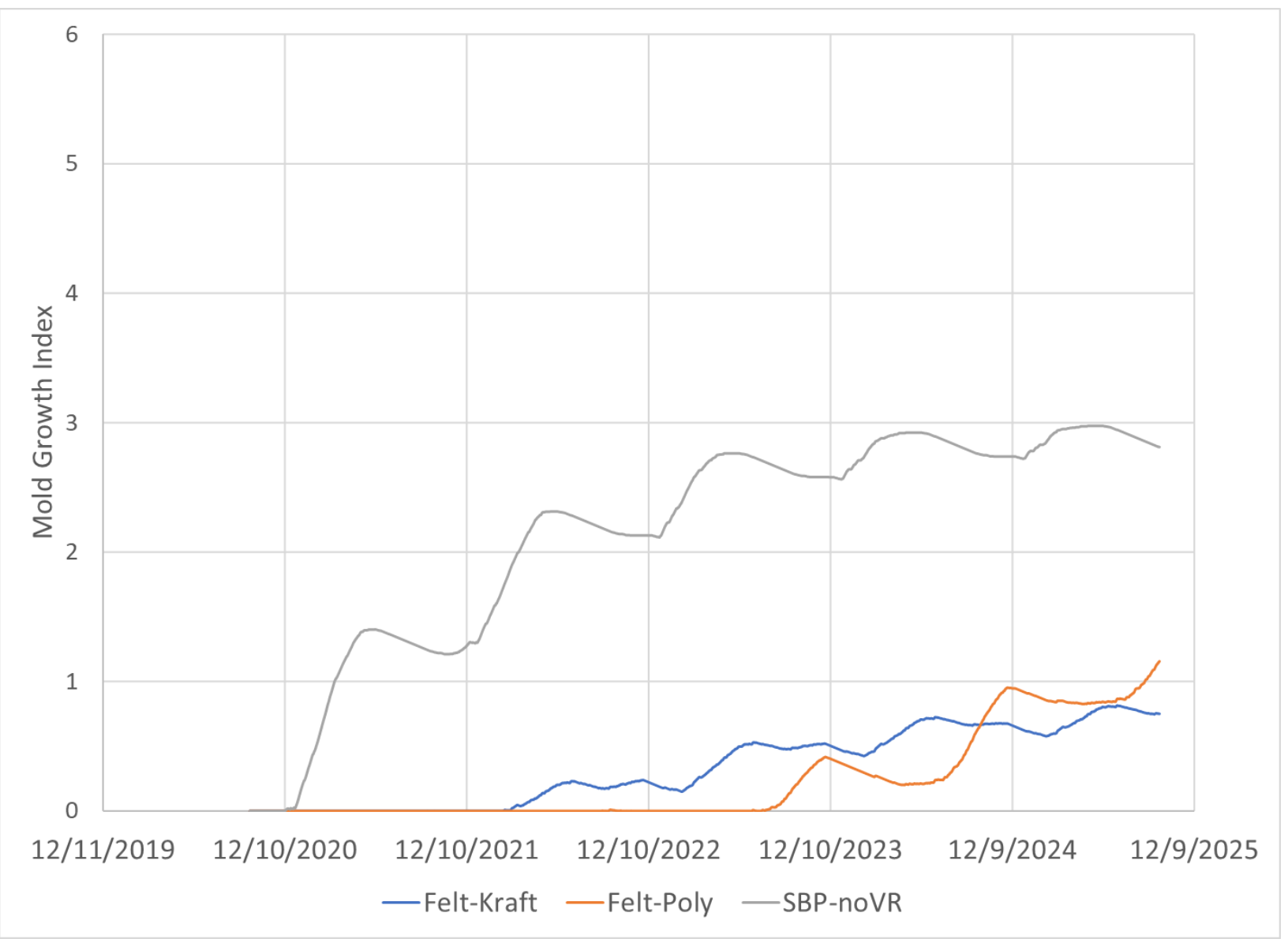

Figure 49. Mold growth index on the exterior sheathing (OSB) cavity side as predicted by the simulation model for Pair 1 walls with different VR options: no VR, Kraft faced insulation, and polyethylene.

Wall 1 with a polyethylene vapor barrier showed an increasing moisture content and RH on the OSB over the 5 years. The trend seems to level out in the fifth year. The moisture content of the OSB leveled out to a safe level around $13 \mathrm{wt} \%$. The RH stayed above $80 \%$, indicating a risk for mold growth. However, Figure 49 shows the mold growth index (MGI) as a function of time for the three simulation cases. After 5 years, the MGI was highest around 1, which is considered safe as per ASHRAE Standard 160, which considers an MGI below 3 to be safe.

Wall 1 with a Kraft VR showed the same moisture content level in the OSB, but the RH was lower, crossing $80 \%$ annually. That resulted in fewer hours at the conditions that would allow for mold growth, and the MGI stayed below 1 in the wall with a Kraft VR.

Wall 1 without any VR had the highest moisture content in the OSB and the highest RH on the insulated cavity side of the OSB. The average moisture content of the OSB reaches up to $18 \mathrm{wt} \%$, which can be considered risky. The MGI on the insulated cavity side of the OSB went up to 3, which is at the borderline of being safe.

\subsubsection{Mineral Wool Walls}

Figure 50 and Figure 51 show the temperature and RH on the cavity side of the exterior sheathing (OSB) and the moisture content of the OSB for Walls 1 and 2 of Pair 2, respectively. The walls have 3 in. of mineral fiber insulation as CI. Wall 1 has a \#15 felt water-resistive barrier and a polyethylene vapor 
barrier. Wall 2 has spun-bonded polyolefin as a water-resistive barrier and no VR. The highly permeable $\mathrm{CI}$ and slightly higher R-value (R-12.9 for 3 in. of mineral fiber vs. R-10 for 2 in. of XPS) resulted in low RH (predominantly below $80 \%$ ) on the OSB, which did not promote mold growth. The walls did not show any mold growth. The moisture content of the OSB layers stayed at a low level below $10 \mathrm{wt} \%$.

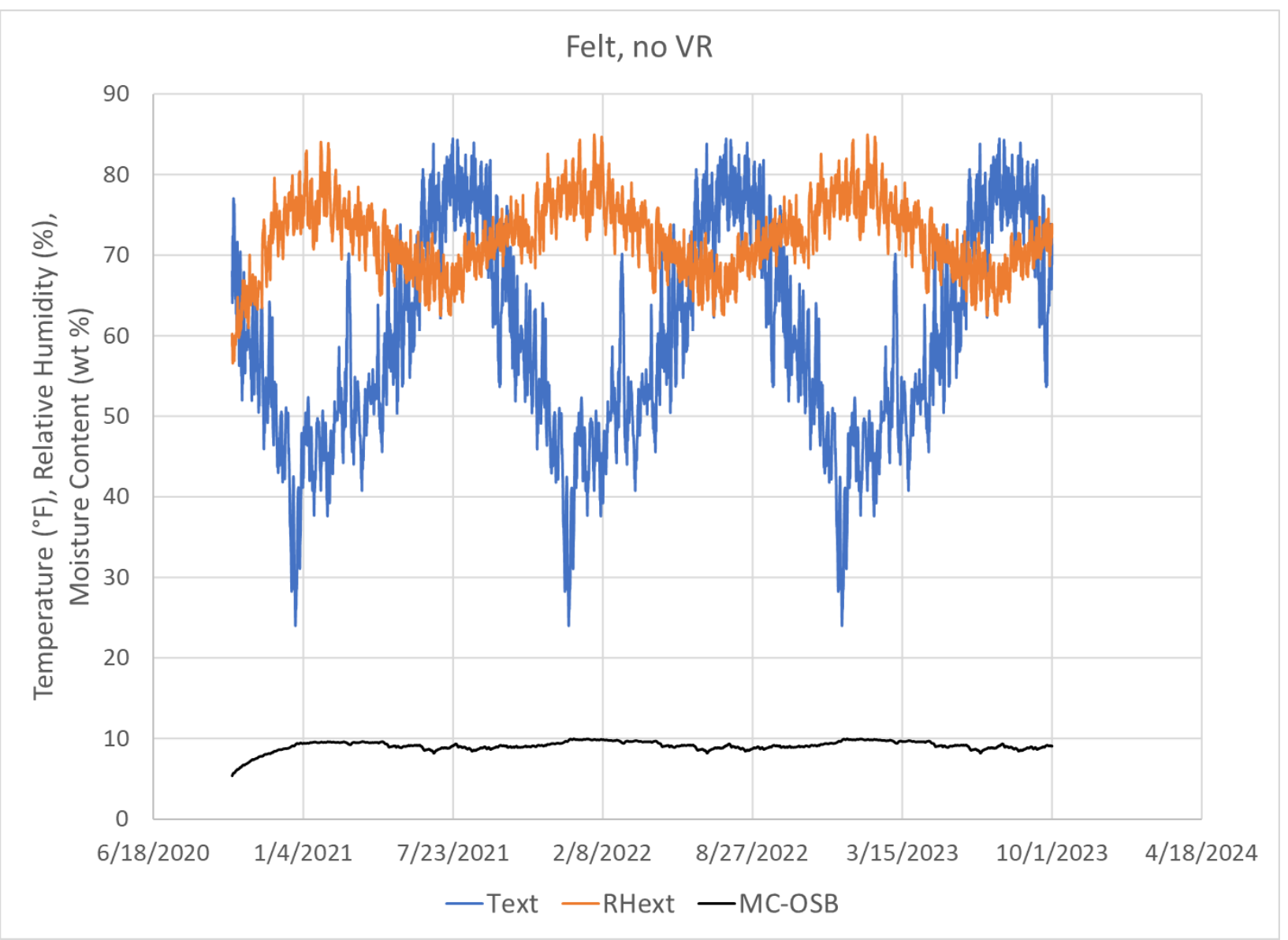

Figure 50. Annual simulation results for Wall 1 of Pair 2. Temperature $\left({ }^{\circ} \mathrm{F}\right)$ and $\mathrm{RH}(\%)$ on the exterior side of the cavity insulation, and the moisture content (MC) of the exterior sheathing (wt \%). 


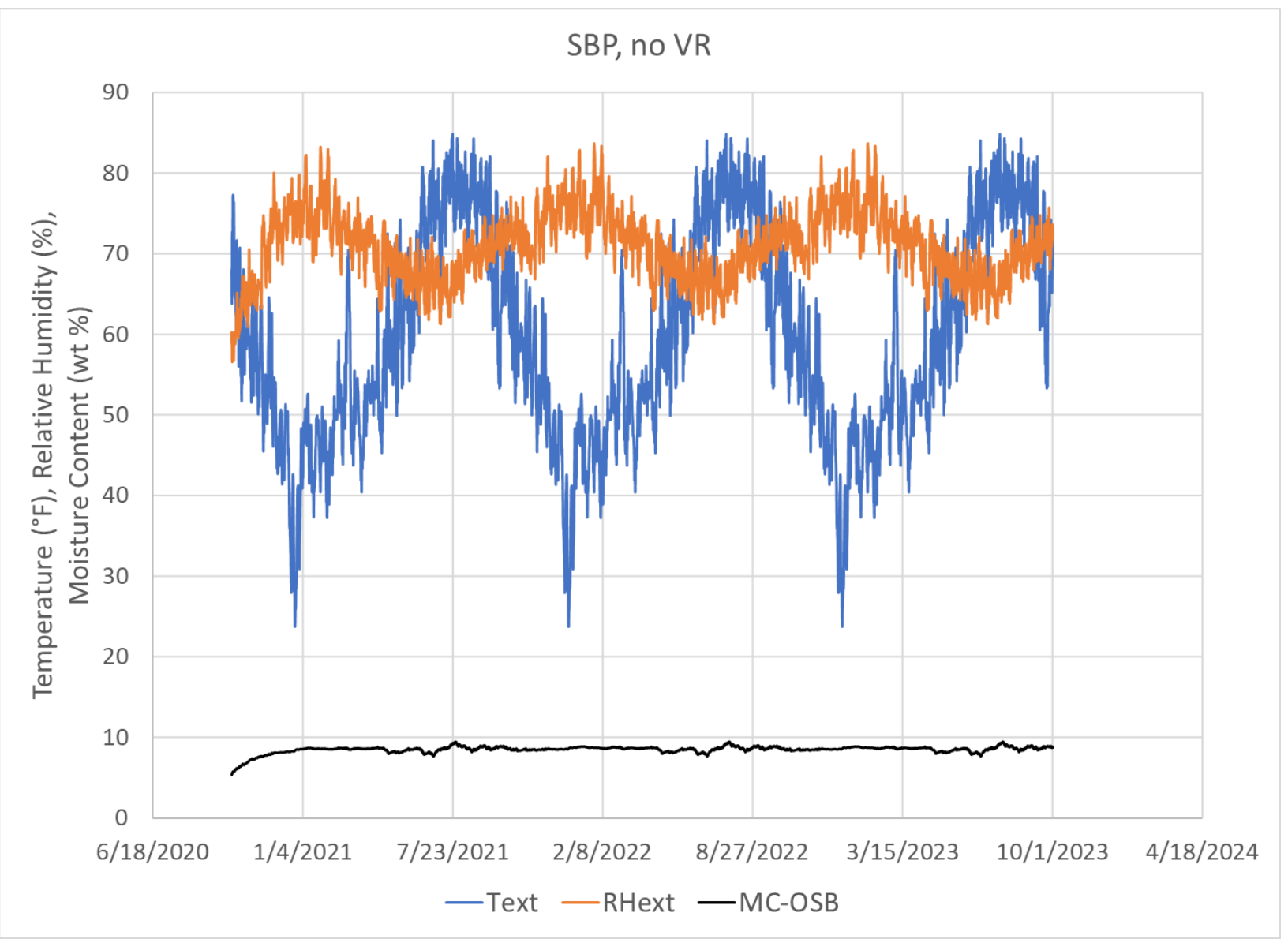

Figure 51. Annual simulation results for Wall 2 of Pair 2. Temperature $\left({ }^{\circ} \mathrm{F}\right)$ and $\mathrm{RH}(\%)$ on the exterior side of the cavity insulation, and the moisture content (MC) of the exterior sheathing (wt \%).

\section{CONCLUSIONS}

This work's primary purpose was to demonstrate confidence in the authors' WUFI simulations by comparing simulation results with measured hygrothermal wall performance in an environmental chamber. Experiments were completed for walls with two different retrofit options: (1) low-permeance CI with and without a vapor barrier, and (2) high-permeance CI with two different water-resistive barriers. Table 5 and Table 6 show the RMSE in each experiment for walls in Pair 1 between measured and simulated results for key measurement locations of temperature and RH. Table 7 shows the RMSE for walls in Pair 2. The RMSEs indicate good agreement between the measured and simulated results when the boundary conditions and air leakage were known. Including the air leaks in the walls in the laboratory tests was critical to achieving good agreement in $\mathrm{RH}$. The air leaks allowed for the humidity to rise faster than with diffusion only. The low-level air leaks in these walls were not important for predicting the wall temperature.

Other conclusions from this work include the following:

1. The month-long chamber test resulted in low measured moisture content in the wood sheathing for both pairs of walls. 
2. Wall 2 of Pair 1 had higher RH measured in the cavity compared with Wall 1 . The RH continued to rise throughout the test. Wall 2 had no interior VR, which could have contributed to the higher RH in the cavity. The vapor diffusion drive would be from the inside to the outside during the winter in a cold climate.

3. Wall 2 of Pair 2 had higher RH measured in the cavity compared with Wall 1. Wall 2 used spunbonded polyolefin as a WRB, which is much more vapor-open than the \#15 felt used on Wall 1. The low-permeance WRB seemed to contribute to the high RH in the cavity.

Finally, the annual simulations in the Chicago climate walls indicated the need for a VR to maintain low moisture content in the OSB and reduce the risk for mold growth when the CI has low permeance, or when the CI's R-value is not high enough to keep the RH on the exterior sheathing below the critical mold growth level. 


\section{REFERENCES}

Boardman, C. R., S. V. Glass, and P. K. Lebow. 2017. "Simple and accurate temperature correction for moisture pin calibrations in oriented strand board." Building and Environment 112:250-60. doi: https://doi.org/10.1016/j.buildenv.2016.11.039.

Boudreaux, P. R., M. Salonvaara, F. Antretter, and A. O. Desjarlais. 2019. "Comparing wall performance predicted from hygrothermal simulations to wall performance measured from environmental chamber experiments." Oak Ridge National Laboratory.

DOE. 2014. "Windows and Building Envelope Research and Development: Roadmap for Emerging Technologies." US Department of Energy Buildings Technologies Office.

"High-R Walls." 2013. Building America Top Innovations Hall of Fame Profile, 2. US Department of Energy Building Technologies Program.

Mendon, V. W., A. Selvacanabady, M. Zhao, and Z. T. Taylor. 2015. "National Cost Effectiveness of the Residential Provisions of the 2015 IECC." Pacific Northwest National Laboratory. 